\title{
Cellular effects of terahertz waves
}

\author{
Olga P. Cherkasova ${ }^{a},{ }^{\text {a,b, } *}$ Danil S. Serdyukov, ${ }^{\text {a,c }}$ Eugenia F. Nemova, ${ }^{\text {a }}$

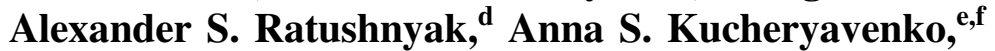 \\ Irina N. Dolganova $\odot,{ }^{\text {e,g,h }}$ Guofu Xu $\odot,{ }^{\text {i }}$ Maksim Skorobogatiy $\odot,{ }^{\text {i }}$ \\ Igor V. Reshetov $\odot$, ${ }^{j, k}$ Peter S. Timashev $\odot,{ }^{g, h, l, m}$ Igor E. Spektor, ${ }^{f}$

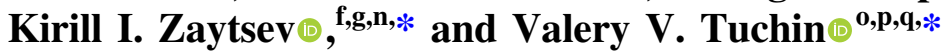 \\ ${ }^{a}$ Institute of Laser Physics of the Siberian Branch of the Russian Academy of Sciences, \\ Russian Federation \\ ${ }^{b}$ Novosibirsk State Technical University, Russian Federation \\ ${ }^{c}$ Federal Research Center Institute of Cytology and Genetics of the Siberian Branch of \\ the Russian Academy of Sciences, Russian Federation \\ ${ }^{\mathrm{d}}$ Institute of Computational Technologies of the Siberian Branch of the Russian Academy \\ of Sciences, Russian Federation \\ e Institute of Solid State Physics of the Russian Academy of Sciences, Russian Federation \\ ${ }^{f}$ Prokhorov General Physics Institute of the Russian Academy of Sciences, Russian Federation \\ ${ }^{g}$ Sechenov University, Institute for Regenerative Medicine, Russian Federation \\ ${ }^{\mathrm{h}}$ Sechenov University, World-Class Research Center "Digital Biodesign and \\ Personalized Healthcare," Russian Federation \\ iPolytechnique Montreal, Department of Engineering Physics, Canada \\ ${ }^{\mathrm{j} S e c h e n o v}$ University, Institute for Cluster Oncology, Russian Federation \\ ${ }^{k}$ Academy of Postgraduate Education FSCC FMBA, Russian Federation \\ ${ }^{1}$ N.N. Semenov Institute of Chemical Physics, Department of Polymers and Composites, \\ Russian Federation \\ ${ }^{\mathrm{m}}$ Lomonosov Moscow State University, Department of Chemistry, Russian Federation \\ ${ }^{\mathrm{n}}$ Bauman Moscow State Technical University, Russian Federation \\ ${ }^{\circ}$ Saratov State University, Russian Federation \\ ${ }^{\mathrm{p}}$ Institute of Precision Mechanics and Control of the Russian Academy of Sciences, \\ Russian Federation \\ ${ }^{\mathrm{q}}$ National Research Tomsk State University, Russian Federation
}

\begin{abstract}
Significance: An increasing interest in the area of biological effects at exposure of tissues and cells to the terahertz $(\mathrm{THz})$ radiation is driven by a rapid progress in $\mathrm{THz}$ biophotonics, observed during the past decades. Despite the attractiveness of $\mathrm{THz}$ technology for medical diagnosis and therapy, there is still quite limited knowledge about safe limits of THz exposure. Different modes of THz exposure of tissues and cells, including continuous-wave versus pulsed radiation, various powers, and number and duration of exposure cycles, ought to be systematically studied.
\end{abstract}

Aim: We provide an overview of recent research results in the area of biological effects at exposure of tissues and cells to $\mathrm{THz}$ waves.

Approach: We start with a brief overview of general features of the THz-wave-tissue interactions, as well as modern $\mathrm{THz}$ emitters, with an emphasis on those that are reliable for studying the biological effects of $\mathrm{THz}$ waves. Then, we consider three levels of biological system organization, at which the exposure effects are considered: (i) solutions of biological molecules; (ii) cultures of cells, individual cells, and cell structures; and (iii) entire organs or organisms; special attention is devoted to the cellular level. We distinguish thermal and nonthermal mechanisms of THz-wave-cell interactions and discuss a problem of adequate estimation of the THz biological effects' specificity. The problem of experimental data reproducibility, caused by rareness of the $\mathrm{THz}$ experimental setups and an absence of unitary protocols, is also considered.

\footnotetext{
*Address all correspondence to Olga P. Cherkasova, o.p.cherkasova@gmail.com; Kirill I. Zaytsev, kirzay@gmail.com; Valery V. Tuchin, tuchinvv@mail.ru.
} 
Results: The summarized data demonstrate the current stage of the research activity and knowledge about the $\mathrm{THz}$ exposure on living objects.

Conclusions: This review helps the biomedical optics community to summarize up-to-date knowledge in the area of cell exposure to $\mathrm{THz}$ radiation, and paves the ways for the development of $\mathrm{THz}$ safety standards and $\mathrm{THz}$ therapeutic applications.

(C) The Authors. Published by SPIE under a Creative Commons Attribution 4.0 International License. Distribution or reproduction of this work in whole or in part requires full attribution of the original publication, including its DOI. [DOI: 10.1117/1.JBO.26.9.090902]

Keywords: THz technology; THz biophotonics; THz medical diagnosis and therapy; THzwave-tissue interactions; $\mathrm{THz}$ dosimetry; $\mathrm{THz}$ exposures of biological molecules, cells, and tissues; thermal and nonthermal effects of $\mathrm{THz}$ waves.

Paper 210179VR received May 31, 2021; accepted for publication Sep. 8, 2021; published online Sep. 30, 2021.

\section{Introduction}

An increasing interest in biomedical applications of terahertz $(\mathrm{THz})$ radiation, featuring the frequencies of 0.1 to $3.0 \mathrm{THz}$, the free-space wavelengths of $\simeq 3 \mathrm{~mm}$ to $100 \mu \mathrm{m}$, or the quantum energies of $\simeq 0.3$ to $10 \mathrm{meV}$ (see Fig. 1 ), has been observed during the past few decades, ${ }^{1-5}$ driven by rapid progress in $\mathrm{THz}$ technology. ${ }^{6,7}$ Numerous research papers demonstrate the potential of $\mathrm{THz}$ technology in label-free early noninvasive, least-invasive, and intraoperative diagnosis of malignant and benign neoplasms with different nosologies and localizations, ${ }^{3,4,8-18}$ sensing of glycated tissues and blood in the context of diabetes diagnosis, ${ }^{1,19-21}$ determining the degree of traumatic injuries, ${ }^{22-25}$ hydration levels, ${ }^{26-29}$ and viability ${ }^{30}$ of tissues. Along with the diagnostic applications, THz technology holds strong potential in therapeutics, ${ }^{31,32}$ for example, in nonthermal regulation in expression of genes associated with cancer and inflammatory diseases. ${ }^{33}$ Nevertheless, THz therapy is still at the initial stage of its development.

Despite the attractiveness of $\mathrm{THz}$ technology for medical diagnostics and therapy, currently, the accumulated data on the safe limits of its effects on tissues and its harmlessness to the human body are rather limited. ${ }^{34-37}$ The existing recommendations of THz-radiation safety limits were developed relying on extrapolation of the data from the neighboring millimeter-wave (MMW) and infrared (IR) ranges. ${ }^{38-42}$ Therefore, THz-wave biological effects require thorough investigation for defining the safety limits in $\mathrm{THz}$ biomedical diagnostics and determining the optimal dose for THz therapeutics. In Fig. 2, an annually increasing number of research items according to Scopus and Web of Science is shown, illustrating a growing interest in the considered issues. To objectively uncover benefits and weaknesses of THz medical diagnosis and therapy and to define safe limits of tissue exposure to $\mathrm{THz}$ waves, appropriate modes of continuous-wave $(\mathrm{CW})$ and pulsed THz exposure (average power, duration, and number of exposure cycles) ought to be systematically studied and analyzed.

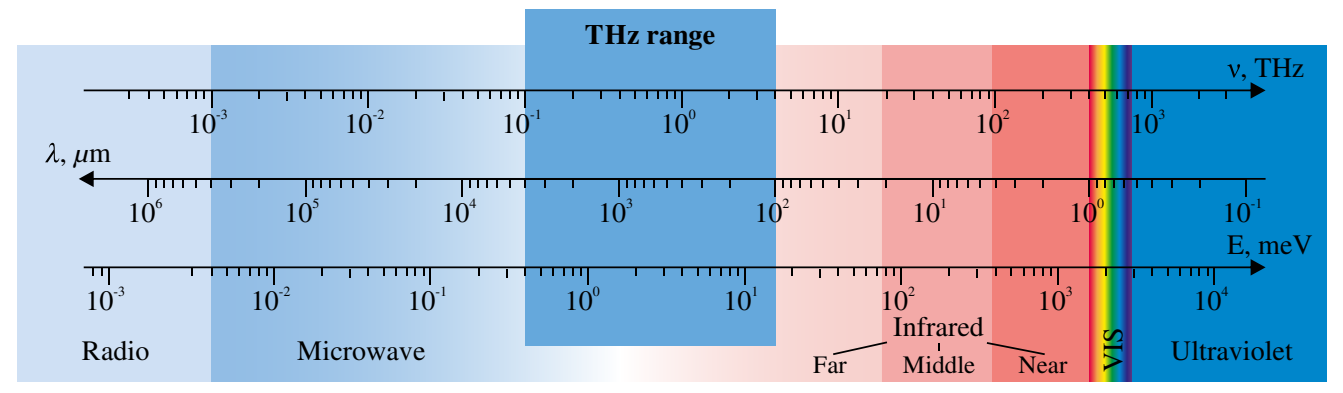

Fig. 1 The THz range of the electromagnetic spectrum. Courtesy of the authors. 


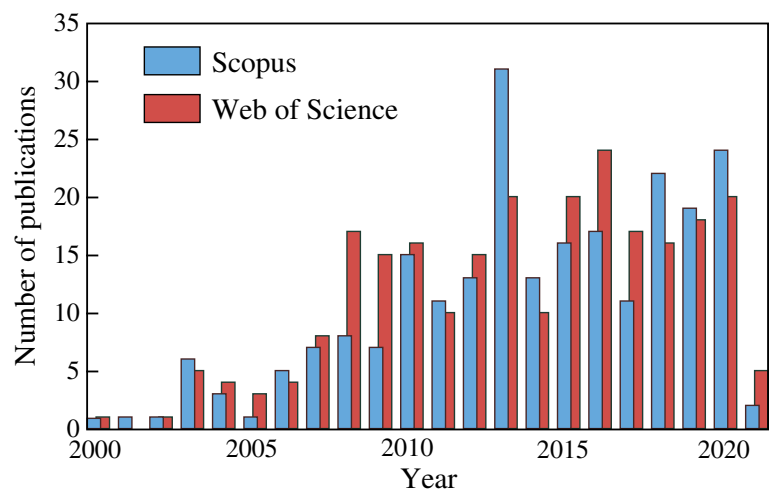

Fig. 2 Increasing number of research items in the area of biological objects exposure to THz waves according to Scopus and Web of Science; report dated February 2, 2021. Courtesy of the authors.

In this review, we begin with the technical aspects of the effect of $\mathrm{THz}$ waves on biological objects. Next, we discuss and compare modern $\mathrm{THz}$ emitters and their applicability for studying biological effects. We then describe the three levels of organization of biological systems, at which the effects of exposure to radiation are usually studied:

- biological molecules,

- cultures of cells, individual cells, and cell structures,

- entire organs or organisms.

We perform an in-depth analysis of cell exposure to $\mathrm{CW}$ and pulsed $\mathrm{THz}$ radiation, considering different types of cells (such as blood, skin, neuronal, epithelial, and stem cells) and distinguishing two distinct mechanisms of the THz-wave-cell interactions:

- heating due to the strong THz-wave absorption by polar water molecules; ${ }^{34}$

- nonthermal effects, including changes in the deoxyribonucleic acid (DNA) molecule dynamics (local breaks of hydrogen bonds and the DNA chains' melting) and gene expression. ${ }^{43-45}$

Original contributions of the authors to the described research areas are discussed, including studies of THz biological effects on neurons and fibroblasts, and evaluation of biological objects' heating by pulsed and CW THz radiation. Finally, this review addresses the problem of adequate estimation of the THz biological effects' specificity, as well as the problem of reproducibility of experimental data, originating from both rareness and uniqueness of the $\mathrm{THz}$ systems and absence of unitary irradiation protocols, which sometimes leads to contradictions of the results obtained by different research groups. ${ }^{35}$ Thereby, this review summarizes up-to-date knowledge in the area of cell exposure to $\mathrm{THz}$ radiation and poses important problems that hinder further developments in $\mathrm{THz}$ safety standards and in diagnostic and therapeutic applications.

\section{THz-Wave-Tissue Interactions}

Before proceeding to biological effects of $\mathrm{THz}$ waves, we should briefly overview some general principles of THz-wave-tissue interactions, which together with the rapid development of $\mathrm{THz}$ components and instruments ${ }^{6,7}$ cause significant interest to different $\mathrm{THz}$ applications. ${ }^{2,34,46,47}$ The following remarkable features of these interactions attract special attention:

- $\mathrm{THz}$ radiation is nonionizing in nature due to quite low photon energy, as compared with the ionization energy, which leads to dissociation of atoms and molecules.

- THz radiation interacts with free charges, low-frequency molecular motions, and collective excitations of media. Energy of THz quanta corresponds to the energy of hydrogen bounds and Van der Waals intramolecular interactions. 
- Solid state materials and molecular crystals might be characterized by unique "fingerptints" in the $\mathrm{THz}$ range, i.e., resonant spectral absorption peaks.

- $\mathrm{THz}$ radiation is strongly absorbed by polar molecules, such as water in liquid and gas states. On the one hand, this makes $\mathrm{THz}$ waves very sensitive to the content and state (free or bound) of water in the measured object, including different biological tissues. On the other hand, this limits the depth of THz-wave penetration in biological tissues by only hundred or even tens of microns, depending on the frequency and tissue type.

- $\mathrm{THz}$ waves penetrate into various nonhydrated dielectric materials, such as plastic, paper, cloths, and wood, especially at the sub-THz frequencies.

- Structural inhomogeneities of many objects, including different biological tissues, are small at the THz-wavelength scale. This reduces the Mie scattering effects, increases the THz-wave penetration depth in such objects as compared to the visible and IR waves, and allows one to apply the effective medium theory for analysis and description.

High water content is a general feature of all living organisms, which is of crucial importance for their interaction with $\mathrm{THz}$ waves. Indeed, water constitutes up to $\simeq 60 \%$ (by weight) of the adult human body; and its content is $\simeq 73 \%$ in tissue of the brain and heart, $\simeq 83 \%$ in the lungs, $\simeq 64 \%$ in the skin, $\simeq 79 \%$ in the muscle tissues and kidney, and $\simeq 31 \%$ in the bones. Blood constitutes $7 \%$ to $8 \%$ of the human body, which is as much as 4.5 to 6.01 for adults. In Fig. 3, structure and effective optical properties of the skin are illustrated in form of the frequencydependent refractive index $n$, absorption coefficient $\alpha$ (by field), and penetration depth $\delta=1 / \alpha$ (by field). The given data are calculated based on the double-Debye model of the tissues dielectric response at $\mathrm{THz}$ frequencies, introduced in Ref. 48. As it is shown in Fig. 3(b), the penetration depth $\delta$ decreases with increasing frequency $\nu$, whereas it is smaller than $0.3 \mathrm{~mm}$ in the considered spectral range.

The above-mentioned features of the $\mathrm{THz}$ waves open wide capabilities of their use in different branches of biology and medicine, which are discussed later with an emphasis on $\mathrm{THz}$ exposure effects.

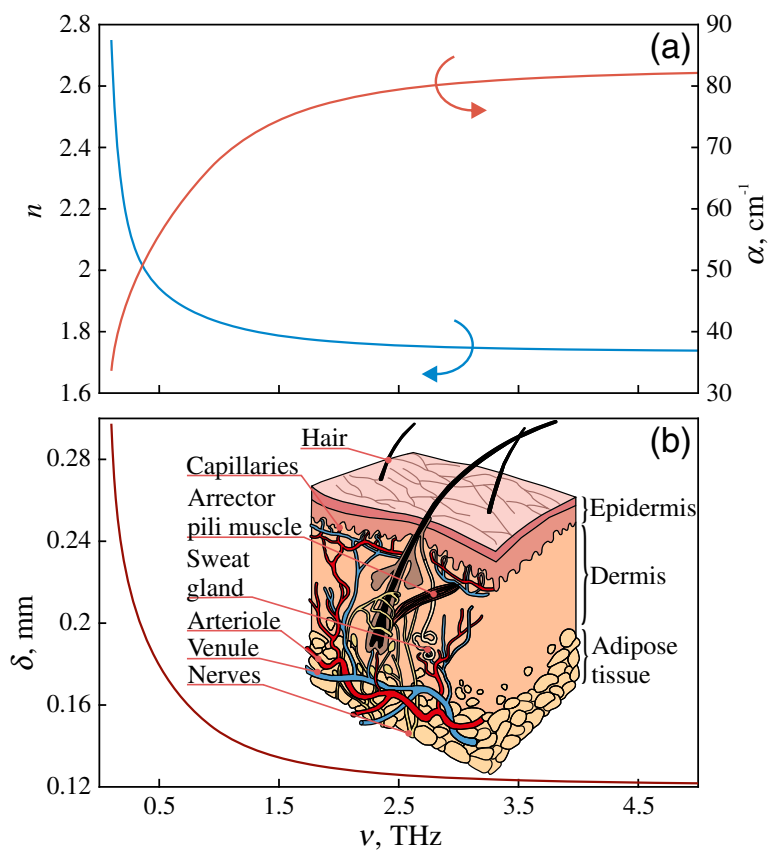

Fig. $3 \mathrm{THz}$ optical properties of the skin (epidermis). (a) Refractive index $n$ and absorption coefficient $\alpha$ (by field), calculated from the double-Debye model described in Ref. 48. (b) THz-wave penetration depth $\delta$ (by field). Inset in (b) shows a scheme of the skin, where (in most cases) only the epidermis is probed by the $\mathrm{THz}$ radiation. Courtesy of the authors. 


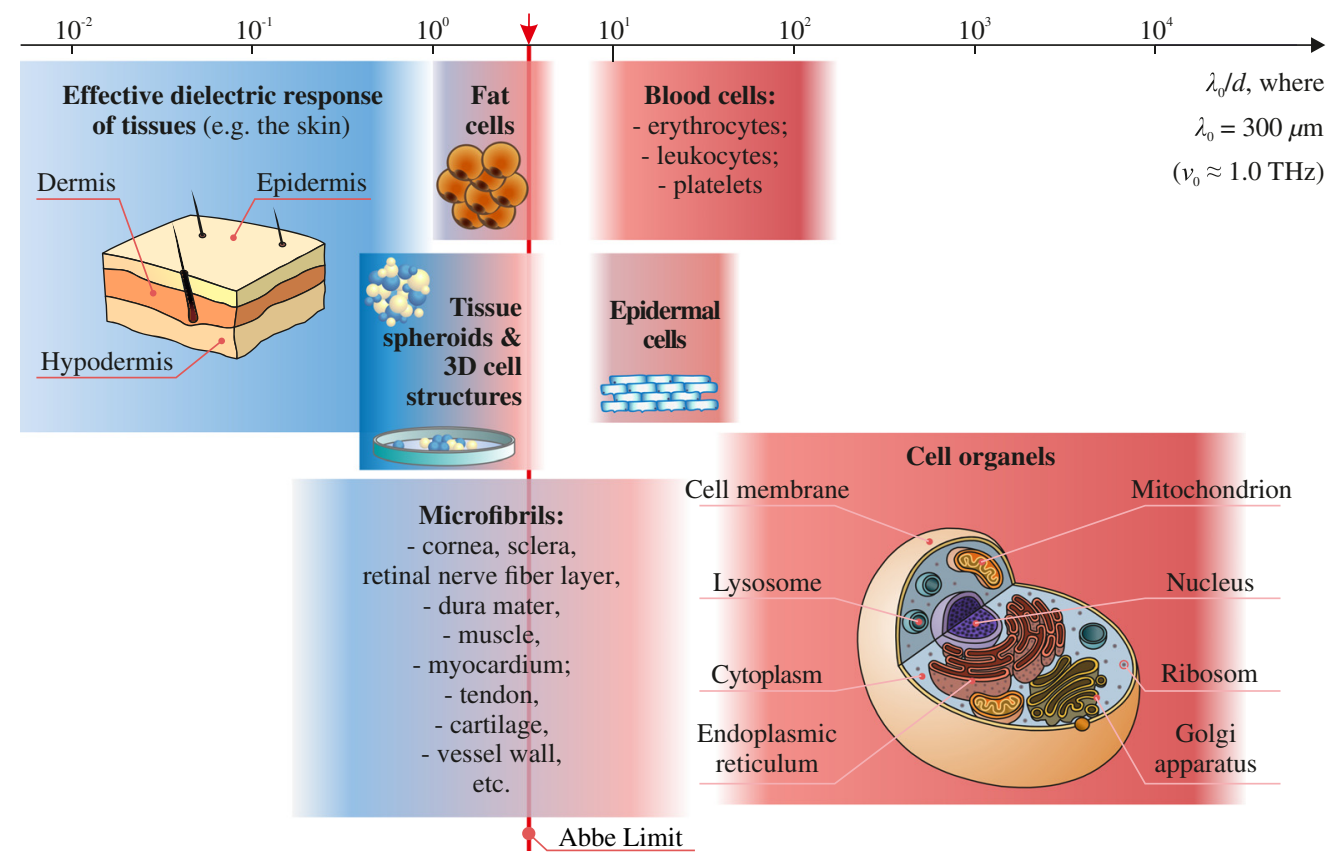

Fig. 4 Dimensions of the tissue structural elements at the THz-wavelength scale. Typical dimensions of the tissue structural elements $\delta$ are normalized by the particular wavelength of $\lambda_{0}=$ $300 \mu \mathrm{m}\left(\nu_{0} \simeq 1.0 \mathrm{THz}\right)$. Vertical solid red line defines the $\lambda / 2$-Abbe diffraction limit. Courtesy of the authors.

\subsection{Dimensions of Tissue Components Versus the THz Wavelengths}

Depending on the ratio between the dimensions of tissue structural elements $\delta$ and the freespace electromagnetic wavelength $\lambda$, one can expect distinct regimes of the electromagnetic wave-tissue interactions, which are governed by different physical regularities. ${ }^{49}$ When the tissue components are small in the wavelength scale $(\delta \ll \lambda)$, the Rayleigh scattering regime takes place and tissues are assumed to be homogeneous. In such case, one can use the effective medium theory ${ }^{2}$ for describing the electromagnetic-wave-tissue interactions, which is widely applied in the MMW range, that bounds the THz gap from its low-frequency side.$^{50}$ Otherwise, when the tissue structural elements have mesoscale dimensions $(\delta \sim \lambda)$, or even appear to be large $(\delta \gg \lambda)$, the Mie scattering effects occur and the radiation transfer theory should be applied to describe the interactions. This theory is widely used in the ultraviolet, visible, and IR bands $;{ }^{51}$ the latter is adjacent to the $\mathrm{THz}$ range at its high-frequency side.

In Fig. 4, dimensions of the typical tissue structural elements, such as microfibrils, separate cells, and cell organelles, ${ }^{52}$ are compared with the characteristic free-space $\mathrm{THz}$ wavelength of $\lambda=300 \mu \mathrm{m}(\nu \simeq 1.0 \mathrm{THz})$. Here, a vertical red solid line points out the $\simeq \lambda / 2$ Abbe diffraction limit of spatial resolution of lens- or mirror-based optical systems. On the one side, the majority of the tissue structural components are much smaller as compared with the defined $\mathrm{THz}$ wavelength, which allows using the effective medium theory for describing the THz-wave interaction with tissues comprised of such components. ${ }^{2}$ On the other side, numerous structural components of tissues are characterized by dimensions that are comparable to the $\mathrm{THz}$ wavelengths and, thus, become a source of the Mie scattering.

Despite the effective medium theory is more usual in THz biophotonics, ${ }^{2,3}$ an intermediate position of the $\mathrm{THz}$ waves between the IR waves (with their strong Mie scattering in tissues) and the MMW waves (almost insensitive to the tissue structural inhomogeneities) poses a challenging problem of selecting appropriate models of the THz-wave-tissue interactions.

\subsection{Effective Medium Theory in the THz Range}

The effective medium theory assumes tissues to be homogeneous at the THz-wavelength scale and describes the THz-wave-tissue interactions using models of their effective dielectric 
response. ${ }^{2,3}$ Such models define simultaneously frequency-dependent real $\varepsilon^{\prime}$ and imaginary $\varepsilon^{\prime \prime}$ parts of a complex dielectric permittivity

$$
\tilde{\varepsilon}=\varepsilon^{\prime}-i \varepsilon^{\prime \prime},
$$

or real $n^{\prime}$ and imaginary $n^{\prime \prime}$ parts of a complex refractive index

$$
\tilde{n}=n^{\prime}-i n^{\prime \prime} \equiv n-i \frac{c}{2 \pi \nu} \alpha \equiv \sqrt{\tilde{\varepsilon}},
$$

where $c \simeq 3 \times 10^{8} \mathrm{~m} / \mathrm{s}$ is the speed of light in free space, and $\alpha$ is an absorption coefficient (by field) in $\mathrm{cm}^{-1}$.

THz waves strongly interact with polar water molecules in liquid water (either free or bound), aqueous solutions, and tissue water. ${ }^{2,3,53}$ Therefore, content and state of water play dominant roles in the formation of the $\mathrm{THz}$ dielectric response of hydrated tissues. ${ }^{21}$ Similarly to the $\mathrm{THz}$ dielectric response of liquid water, aqueous solutions, and biological liquids, ${ }^{2,3}$ the THz-wave losses in tissues, which are defined by $\varepsilon^{\prime \prime}$ or $\alpha$, possess no resonant features. In the THz range, complex dielectric permittivity of water and hydrated media is usually described by the relaxation models, among which the double-Debye model should be emphasised as the most widely applied in $\mathrm{THz}$ biophotonics ${ }^{48,54-60}$

$$
\tilde{\varepsilon}=\varepsilon_{\infty}+\frac{\Delta \varepsilon_{1}}{1+i \omega \tau_{1}}+\frac{\Delta \varepsilon_{2}}{1+i \omega \tau_{2}},
$$

where $\omega=2 \pi \nu$ is a circular frequency, $\tau_{1}, \tau_{2}$ and $\Delta \varepsilon_{1}, \Delta \varepsilon_{2}$ are times and amplitudes of the "slow" and "fast" relaxations, $\varepsilon_{\infty}$ is a constant dielectric permittivity at high frequencies $\left[\omega \gg\left(2 \pi \tau_{i}\right)^{-1}\right]$. In Refs. 2 and 3, one can find parameters of the double-Debye model that are summarized for liquid water, as well as for different healthy and pathologically altered tissues ex vivo and in vivo.

In Figs. 5(a) and 5(b), real $\varepsilon^{\prime}$ and imaginary $\varepsilon^{\prime \prime}$ parts of the complex dielectric permittivity are plotted for the liquid water and epidermis of the skin ex vivo based on the double-Debye model

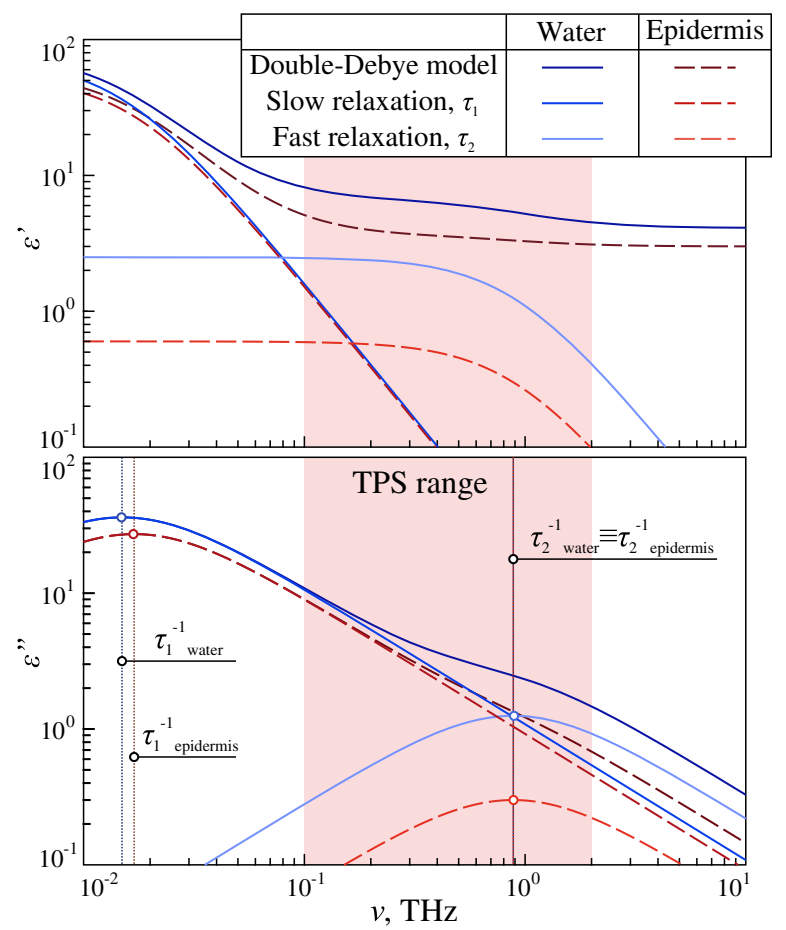

Fig. 5 Double-Debye models of the complex dielectric permittivity $\tilde{\varepsilon}$ for water and epidermis of the skin ex vivo reported in Ref. 48. Peach-colored area defines the spectral operation range of the THz-pulsed spectrometer that was used in Ref. 48 to measure the dielectric data. Courtesy of the authors. 
parameters from Ref. 48, respectively, for liquid water: $\varepsilon_{\infty}=4.1, \Delta \varepsilon_{1}=72.2, \Delta \varepsilon_{2}=2.5$, $\tau_{1}=10.6 \mathrm{ps}$, and $\tau_{2}=0.18 \mathrm{ps}$; for epidermis: $\varepsilon_{\infty}=3.0, \Delta \varepsilon_{1}=56.4, \Delta \varepsilon_{2}=0.6, \tau_{1}=10.0 \mathrm{ps}$, and $\tau_{2}=0.2$ ps. For both water and epidermis, $\varepsilon^{\prime \prime}$-curve is formed by the two broad absorption peaks, where one of them is attributed to the "slow" Debye relaxation $\Delta \varepsilon_{1}$ and centered far below the $\mathrm{THz}$ range [at the inverse relaxation time $\left(2 \pi \tau_{1}\right)^{-1}$ ], whereas another one represents the "fast" Debye relaxation $\Delta \varepsilon_{2}$ and centered at the high-frequency edge of the $\mathrm{THz}$ range [at the frequency of $\left(2 \pi \tau_{2}\right)^{-1}$ ]. In turn, $\varepsilon^{\prime}$-curve decays with increasing frequency, with some pronounced changes near the inverse relaxation times $\left(2 \pi \tau_{1}\right)^{-1}$ and $\left(2 \pi \tau_{2}\right)^{-1}$.

In Eq. (3), for free bulk water, the "slow" Debye relaxation $\Delta \varepsilon_{1}$ describes cooperative reorganization of water molecules connected by hydrogen bonds, whereas the "fast" Debye relaxation $\Delta \varepsilon_{2}$ represents vibrational motions of water molecules that are free from hydrogen bounds. ${ }^{61}$ Hydration of biological molecules in aqueous solutions and tissue might lead to more complex dielectric response. ${ }^{62,63}$ Electric charges of biological molecules create the electric field, which orients surrounding water molecules and leads to formation of hydrated water layers (shells) ${ }^{64}$ with their unique relaxation dynamics. Such hydration can either change the parameter of the double-Debye model ${ }^{65}$ or lead to appearance of additional relaxation or quasiresonant terms in the dielectric permittivity model. ${ }^{66}$ Furthermore, ionic conductivity and spectral fingerprints of hydrated ions might also contribute to the $\mathrm{THz}$ dielectric response of biological systems. ${ }^{67-69}$ However, an in-depth review of modern research works in the area of the $\mathrm{THz}$ dielectric spectroscopy of pure bulk water, aqueous solutions of biomolecules, segregated water, and tissues is far beyond the scope of the present review, but it can be found in Refs. 2 and 21.

Despite the fact that the discussed double-Debye model is generally accepted in $\mathrm{THz}$ biophotonics, physically it is not rigorous. Indeed, on the one hand, it implies fitting of the experimental data by the two broad absorption bands, centered either beyond or at the edges of the THz range (see Fig. 5). In other words, when using the double-Debye model, one deals with something similar to the experimental data extrapolation. However, in the case of taking appropriate initial conditions during the fitting procedure, the double-Debye model yields very convenient parametrization of the spectral curves by only five independent parameters: $\varepsilon_{\infty}, \Delta \varepsilon_{1}$, $\Delta \varepsilon_{2}, \tau_{1}$, and $\tau_{2}$. On the other hand, the Debye kernels in Eq. (3) do not fulfill the sum rule for the oscillator strength and, thus, predict infinite number of charge carriers/dipoles $N$ underlying the dielectric response of a medium: ${ }^{70}$

$$
N \propto \int_{0}^{\infty} \omega \varepsilon^{\prime \prime} \mathrm{d} \omega=\text { finite }
$$

To mitigate this drawback, the double-overdamped oscillator model was applied to describe the $\mathrm{THz}$ dielectric response of tissues in Ref. 15. As compared with the double-Debye model, a pair of the overdamped oscillators provides almost equal dielectric curves $\varepsilon^{\prime}$ and $\varepsilon^{\prime \prime}$ in the analyzed THz range but predicts considerably lower losses $\varepsilon^{\prime \prime}$ at high frequencies $\omega \gg\left(2 \pi \tau_{i}\right)^{-1}$ and, thus, satisfies the sum rule. Other semiempirical relaxation models of a complex dielectric permittivity exist and are sometimes applied for fitting the $\mathrm{THz}$ data, including the ColeCole,${ }^{71,72}$ Davison-Cole,${ }^{73}$ or Havriliak-Negami ${ }^{74}$ models. They imply more parameters to take into account possible asymmetry of the discussed broad absorption peaks in the $\varepsilon^{\prime \prime}$-curves.

Moreover, the aforementioned models of the tissue complex dielectric permittivity in the $\mathrm{THz}$ range have quite qualitative character. In fact, earlier, the two broad absorption peaks, predicted by these models, were observed experimentally mostly for the liquid water and aqueous solutions $;{ }^{53}$ at the same time, for biological tissues, they have not been observed experimentally yet involving broadband dielectric measurements, which is, probably, due to complexity of such experiment. Thus, these relaxation models are applied to describe the tissues response only intuitively. Moreover, structure, relaxation dynamics, and $\mathrm{THz}$ response of liquid water and, thus, water-containing biological systems can be more complex. Their dielectric permittivity model can comprise three or even more relaxation terms, each representing a particular fraction of free/ bound or segregated water, with distinct electrodynamic characteristics, that can be predicted, for example, by numerical simulations using first principles. ${ }^{66,75}$ Detailed overview of picosecond 
dynamics of water and water-containing media, as well as their $\mathrm{THz}$ dielectric response, deserves separate in-depth review, being out of the scope of this paper.

Nevertheless, information about a tissue complex dielectric permittivity (or a complex refractive index) helps to model the THz-wave-tissue interaction within the framework of classical electrodynamics, which is of crucial importance in $\mathrm{THz}$ spectroscopy and imaging of tissues aimed at medical diagnosis of different pathological processes. These data can be also useful in $\mathrm{THz}$ exposure of tissues since they provide an information about the penetration depth of $\mathrm{THz}$ waves into the tissues $\delta=1 / \alpha$ or the volume of the exposed tissue $V \simeq \pi D^{2} \delta / 4$, where $D$ is the $\mathrm{THz}$ beam spot diameter.

\subsection{Fingerprints of the Mie Scattering in the $\mathrm{THz}$ Range}

Despite the aforementioned effective medium theory is widely applied in $\mathrm{THz}$ biophotonics, a lot of biological objects and tissues possess structural inhomogeneities with the dimensions comparable to the THz wavelengths; see Fig. 4. For such objects, the Mie scattering effects should be taken into account. ${ }^{51}$

For example, in Refs. 3 and 76, considerable structural inhomogeneities of fibrous connective tissues of the breast were studied both experimentally, using the $0.15 \lambda$-resolution $\mathrm{THz}$ solid immersion microscopy, ${ }^{77}$ and theoretically, using analytical methods of the Mie scattering theory. $\mathrm{THz}$ optical properties of separate fat cells and their agglomerates were found to differ from that of the surrounding fibrous connective tissues of the human breast ex vivo. Such cells form sources of the Mie scattering at $\mathrm{THz}$ frequencies. The calculated parameters of such scatterers (i.e., their scattering phase function, differential and integral cross sections, and scattering anistoropy factor) considerably differ from those inherent to the Rayleigh scattering regime. In Refs. 17 and 29, THz solid immersion microscopy revealed structural heterogeneities of intact brain tissues and glioma model 101.8 from rats ex vivo, as well as heterogeneous character of decellularized bovine pericardium collagen matrices. Finally, in Refs. 78-80, polarizationsensitive $\mathrm{THz}$ imaging provided useful information for the differentiation between healthy and pathologically altered tissues, which also indirectly justified the Mie-like character of the THzwave scattering in tissues. Namely, in this imaging modality, one observes changes in polarization of the $\mathrm{THz}$ wave interacting with tissues, which could not be described in the framework of the above-mentioned effective medium theory. All these experimental findings stimulate further research and development of approaches for describing the THz-wave-tissue interactions that simultaneously account for the dispersion and absorption properties of tissue components, as well as geometry and organization of scatterers in tissues.

This approach could rely on the radiation transfer theory, applied for describing the electromagnetic-wave-tissue interactions in the ultraviolet, visible, and IR ranges. ${ }^{51}$ The basis of the radiation transfer theory is a radiation transfer equation, ${ }^{49}$ which defines a radiance $I(\mathbf{r}, \hat{s})$ at a point $\mathbf{r}$ in the direction $\hat{s}$ :

$$
\frac{\partial I(\mathbf{r}, \hat{s})}{\partial s}=-\mu_{\mathrm{t}} I(\mathbf{r}, \hat{s})+\mu_{\mathrm{s}} \int_{4 \pi} I\left(\mathbf{r}, \hat{s}^{\prime}\right) p\left(\hat{s}, \hat{s}^{\prime}\right) \mathrm{d} \mathbf{\Omega}^{\prime}+I_{0}(\mathbf{r}, \hat{s}),
$$

where $\mu_{\mathrm{s}}$ and $\mu_{\mathrm{t}}$ are the scattering and total (power absorption $\alpha_{\mathrm{p}}$ and scattering $\mu_{\mathrm{s}}$ ) coefficients in $\mathrm{cm}^{-1}, p\left(\hat{s}, \hat{s}^{\prime}\right)$ is the scattering phase function, $\boldsymbol{\Omega}^{\prime}$ is the unit solid angle around $\hat{s}^{\prime}$, and $I_{0}(\mathbf{r}, \hat{s})$ is the radiance of internal sources. Scattering phase function accounts for the characteristic angular distribution of the Mie scattering, including anisotropy of the tissue scattering properties.

Studying the scattering effects in tissues seems to be important for the $\mathrm{THz}$ diagnosis, where they can either complicate differentiation of tissues or become a source of additional useful information. In $\mathrm{THz}$ exposure of tissues, scattering effects can play an important role due to the effects of electromagnetic field confinements at the shadow side of mesoscale dielectric obstacles that can considerably (by few orders of magnitude) enhance local irradiance of tissues by $\mathrm{THz}$ waves and, thus, increase efficiency of tissue exposure to $\mathrm{THz}$ waves. 


\section{Modern THz-Wave Emitters}

Currently, tremendous efforts are still paid to boost the development of $\mathrm{THz}$ emitters. The $\mathrm{THz}$ spectral range and, particularly, the exposure technologies attract increasing interest owing to the appearance of solutions for THz-wave generation. ${ }^{6,7}$ Such emitters working either in $\mathrm{CW}$ or pulsed mode allow generation of the output power ranging from the nanowatts to kilowatts. Here, we briefly overview the recent progress in this area with an emphasis on the practically important devices that are capable of solving modern research and engineering problems of tissue exposure to $\mathrm{THz}$ waves.

Despite a wide variety of existing THz-wave emitters with their rich diversity of operation principles and regimes, output frequencies, and powers, this review focuses only on widespread systems that went beyond the research work of a physical laboratory and, in our opinion, can be applied for studying biological effects of $\mathrm{THz}$ waves or even for therapeutic applications of $\mathrm{THz}$ technology. Thus, in Tables 1 and 2, we summarize only the typical technical characteristics of the discussed principles and devices. However, we should stress that unique THz systems developed for experiments in a physical laboratory can provide somewhat higher performance, i.e., broader spectral range, higher power, and wider tunability. In fact, in Tables 1 and 2, we deliberately underestimate the spectral operation ranges of some $\mathrm{THz}$ emitters. We consider only those parts of the spectral operation ranges, where $\mathrm{THz}$ emitters provide reliable output power, and neglect, at the same time, much less-intense side lobes and tails of the emitted THz spectra.

Table 1 Typical CW THz emitters.

\begin{tabular}{|c|c|c|c|c|c|c|}
\hline Source and principle & Frequency & $\begin{array}{l}\text { Output } \\
\text { power }\end{array}$ & $\begin{array}{l}\text { Tunable } \\
\text { bandwidth }\end{array}$ & $\begin{array}{l}\text { Conversion } \\
\text { efficiency }\end{array}$ & $\begin{array}{l}\text { Operation } \\
\text { temp. }\end{array}$ & Refs. \\
\hline $\begin{array}{l}\text { Interaction between electron beam and } \\
\text { back-traveling electromagnetic wave }\end{array}$ & $<1.0 \mathrm{THz}$ & $\begin{array}{c}\mathrm{mW} \text { to } \\
\mathrm{kW}\end{array}$ & ++ & $<10^{-2}$ & $293 \mathrm{~K}$ & $82-86$ \\
\hline \multicolumn{7}{|l|}{ DFG and PG } \\
\hline $\begin{array}{l}\text { Nonlinear optical process by frequency } \\
\text { difference of two optical beams or two } \\
\text { stimulated photons in a nonlinear crystal }\end{array}$ & $<5.0 \mathrm{THz}$ & $\begin{array}{c}\mathrm{mW} \text { to } \\
\mathrm{kW}\end{array}$ & ++++ & $<10^{-3}$ & $293 \mathrm{~K}$ & $6,88-96$ \\
\hline \multicolumn{7}{|l|}{ OPGL } \\
\hline $\begin{array}{l}\text { Rotational transitions between vibrational } \\
\text { modes in optically pumped molecular } \\
\text { gases }\end{array}$ & $<8.0 \mathrm{THz}$ & $\mu \mathrm{W}$ & ++ & $<10^{-2}$ & $293 \mathrm{~K}$ & $97-102$ \\
\hline \multicolumn{7}{|l|}{ Diode-based frequency multiplier } \\
\hline $\begin{array}{l}\text { Frequency multiplication of diode-based } \\
\text { microwave sources with nonlinear media }\end{array}$ & $<2.5 \mathrm{THz}$ & $\mu \mathrm{W}$ & +++ & $<0.4$ & $<293 \mathrm{~K}$ & $103-109$ \\
\hline \multicolumn{7}{|l|}{ Photomixing } \\
\hline $\begin{array}{l}\text { Photocurrent oscillation in photomixer } \\
\text { by frequency difference of two optical } \\
\text { beams }\end{array}$ & $<4.0 \mathrm{THz}$ & $\begin{array}{l}\mu \mathrm{W} \text { to } \\
\mathrm{mW}\end{array}$ & ++++ & $\begin{array}{l}\sim 10^{-6} \text { to } \\
10^{-3}\end{array}$ & $293 \mathrm{~K}$ & $110-114$ \\
\hline \multicolumn{7}{|l|}{ Quantum cascade laser } \\
\hline $\begin{array}{l}\text { Electrons cascading in intersubband } \\
\text { transitions with quantum well } \\
\text { semiconductor heterostructures }\end{array}$ & $\begin{array}{l}1.0 \text { to } \\
6.0 \mathrm{THz}\end{array}$ & $\begin{array}{c}\mathrm{mW} \text { to } \\
\mathrm{W}\end{array}$ & ++++ & $<0.3$ & $<200 \mathrm{~K}$ & $115-121$ \\
\hline \multicolumn{7}{|l|}{ Gyrotron } \\
\hline $\begin{array}{l}\text { Coherent bremsstrahlung radiation } \\
\text { between the gyrating beam electrons } \\
\text { and electromagnetic wave }\end{array}$ & $<1.5 \mathrm{THz}$ & $\begin{array}{l}\mathrm{W} \text { to } \\
\mathrm{kW}\end{array}$ & ++ & $\begin{array}{c}10^{-3} \text { to } \\
10^{-1}\end{array}$ & $293 \mathrm{~K}$ & $151-160$ \\
\hline
\end{tabular}


Table 2 Typical pulsed THz emitters.

\begin{tabular}{|c|c|c|c|c|c|}
\hline Source and principle & Frequency & $\begin{array}{c}\text { Average } \\
\text { power }\end{array}$ & $\begin{array}{l}\text { Conversion } \\
\text { efficiency }\end{array}$ & $\begin{array}{l}\text { Operation } \\
\text { temp. }\end{array}$ & Refs. \\
\hline \multicolumn{6}{|l|}{ Generation in PCA } \\
\hline $\begin{array}{l}\text { Acceleration and decay of free charge } \\
\text { carriers in biased semiconductor gap } \\
\text { pumped with ultrafast laser pulse }\end{array}$ & $<3.0 \mathrm{THz}$ & $\mu \mathrm{W}-\mathrm{mW}$ & $\sim 10^{-6}-10^{-2}$ & $293 \mathrm{~K}$ & $\begin{array}{c}122-124,126 \\
130-132\end{array}$ \\
\hline \multicolumn{6}{|l|}{ OR } \\
\hline $\begin{array}{l}\text { Time varying nonlinear polarization in } \\
\text { nonlinear crystal pumped with } \\
\text { ultrafast laser pulse }\end{array}$ & $<7.0 \mathrm{THz}$ & $\mu \mathrm{W}-\mathrm{mW}$ & $\sim 10^{-7}-10^{-2}$ & $293 \mathrm{~K}$ & $136-150$ \\
\hline \multicolumn{6}{|l|}{ Gyrotron } \\
\hline $\begin{array}{l}\text { Coherent bremsstrahlung radiation } \\
\text { between the gyrating beam electrons } \\
\text { and electromagnetic wave }\end{array}$ & $<1.5 \mathrm{THz}$ & $\mathrm{kW}-\mathrm{MW}$ & $<0.6$ & $293 \mathrm{~K}$ & $161-164$ \\
\hline
\end{tabular}

\subsection{CW or Quasi-CW THz Sources}

\subsubsection{Backward wave oscillator}

In terms of the CW sources, backward wave oscillator (BWO) ${ }^{81}$ is one of the well-known methods to generate intense $\mathrm{THz}$ radiation. Nanosecond pulse with a maximum output power in $\mathrm{kW}$ level is also achievable by this method. ${ }^{82} \mathrm{In} \mathrm{BWO}$, the $\mathrm{THz}$ radiation is generated based on the interaction between an electron beam and an electromagnetic wave traveling in the opposite direction. An electron beam is emitted from a heated cathode and collimated by magnetic field. A modulation device, such as metal grating or corrugated rectangular waveguide, is carefully arranged to modulate the electron beam and give rise to a surface electromagnetic wave. The frequency of the electromagnetic wave could be tuned by adjusting the velocity of electron beam, thus, obtaining the $\mathrm{THz}$ radiation. ${ }^{83}$ Mineo et al. demonstrated a BWO featuring a $20 \%$ tuning bandwidth at the central frequency of $1.0 \mathrm{THz}$ with the output power of $\sim 100 \mathrm{~mW} .{ }^{84} \mathrm{In} 2015$, a plasma wave-assisted BWO was employed to radiate $\mathrm{THz}$ waves in the range of 186 to $202 \mathrm{GHz}$ with the maximum power of $20 \mathrm{~W}$ by adopting a pseudospark-sourced electron beam. ${ }^{85}$ Recently, oversized BWOs operated in the frequency ranges of 260 to $340 \mathrm{GHz}$ and 310 to $390 \mathrm{GHz}$ were studied theoretically and experimentally. Two BWO types were designed and tested, and the detected peak power of a few hundred of $\mathrm{mW}$ was obtained by adopting the optimal structures. ${ }^{86}$

BWOs are capable of operation in a pure $\mathrm{CW}$ regime ${ }^{81}$ with the monochromatic spectral output, quite wide spectral tunability, the spectral line-width of down to $\sim 10^{-5} \nu$, and the average output power of $\sim 10^{-1}$ to $10^{-4} \mathrm{~W}$. Note that the output power decreases with increasing operation frequency $\nu$. Such CW BWOs are widely applied in the THz dielectric measurements. ${ }^{81}$

\subsubsection{Difference frequency generation and parametric generation}

The principles of difference frequency generation (DFG) and parametric generation (PG) are all based on nonlinear optical process. ${ }^{6}$

For DFG, two optical beams featuring narrow bandwidth and slightly different frequencies colinearly propagate into a nonlinear crystal, leading to a $\mathrm{THz}$ radiation generated by the secondorder nonlinear polarization at the difference frequency of the two optical beams. ${ }^{87}$ So far, various nonlinear crystals, for example, $\mathrm{GaSe}^{88}$ and $\mathrm{GaP},{ }^{89}$ were utilized to generate radiation up to $5.0 \mathrm{THz}$ based on DFG. The output $\mathrm{THz}$ power of DFG was also improved from the $\mathrm{mW}$ to $\mathrm{kW}$ level. In 2014, by stacking four GaP plates reversely, the highest output power of $2.73 \mathrm{~kW}$ 
was achieved at around $2.7 \mathrm{THz}$ and the conversion efficiency was demonstrated to be $\sim 10^{-3}$. It was also proved that the reversed $\mathrm{GaP}$ plates demonstrate stronger photon conversion than aligned $\mathrm{GaP}$ plates. ${ }^{90}$

For PG, only one optical pump beam is used to stimulate two photons, one is commonly named as "idler," whereas another is the THz one. ${ }^{91}$ The THz wave could obtain dramatic amplification when a phase-matching condition is satisfied. The tuning of the $\mathrm{THz}$ frequency is continuously achievable by controlling the relative angle between the idler and pump beam. ${ }^{92,93}$ Kawase et al. developed a widely tunable $\mathrm{THz}$ wave parametric generator in the range of 0.7 to $2.4 \mathrm{THz}$ using injection seeding. The maximum peak output $\mathrm{THz}$ power exceeded $200 \mathrm{~mW}^{94}$ The performance of injection-seeding-based parametric generator was further improved through utilizing the laser light scattering from a nonlinear crystal by the same group. It helped to achieve the $\mathrm{THz}$ radiation in the range between 0.7 and $3.0 \mathrm{THz}$ and improve the maximum output power from the $\mathrm{mW}$ to $\mathrm{kW}$ level. ${ }^{91}$ Afterward, the maximum output power was increased to $\simeq 50 \mathrm{~kW}$ by Minamide et al. ${ }^{95}$ and Hayashi et al., ${ }^{96}$ respectively, with or without using the microchip laser.

\subsubsection{Optically pumped gas laser}

Optically pumped gas laser (OPGL) features the capability of generating $\mathrm{THz}$ waves with narrow linewidth. ${ }^{6}$ The basic principle of OPGL is based on population inversion in the gas molecules. This population inversion occurs when the gas molecules, possessing lower vibrational mode, are optically pumped. Since the gas molecules feature permanent dipole moments, the induced rotational transitions between high and low vibrational modes can be directly coupled to electromagnetic radiation, thus, generating $\mathrm{THz}$ wave. ${ }^{97}$

Various molecular gases have been demonstrated for generating $\mathrm{THz}$ wave in the range of 0.1 to $8 \mathrm{THz}$, such as $\mathrm{CH}_{3} \mathrm{~F}, \mathrm{CH}_{3} \mathrm{OH}, \mathrm{NH}_{3}$, and $\mathrm{CH}_{2} \mathrm{~F}_{2} \cdot{ }^{98,99}$ Recently, Chevalier et al. proposed a research on widely tunable $\mathrm{THz}$ gas laser, in which over 37 laser lines were observed from 0.25 to $0.96 \mathrm{THz}$ using optically pumped nitrous oxide $\left(\mathrm{N}_{2} \mathrm{O}\right)$ laser. The possibility of achieving electromagnetic waves with frequencies above $1.0 \mathrm{THz}$ with a mW-level output power based on QCL pumped gas laser was predicted by theoretical analysis. ${ }^{100}$ Wienold et al. ${ }^{101}$ presented a gas laser based on QCL pumped ${ }^{15} \mathrm{NH}_{3}$ molecules; several laser lines with the output power of up to $30 \mu \mathrm{W}$ were obtained around $4.5 \mathrm{THz}$ by exploiting the molecular symmetry and employing an alternative resonator. Liu et al. ${ }^{102}$ proposed a tunable optically pumped $\mathrm{CH}_{3} \mathrm{~F}$ gas laser with a germanium ealton serving as spectrum splitter, four $\mathrm{THz}$ laser lines corresponding to a conversion efficiency of $\sim 10^{-3}$ were observed in the range of 0.5 to $1.7 \mathrm{THz}$ by tuning the incident angles and pump wavelengths.

\subsubsection{Diode-based frequency multiplier}

Diode-based frequency multiplier is a solid-state $\mathrm{THz}$ source, which implements microwave multiplication from IMPATT (IMPact ionization Avalanche Transit-Time), Gunn, tunnel, and other diodes. By making appropriate operations, the negative resistance devices could be built based on the aforementioned diodes. A resonator coupled with the negative resistance devices is used to generate an AC signal intended for $\mathrm{CW}$ microwave radiation. In this process, the zeroattenuation oscillator is a crucial element for the microwave radiation, which is obtained through adjusting the magnitude of the negative resistance devices. Consequently, the $\mathrm{THz}$ wave can be received after the microwave passing through a series of frequency multiplier chains, where the Schottky diodes are commonly used as a nonlinear media for harmonic generation of microwave. $^{6}$

The diode-based THz sources are usually compact and operate at room temperatures, which is convenient for practical application. The average output power reaches the $\mathrm{mW}$ level and can be improved by cooling. For example, in 2002, Maiwald et al. ${ }^{103}$ demonstrated a peak output power of $120 \mu \mathrm{W}$ (at $1.178 \mathrm{THz}$ ) at room temperatures and an improved peak output power of $190 \mu \mathrm{W}$ (at $1.183 \mathrm{THz}$ ) by cooling down to $113 \mathrm{~K}$. Most of the reported multipliers feature the output power of 1 to $200 \mu \mathrm{W}$ at the frequencies of $<2.5 \mathrm{THz}{ }^{104-109}$ 


\subsubsection{Photomixing}

Photomixing, also known as optical heterodyne generation, is one of the solid-state $\mathrm{CW} \mathrm{THz}$ generation technique, capable of making narrow band signals with exceptional tunability. ${ }^{110}$ Two CW laser beams with identical polarization and slightly different frequencies are utilized to generate a $\mathrm{THz}$ beat, which illuminates a photomixer, resulting in a modulated photocurrent. The induced photocurrent oscillations adjusted by tuning the frequency difference between the applied lasers determine the desired parameters of THz radiation. ${ }^{111}$ The main well-known disadvantage of this technique is the relatively low output power due to the requirement of $\mathrm{CW}$ optical excitation and shortage of semiconductor materials with high thermal conductivities.

Low-temperature-grown GaAs has been employed as the photomixer material in the last few years to generate $\mathrm{THz}$ radiation with the frequencies up to $3.0 \mathrm{THz} .{ }^{112}$ The typical optical-to-THz conversion efficiency for the photomixing method is $\sim 10^{-6}$ to $10^{-5}$, which limits the output power in the order of mWs. ${ }^{113}$ Despite tremendous efforts have been put in the enhancement of photomixer performance, the output $\mathrm{CW}$ power is still limited by the $\mathrm{mW}$ level. Recently, Ironside et al. ${ }^{114}$ proposed a metamaterial-enhanced photomixer by employing a metalsemiconductor-metal cavity; such photomixer is characterized by the conversion efficiency of $\sim 10^{-3}$ and is capable of generating $\mathrm{THz}$ radiation in the $\mathrm{mW}$ range.

\subsubsection{Quantum cascade laser}

Quantum ascade laser (QCL) is undisputedly the only solid-state source that can generate $\mathrm{THz}$ radiation above $1.0 \mathrm{THz}$ with an average output power at $\mathrm{W}$ level. ${ }^{115}$ The QCL realization is generally based on electrons cascading in intersubband transitions. Driven by electric field, the electrons are injected through a semiconductor heterostructure possessing multiple quantum wells, during which the electrons transit from a state with higher valence band energy to a lower state, thus, generating radiative emission. The efficient laser emission can be obtained, when a large population inversion condition is satisfied. ${ }^{6}$ The QCL tunability is mainly based on the structure of the semiconductor that offers superior bandwidth as compared with the diode-based sources.

To date, the high-power QCLs, operating in the frequency range of 1.0 to $6.0 \mathrm{THz}$, were demonstrated, with a few-W output power in pulsed mode and up to hundreds of $\mathrm{mW}$ in CW. ${ }^{115-117}$ In Ref. 118, Li et al. proposed a surface-plasmon waveguide embedded with an active region featuring a bound-to-continuum transition, based on which a THz QCL with the peakpulsed output power of $>1 \mathrm{~W}$ from the single facet at $3.4 \mathrm{THz}$ was demonstrated. Williams et al. ${ }^{119}$ proposed CW QCL, with the power of $138 \mathrm{~mW}$ and the frequency of $4.4 \mathrm{THz}$, that employs a semiinsulating surface-plasmon waveguide and a resonant-phonon depopulation scheme. With 10 years of development, Wang et al. ${ }^{120}$ significantly improved the CW QCL output power to $230 \mathrm{~mW}$ by adopting a hybrid bound-to-continuum transition and resonant phonon extraction. One of the main challenges for QCL technology is the operation at room temperatures since the output power of QCLs decreases drastically as the temperature increases. The highest-reported operation temperature for QCLs without magnetic field assistance is close to 200 and $130 \mathrm{~K}$ for the pulsed and $\mathrm{CW}$ modes, correspondingly. ${ }^{121}$

\subsection{Pulsed THz Sources}

\subsubsection{Photoconductive antennas}

The initial exploration of pulsed broadband $\mathrm{THz}$ wave generation using photoconductive antenna (PCA) could be traced back to 1970 s to 1980 s. ${ }^{122-125}$ The PCA generation principle is based on the free charge carries (electron and hole) excited in a biased semiconductor gap with femtosecond laser pulses. ${ }^{126-128}$ These free charge carries are accelerated by the applied static or alternating electric field that gives rise to a transient photocurrent. Simultaneously, the density of charge carries goes down due to the their trapping and recombination. The pulsed $\mathrm{THz}$ radiation is generated during the acceleration and trapping of these free charge carries. The decay time of the charge carries, which influence the duration and spectral bandwidth of thus generated 
$\mathrm{THz}$ pulse, is defined by the lifetime and mobility of carriers in a photoconductor. Therefore, photoconductors with shorter carrier lifetime are preferred to generate $\mathrm{THz}$ pulses with a broader frequency-domain bandwidth. ${ }^{126,129}$

To date, tremendous studies have been done to improve the performance of PCAs. Berry et al. ${ }^{130}$ demonstrated a plasmonic photoconductive $\mathrm{THz}$ source with enhanced output power by employing two-dimensional plasmonic contact electrodes. An average output power of $\simeq 0.25 \mathrm{~mW}$, which is 20 times higher than conventional PCAs, was achieved in the frequency range of up to $1.5 \mathrm{THz}$. In Ref. 131, Yang et al. reported a photoconductive emitter with the optical-to-THz power conversion efficiency as high as $7.5 \%$ using three-dimensional (3D) plasmonic contact electrodes. A broadband $\mathrm{THz}$ wave in the 0.1 to $2.0 \mathrm{THz}$ range with the output power higher than $0.1 \mathrm{~mW}$ was experimentally observed at a 1.4-mW optical pump. Thereby, as compared with conventional PCA-based THz sources, the above-mentioned hybrid PCAs offer higher optical-to-THz conversion efficiency. ${ }^{130,132-135}$

\subsubsection{Optical rectification}

Optical rectification (OR) is one of the most commonly used methods to generate pulsed $\mathrm{THz}$ radiation, which is based on second-order nonlinear optical effect. In the OR process, an ultrafast optical pulse is normally employed to illuminate a nonlinear optical crystal. The pulsed $\mathrm{THz}$ radiation is then generated by the time-varying nonlinear polarization. ${ }^{136}$ The bandwidth of the pulsed $\mathrm{THz}$ wave is roughly inversely proportional to the duration of the ultrafast optical pulse. The intensity of generated $\mathrm{THz}$ wave can be optimized by aligning the polarization of the incident optical beam. ${ }^{6}$

Schneider et al. ${ }^{137}$ and Venkatesh et al. ${ }^{138}$ demonstrated broadband $\mathrm{THz}$ radiations in the ranges of 0.4 to $6.7 \mathrm{THz}$ and 0.1 to $3.0 \mathrm{THz}$, respectively, using a nonlinear organic salt. A near single-cycle $\mathrm{THz}$ pulses with the average power of $100 \mu \mathrm{W}$ were demonstrated by the lithium niobite crystal $\left(\mathrm{LiNbO}_{3}\right)$ pumping with femtosecond optical laser pulses. The maximum energy of up to $10 \mu \mathrm{J}$ was detected at the frequency of $0.5 \mathrm{THz}$, which corresponds to the opticalto-THz energy conversion efficiency of $\sim 6 \times 10^{-4} .{ }^{139}$ The maximum energy of pulsed THz wave radiated from $\mathrm{LiNbO}_{3}$ crystal was improved to $180 \mu \mathrm{J}$ by Jang et al. ${ }^{140}$ The highest average $\mathrm{THz}$ power of about $66 \mathrm{~mW}$ in the 0.1 to $4.0 \mathrm{THz}$ range has been obtained with a few-cycle ultrafast laser-driven $\mathrm{THz}$ source by Meyer et al. ${ }^{141}$ through optimizing pump spot size and pump pulse duration. Both studies achieved a conversion efficiency on the order of $\sim 10^{-4}$. In Refs. 142 and 143 , by satisfying the phase-matching condition, the conversion efficiency was dramatically improved to $\sim 10^{-2}$, pulsed $\mathrm{THz}$ generation with the pulse energies of 20 and $270 \mu \mathrm{J}$ and the frequency ranges of 0.1 to $5.0 \mathrm{THz}$ and 0.1 to $6.0 \mathrm{THz}$ was demonstrated.

In Ref. 144, Tripathi et al. demonstrated high-power THz-wave generation via OR of femtosecond pulses in 4-dimethylamino-N-methyl-4-stilbazolium tosylate crystal using a fiber-based laser pump, which paths the way for creating ergonomic high-power THz emitters. In Refs. 145148 , THz-wave generation was demonstrated in $\simeq 0.1$ to $10.0 \mathrm{THz}$ range, using OR of near-IR femtosecond laser pulses (a Cr:forsterite laser system with a TW peak power) in a nonlinear organic crystal, with the output pulse duration and energy of $\simeq 0.5$ to $0.7 \mathrm{ps}$ and $<75 \mu \mathrm{J}$, respectively. An experimental system for studying the THz-wave biological effects was developed relying on these unique $\mathrm{THz}$ setups. ${ }^{149,150}$

\subsection{THz Gyrotrons}

Gyrotron is one of the most powerful THz-wave sources in both $\mathrm{CW}$ and pulsed mode. Therefore, it is increasingly contributing to many application fields, such as nuclear magnetic resonance with signal enhancement using dynamic nuclear polarization, electron cyclotron resonance heating of fusion plasma, electron spin resonance spectroscopy, and x-ray detected magnetic resonance. ${ }^{151,152}$

The operation principle of gyrotron is based on the electron cyclotron resonance maser instability. The azimuthal and axial bunching of the helically moving beam electrons occurs due to the electromagnetic field stimulation, resulting in a proper synchronism between the electron beam and the electromagnetic wave excited in the resonant cavity, during which the transverse energy 
of the gyrating beam electrons can be transferred via coherent bremsstrahlung radiation for enhancing the excited electromagnetic wave. ${ }^{153}$ Due to the above principle, gyrotron generally operates at a fixed frequency close to the resonance frequency, and there are two ways that are commonly adopted for the frequency tunability in gyrotrons: tuning the magnetic field intensity or harmonic number of the cyclotron resonance. Nowadays, the highest frequency that can be achieved with the gyrotrons has already exceeded $1.0 \mathrm{THz}$ for both $\mathrm{CW}$ and pulsed mode.

A CW gyrotron that is based on a 20-T superconducting pulsed magnet achieved for the first time a breakthrough of $1.0 \mathrm{THz} .{ }^{154}$ Its operation frequency and the output power were as high as $1.08 \mathrm{THz}$ and $\sim 100$ to $200 \mathrm{~W}$, respectively. Nevertheless, majority of the reported CW gyrotrons possess an output power at W-level and sub-THz operation frequencies, ${ }^{155-157}$ whereas a few can obtain kW-level output power. For example, in Ref. 158, a continuously tunable CW gyrotron with the maximum output power of $\sim 400 \mathrm{~W}$ was demonstrated at the vicinity of $\sim 0.395 \mathrm{THz}$, with the corresponding maximum energy conversion efficiency of $4.3 \%$. Another $\mathrm{CW}$ gyrotron, which was developed for the high frequency material processing, features the output power and operation frequency of $\sim 2 \mathrm{~kW}$ and $0.3 \mathrm{THz}$, respectively, operates in the magnetic field of up to $12 \mathrm{~T}$, and provides the maximum power efficiency of $\sim 15 \% .{ }^{159,160}$

For pulsed gyrotrons, the output power is even higher, which is generally at the level of $\mathrm{kW}$ and up to MW. ${ }^{152,156,161}$ For example, the MW-level gyrotrons with the output frequencies of 110 and $170 \mathrm{GHz}$ were developed based on the depressed collector and the low-loss synthetic diamond window for efficiency improvement and high power Gaussian beam output. ${ }^{162}$ For these systems, the maximum efficiency of $\sim 57 \%$ was obtained at a 1.1-MW short pulse operation. The generation frequency of the pulsed gyrotron was significantly increased over $1.0 \mathrm{THz}$ by the research group from IAP RAS through the use of intense magnetic fields. In Ref. 163, the radiation power and energy of $\sim 1.5 \mathrm{~kW}$ and $75 \mathrm{~mJ}$, respectively, in a single shot regime were observed at the frequency of $1.022 \mathrm{THz}$ with the magnetic field of $38.5 \mathrm{~T}$. Afterward, a pulsed gyrotron was reported to operate at even higher frequency in the fundamental cyclotron resonance with a magnetic field strength of $\sim 50 \mathrm{~T} .{ }^{164}$ The highest generation frequency of $1.3 \mathrm{THz}$ was achieved, whereas the average output power was $\sim 0.5 \mathrm{~kW}$.

\section{Terahertz Exposure of Biological Objects with Different Levels of Organization}

Rapid progress in $\mathrm{THz}$ technology, together with appearance of effective $\mathrm{THz}$ optoelectronic components and THz-wave generation principles, forces a translation of the $\mathrm{THz}$ technology into everyday practice, as well as increase an effect of $\mathrm{THz}$ radiation on humans. This rises the questions about the safety limits of biological systems' exposure to $\mathrm{THz}$ waves. Defining the permissible exposure doses is impossible without a knowledge of the mechanisms of the THzradiation-biological objects interactions during the THz exposure. ${ }^{37}$ Two distinct mechanisms of such interactions are usually distinguished.

\subsection{Thermal Mechanism of THz Exposure}

In the thermal mechanism, $\mathrm{THz}$ radiation causes heating of the irradiated object due to the strong THz-wave absorption by water. ${ }^{34,41,165,166}$ Such mechanism is predominantly observed when using $\mathrm{CW}$ THz emitters. Mathematical modeling of THz-radiation interactions with different biological tissues ${ }^{167,168}$ shows that even quite low duration of $\mathrm{THz}$ exposure (such as few milliseconds) can cause notable increase in the tissue temperature. ${ }^{168,169}$ An increase in the cornea temperature of up to $70^{\circ} \mathrm{C}$ was shown when it was exposed to a $\mathrm{CW} 1.0 \mathrm{THz}$ radiation with the irradiance of $0.6 \mathrm{~W} / \mathrm{cm}^{2}$; see Fig. 6 . At the same time, experiments on $\mathrm{THz}$ exposure effects are often performed under thermostatically controlled conditions at physiological temperatures of $\simeq 37^{\circ} \mathrm{C}$, which prevents general heating of an exposed object. ${ }^{42,170-172}$

Several research groups reported the presence of microthermal effects of $\mathrm{THz}$ exposure that are difficult to detect during the experiments. ${ }^{34,173}$ However, significance of such effects still remains unexplored. The THz radiation is not perceived by the living systems as a thermal agent. This can be illustrated by special biological tests, such as studying the expression of genes 

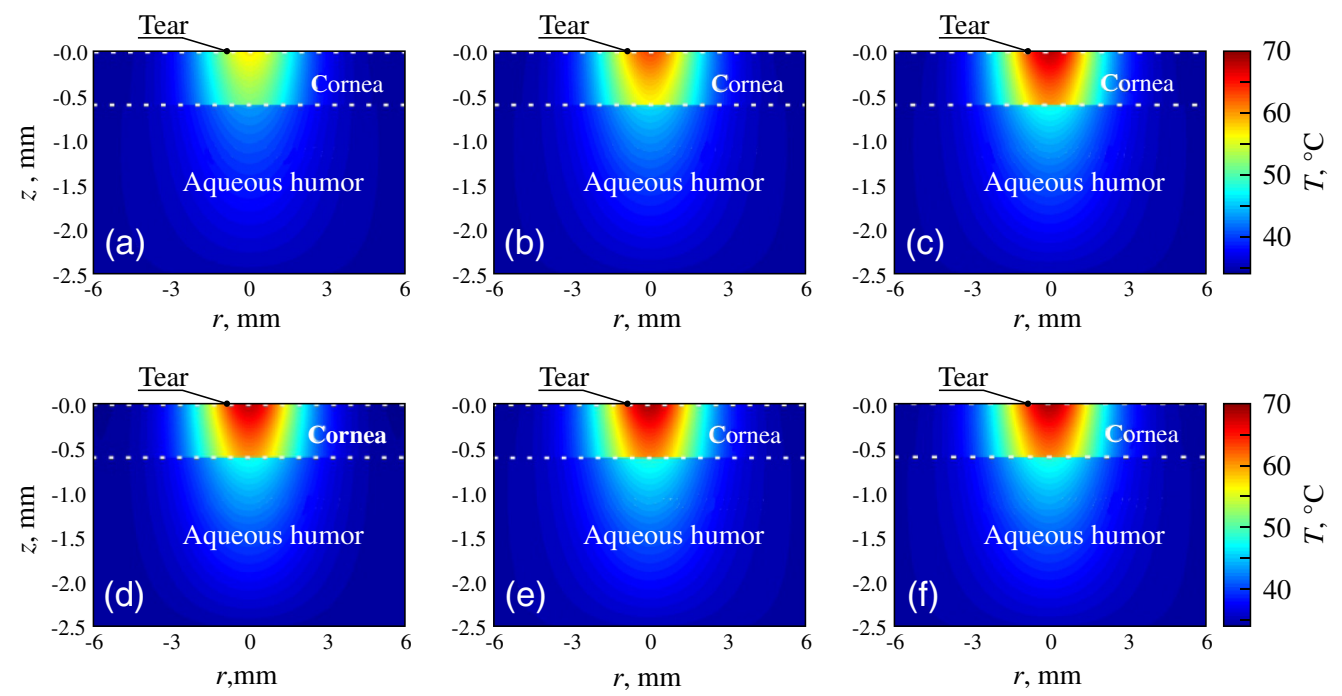

Fig. 6 Simulated time-dependent evolution of the temperature distributions in cornea heated by the $\mathrm{THz}$ beam with the radius of $3 \mathrm{~mm}$ and the irradiance of $0.6 \mathrm{~W} / \mathrm{cm}^{2}$, for the exposure times of (a) 10, (b) 30, (c) 60, (d) 180, (e) 300, and (f) $1200 \mathrm{~s}$. Adapted from Ref. 169 with the permission of MDPI.

associated with heat shock proteins. Their expression increases while the temperature rises by only several degrees from its optimal value. For example, the expression increases considerably at $41^{\circ} \mathrm{C}$ for humans..$^{34,171}$

\subsection{Nonthermal Mechanism of THz Exposure}

To explain the nonthermal effects of THz exposure, theories of the Fröhlich long-range coherent oscillations, ${ }^{174}$ the Davydov molecular solitons, ${ }^{175}$ and the coherent acoustoelectric waves ${ }^{176}$ are commonly applied. Namely, Fröhlich postulated the presence of collective oscillations of electric dipoles in biological macromolecules and membranes, ${ }^{173,177}$ which can interact with low-energy quanta, including that from the $\mathrm{THz}$ range. These dipole coherent oscillations are due to the nonlinear interaction between modes, as well as to the energy flow into the lowest-frequency mode. Cell metabolism serves as a source of energy, whereas the nonlinearity is caused by a strong static electric field on the cell membranes. ${ }^{178}$ Modern experimental data provide confirmation of this hypothesis. For example, consider the first experimental observation of the Fröhlich condensation in a protein structure, reported few years ago in Ref. 179. Theoretical studies are carried out aimed at describing the Fröhlich condensates. ${ }^{180-182}$ This effect was analyzed in the semiclassical ${ }^{181}$ and quantum frameworks, ${ }^{182}$ whereas the full-quantum statistical theory relies on the nonequilibrium Fröhlich condensate motion equations.

The theoretical calculations revealed that, under certain conditions, a resonant (linear or nonlinear) interaction between the THz wave and DNA is possible. ${ }^{183,184}$ Such an interaction significantly changes the molecular dynamics and leads to the local breaks of hydrogen bonds in DNA chains, which induces changes in gene expression. Based on a simple nonlinear model of DNA dynamics, it was demonstrated that $\mathrm{THz}$ radiation can influence both the vibrational excitations and proton motion in DNA hydrogen bonds. When the radiation frequency matches the vibrational mode, localized excitations in the form of dissipative solitons are generated. ${ }^{185}$ The low-amplitude collective breathing of the DNA modes can serve as precursors of generation of the transcription bubbles and other large-scale conformation changes.

Resonant interactions can be observed when using high-power pulsed THz sources. ${ }^{43,186,187}$ Indeed, while the average power of picosecond $\mathrm{THz}$ pulses is usually quite low (on the order of $\mu \mathrm{W}$ or $\mathrm{mW}$ ), their peak powers can be as high as 1 to $30 \mathrm{GW} \cdot{ }^{145,146,188}$ Such powerful THz waves can pass the cytoplasmic and nuclear membranes. ${ }^{45,189}$

Nonthermal effects of THz waves can occur for other structural components of living cell, such as proteins ${ }^{179}$ and membranes. ${ }^{165}$ An important role in THz-radiation-biological system 

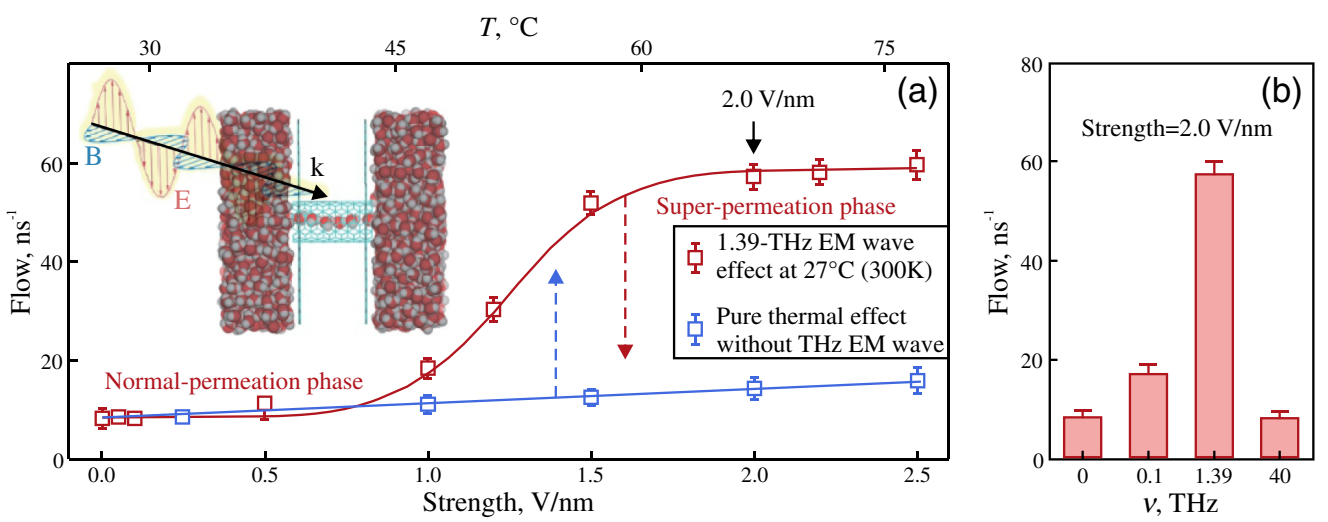

Fig. 7 Numerical data on transition to a superpermeation phase of confined water across a onedimensional (1D) water channel, that is, nonthermally modulated by $\mathrm{THz}$ radiation. (a) Water permeation is strongly and nonlinearly modulated by a 1.39-THz radiation (red squares), but weakly and linearly affected by temperature (blue squares). Inset shows a scheme of the simulated system, where red and gray balls indicate the oxygen and hydrogen atoms, respectively, whereas cyan tube stands for the 1D water channel, and two cyan sheets denote the supporting membrane. (b) Dependence of the permeation transition on the THz-wave frequency. The electric field strength of $2.0 \mathrm{~V} / \mathrm{nm}$ is applied, corresponding to the region of the high plateau, at which the superpermeation phase occurs under the action of a 1.39-THz radiation. Adapted from Ref. 191 with the permission of the American Chemical Society.

interactions is played by water molecules, which are associated with biomolecules and impact their long-range interactions, collective vibrations, and transitions. Since THz radiation is strongly absorbed by water, the latter is involved into interaction with rapidly alternating electromagnetic fields. ${ }^{32,190}$ Molecular dynamics simulations revealed an enhanced permutation (by $\simeq 1$ order of magnitude) of confined water molecules across a water membrane channel, which is caused by a 1.39-THz radiation with a limited thermal effect; see Fig. 7. The underlying mechanism is due to a combination of the strength matching and frequency resonance between a relatively weak stimulus and the hydrogen bond network of confined water, rather than the bulk water outside. Such combination causes an anomalously structural phase transition of only the confined water while efficiently limiting the thermal effect of bulk water. ${ }^{191}$

\subsection{Dosimetry in the THz Range}

Currently, no comprehensive safety standards exist that consider both thermal and nonthermal THz-wave effects and regulate applications of the 0.1 to $10.0 \mathrm{THz}$ radiation for general population and occupational exposure ${ }^{37}$ On the one hand, exposure to radiation with the frequencies of $<0.3 \mathrm{THz}$ is governed by the International Commission on Non-Ionizing Radiation Protection (ICNIRP). ${ }^{40}$ It considers the frequency range of $100 \mathrm{KHz}$ to $300 \mathrm{GHz}$ and was updated in $2020 .{ }^{192}$ On the other hand, exposure to radiation with the frequencies of $>0.3 \mathrm{THz}$ is regulated by the ICNIRP standard $2013 .{ }^{193}$ This standard defines exposure to laser radiation with the $180 \mathrm{~nm}$ to $1 \mathrm{~mm}$ wavelengths, and it is based on the proven thermal effects. However, there is a significant discrepancy between these two guidelines, namely, the $>0.3 \mathrm{THz}$ standard allows for the 20 to 100 times higher exposure intensity, as compared with the $<0.3 \mathrm{THz}$ one.

For the exposure duration of $>10 \mathrm{~s}$ and the frequencies $>0.3 \mathrm{THz}$, the maximum power density is limited by $1 \mathrm{~kW} / \mathrm{m}^{2}$. Whereas for the frequencies $<0.3 \mathrm{THz}$, the general public exposure limit is two orders of magnitude lower, i.e., $10 \mathrm{~m}^{2}$. Such a discrepancy between the two standards is due to different rules of the exposure threshold selection. The first standard ${ }^{192}$ defines the safety limits based on the increase in the body core temperature by only $1^{\circ} \mathrm{C}$, i.e., from $37^{\circ} \mathrm{C}$ to $38^{\circ} \mathrm{C}$. Such a small deviation of the body temperature can not cause any considerable hazard to an organism. In turn, the second standard ${ }^{193}$ is based on the $45^{\circ} \mathrm{C}$ temperature 
Table 3 Basic restrictions for the tissue exposure to the electromagnetic waves.

\begin{tabular}{lcccc}
\hline \hline $\begin{array}{l}\text { Exposure } \\
\text { scenario }\end{array}$ & $\begin{array}{c}\text { Frequency, } \\
\text { GHz }\end{array}$ & $\begin{array}{c}\text { Exposure time, } \\
\text { min }\end{array}$ & $\begin{array}{c}\text { Whole-body average } \\
\text { specific absorption } \\
\text { rate, W/kg }\end{array}$ & $\begin{array}{c}\text { Irradiance, } \\
\mathrm{W} / \mathrm{m}^{2}\end{array}$ \\
\hline Occupational & $6-300$ & $\geq 6$ & 0.4 & 100 \\
General public & $2-300$ & 30 & Not applicable & 50 \\
& $6-300$ & $\geq 6$ & 0.08 & 20 \\
\hline \hline
\end{tabular}

threshold of the skin injury. At the same time, both standards do not account the nonthermal effects of the THz waves. ${ }^{194}$ Meanwhile, the International Agency for Research on Cancer (IARC) of the World Health Organization (WHO) classified radiofrequency radiation in the $30 \mathrm{kHz}$ to $300 \mathrm{GHz}$ range as a human carcinogen, group $1 .{ }^{195}$

From a health risk perspective, ICNIRP are generally interested in the fraction of electromagnetic-wave power, which is absorbed by biological tissues and leads to their heating. This is typically described as a function of a relevant dosimetric quantity. ${ }^{40,192}$ For the frequencies $<6 \mathrm{GHz}$, where electromagnetic waves penetrate deeper into tissue, specific energy absorption rate (SAR) in $\mathrm{W} / \mathrm{kg}$ is introduced denoting the radiation power absorbed by unit mass. Oppositely, in the 6 to $300 \mathrm{GHz}$ range, electromagnetic waves are strongly absorbed by tissue water and, thus, penetrate only the superficial tissues. Therefore, tissue irradiance in $\mathrm{W} / \mathrm{m}^{2}$ (i.e., incident power density per unit area of tissue surface) is used to define the exposure conditions. Considering these two dosimetric quantities, basic limitations of biological object's exposure to electromagnetic waves ${ }^{192}$ are summarized in Table 3.

In Ref. 196, different energy quantities that measure safety guidelines to protect humans from thermal effects of the MMW and sub-MMW exposure were analyzed. The power density inside tissues correlates with the surface temperature elevations. Since different tissues possess distinct effective dielectric response in the THz range, their complex dielectric permittivity [Eq. (1)] or complex refractive index [Eq. (2)] should be taken into account during estimations of SAR. Methods for the SAR analysis at THz frequencies were developed by several research groups. ${ }^{42,197,198}$ In Ref. 199, simulations of a 0.45 -THz-wave absorption by the skin revealed that the electromagnetic-wave energy is mostly absorbed in the upper stratum spinosum, whereas the maximal temperature rise is observed in the lower stratum spinosum. The authors showed that the skin temperature can rise beyond the skin injury threshold of $45^{\circ} \mathrm{C}$, when the skin is already under the initial heat stress or when a number of radiation sources are applied simultaneously, each within the ICNIRP guidelines.

For obtaining the reproducible THz-wave effects and adequate dosimetry, the following important conditions should be satisfied during experiments:

1. Technical parameter of the THz emitter (see Fig. 8), conditions and geometry of the THz exposure should be known a priori.

2. Cuvette for the $\mathrm{THz}$ exposure experiments should be transparent in the $\mathrm{THz}$ range.

3. Optical properties $n$ and $\alpha$ of an exposed object should be known a priori.

4. THz exposure of an object should be performed in a suitable environment. For example, undisturbed cell growth requires the temperature of $\simeq 37^{\circ} \mathrm{C}$, certain humidity, and $\simeq 5 \% \mathrm{CO}$ content in an ambient atmosphere. Thus, the exposure of cells is performed in an incubator.

5. Adequate controls must be used during the THz exposure: ${ }^{31}$

- Sham control: reference cells are handled near the exposed ones, but they are not irradiated by $\mathrm{THz}$ waves.

- Temperature control: $\mathrm{THz}$ exposure is carried out at the temperatures above the expected thermal heating, for example, $45^{\circ} \mathrm{C}$. 


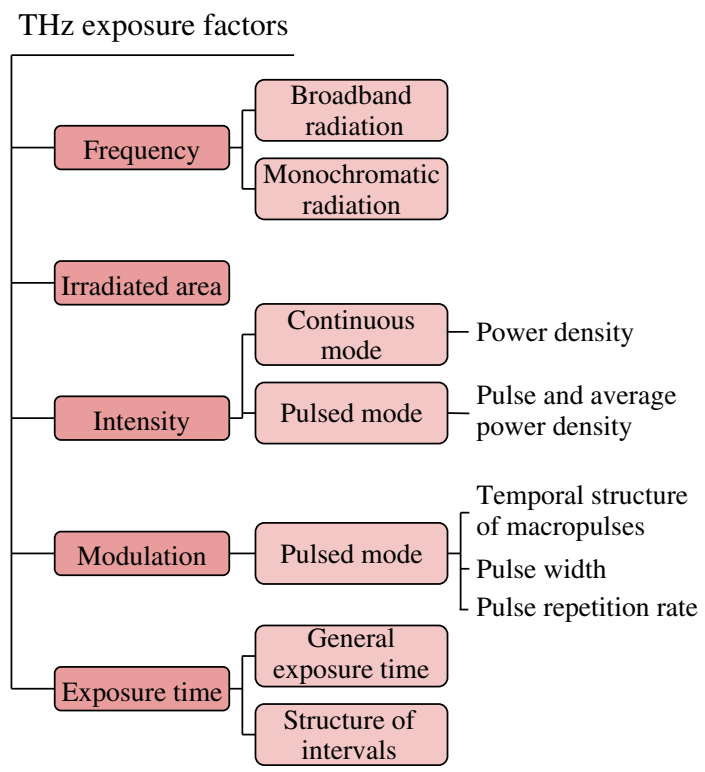

Fig. 8 Important technical factors for the experimental studies on $\mathrm{THz}$ irradiation. Courtesy of the authors.

- Positive control: specific agents/substances are applied to activate some function of cells that can be affected by $\mathrm{THz}$ waves.

- Negative control: specific agents/substances are applied to inhibit some function of cells that can be affected by $\mathrm{THz}$ waves.

- Blind control: analysis of the THz exposure effects is performed by a researcher who has no information on what samples were exposed to $\mathrm{THz}$ waves and what were used as control group.

All studies of the nonthermal THz-wave effects can be divided into two main categories:

- First one uses low-power THz-wave emitters, which either lead to a small increase in the sample temperature $\left(\leq 1^{\circ} \mathrm{C}\right)$ or do not cause any temperature alterations at all. The results of such $\mathrm{THz}$ exposure experiments are compared with control samples that are not irradiated by $\mathrm{THz}$ waves but are in the equal ambient conditions with the same temperature background.

- Second one uses powerful THz-wave emitters, which leads to a pronounced heating of a sample and often induces its thermal stress. In such experiments, an exposed sample is compared with the control one, which is heated to the temperature observed for the exposed sample.

When overviewing consistently different $\mathrm{THz}$ exposure experiments below, we consider both the temperature conditions of the experiments and the results of heat shock testing only for those experiments, which belong to the second category.

An important point in studying the biological effects of $\mathrm{THz}$ waves concerns selection and sustaining the time intervals between the beginning/end of the $\mathrm{THz}$ exposure and the analysis. Response of a living organism to any external factor, including the THz radiation, is developed in several stages, including a compensatory stage. The complexity of these stages in each specific case is still impossible to trace since any radiation-induced processes can begin later or finish earlier than some particular features are analyzed. Therefore, such parameter as the time intervals between the beginning/end of the THz exposure and analysis varied to a large extent in different studies. They can range from several minutes to several days or (in some cases) can be not indicated at all. While surveying the research results below, the experiment metrology and these time intervals are not considered comprehensively. 


\subsection{Effects of THz Radiation on the Structural Components of Cells}

Considerable amount of data have been accumulated on the $\mathrm{THz}$ dielectric spectra of molecular components of cells, such as amino acids, ${ }^{200,201}$ proteins, ${ }^{202-204}$ nucleic bases, ${ }^{205,206}$ and acids,${ }^{207}$ as well as sugars. ${ }^{32,66}$ At the same time, very limited knowledge about the nonthermal THz-wave effects on such important molecular components of a living cell exist nowadays.

The effect of CW THz radiation on the fluorescence of the tryptophan (Trp) amino acid and proteins was studied in Ref. 208. A remarkable feature of these experiments is a combination of the $\mathrm{THz}$ exposure and the fluorescence spectroscopy in a unitary experimental setup. Such favorable combination allows for observing the $\mathrm{THz}$ exposure effects either in situ or immediately after the exposure. The experimental setup and related fluorescence spectra are shown in Fig. 9. During the $\mathrm{THz}$ exposure, changes in the sample temperature were monitored using a microbolometric camera ${ }^{209,210}$ and a thermocouple. A 90-s-long exposure of the Trp sample to the CW $2.55 \mathrm{THz}$ radiation, with the irradiance of $11.7 \mathrm{~W} / \mathrm{cm}^{2}$, caused a decrease in the fluorescence signal by $\simeq 54 \%$. $^{208}$ This drop of the fluorescence signal depends linearly on the THz-radiation intensity, and it closely follows the changes in the sample absorptivity. This points out at the resonant character of the THz-wave-Trp interaction. ${ }^{208}$ For the whey proteins, similar THz exposure leads to the drop of the fluorescence signal by $\simeq 10 \%$ and $\simeq 0.26 \%$ at the frequencies of 0.2 and $2.55 \mathrm{THz}$, correspondingly. This exposure simultaneously leads to an increase in the sample temperature by $\simeq 1^{\circ} \mathrm{C}$. The control experiments with a simple sample heating confirmed that the observed THz-wave-induced changes are nonthermal in nature, as well as that such nonthermal effects dominate at the lower THz frequencies.

$\mathrm{THz}$ exposure of the green fluorescent protein (GFP) demonstrated an opposite dynamics of the fluorescence quenching at $0.2 \mathrm{THz}$, as well as the fluorescence enhancement by $\simeq 5 \pm 0.3 \%$ at $2.55 \mathrm{THz}$ while the irradiance was $120 \mathrm{~mW} / \mathrm{cm}^{2} .{ }^{208}$ Possible mechanism of such a frequencyselective response can be associated with the vibrational resonant coupling between the $\mathrm{THz}$ radiation and the protein structure, as explained in the framework of the Fröhlich's theory. ${ }^{174}$ In Ref. 179, THz exposure of a hen-egg white lysozyme was combined with a highly sensitive $\mathrm{x}$-ray crystallography to visualize low-frequency vibrational modes in the protein structure. It was found that $\mathrm{CW} 0.4 \mathrm{THz}$ radiation induces a local increase in the electron density in a long $\alpha$-helix motif consistent with a subtle longitudinal compression of the lysozyme helix. The observed electron density changes can only be explained by a collective excitation of dipole oscillators in the protein, as envisaged by Fröhlich. ${ }^{174}$

(a)

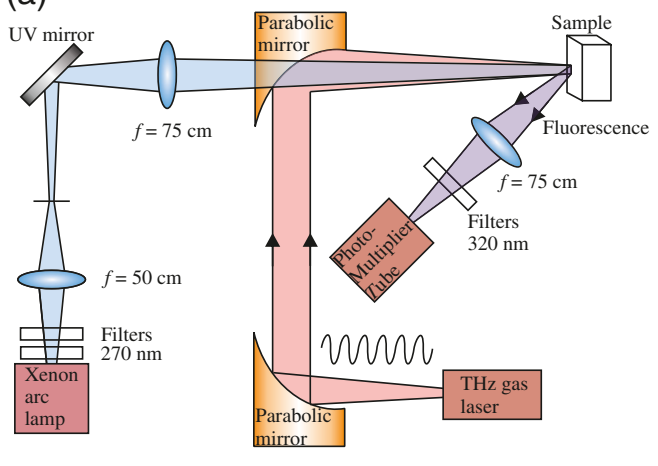

(b)

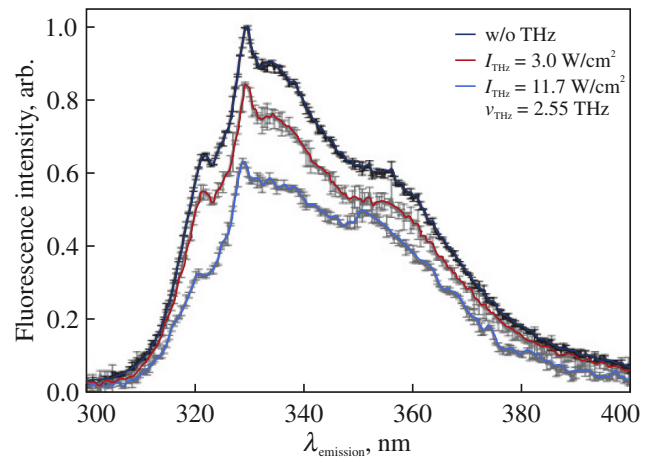

Fig. 9 (a) Schematic of the experimental setup. The UV beam at $270 \mathrm{~nm}$ was isolated from the broadband light generated by a xenon-UV-enhanced arc lamp to excite a sample. A tunable far-IR gas laser produced $\mathrm{CW} \mathrm{THz}$ radiation. CW UV and $\mathrm{CW} \mathrm{THz}$ radiations were combined using a parabolic mirror with a hole that allowed UV radiation to pass through it. The fluorescence signal emitted by a sample was isolated using an interference filter, with the central wavelength of $320 \mathrm{~nm}$ and the bandwidth of $10 \mathrm{~nm}$, and, then, collected by a lens and detected by a photomultiplier tube. (b) Fluorescence spectra of Trp pellet sample, either with or without the $\mathrm{THz}$ exposure. The frequency of $\mathrm{CW} \mathrm{THz}$ radiation was $2.55 \mathrm{THz}$, whereas the $\mathrm{THz}$ irradiance was 3.0 and $11.7 \mathrm{~W} / \mathrm{cm}^{2}$. Adapted from Ref. 208 with the permission of the Taylor and Francis Group. 
In Ref. 211, bovine serum albumin (BSA) was exposed, for $60 \mathrm{~min}$, to the CW $3.67 \mathrm{THz}$ waves with the irradiation of $20 \mathrm{~mW} / \mathrm{cm}^{2}$. As the result, changes in the UV and circular dichroism (CD) spectra of the irradiated protein were observed. They were attributed to modifications in the BSA conformation, as was further confirmed by an increase in the Trp fluorescence of BSA $^{212}$ and a twofold decrease in the progesterone binding constant. ${ }^{211,212}$ In Ref. 213, BSA was exposed, for $60 \mathrm{~min}$, to the pulsed THz radiation with the 0.2 - to $1.5-\mathrm{THz}$ spectral bandwidth and the peak irradiance of $10 \mathrm{~mW} / \mathrm{cm}^{2}$ (or the average irradiance of $10 \mathrm{nW} / \mathrm{cm}^{2}$ ), whereas the sample was in the form of thin films on a crystalline $\mathrm{SiO}_{2}$ substrate. Then, BSA was dissolved in water and brought into interaction with some adsorbates with high biological relevance, i.e., oxygen, ozone, and nitric oxide. It was found that $\mathrm{THz}$ waves caused evident changes in such interactions. Interaction between BSA and oxygen was studied by means of in situ spin probing technique. A spin probe was formed directly in solution through the interaction of a diamagnetic dinitrone compound with the reaction sites of BSA, on which oxygen molecules were adsorbed. Quantitative electron paramagnetic resonance spectroscopy demonstrated that the number of reaction sites of the BSA molecule increased by a factor of $\simeq 2$ as a result of $\mathrm{THz}$ exposure. $\mathrm{THz}$ irradiation excites definite collective rotational motions, which partially eliminate steric hindrance for the adsorption of molecular oxygen on the functional groups of BSA. ${ }^{213}$

In other studies, $\mathrm{THz}$ exposure of several proteins resulted in the following effects:

- a decrease in the enzymatic activity of alkaline phosphatase, ${ }^{214}$

- an increase in the activity of $\mathrm{T} 7$ endonuclease; ${ }^{215}$

- a decrease in the stability of the antigen-antibody complex for dinitrophenol (conjugated with BSA) and mouse monoclonal antibodies against it; ${ }^{214}$

- a dose-dependent change in the activity of alcohol dehydrogenase from yeast, horseradish peroxidase, and BSA. ${ }^{216}$

In Ref. 217, modulation of actin polymerization and change in the stability of its filaments, as a result of exposure to intense $\mathrm{THz}$ radiation of a free electron laser, were demonstrated; see Fig. 10. At the same time, when actin polymerization was performed under the exposure to the $0.46 \mathrm{THz}$ waves of a gyrotron, the number of actin filaments was increased by a factor of 3.5. In Ref. 218, a change in the conformation (i.e., a decrease in the number of $\beta$-sheets and an increase in $\alpha$-helices) was shown in a five-residue peptide with the amino acid sequence of the calcitonin hormone fragment. In Ref. 216, a reduction in the disordered structure due to an increase of the $\alpha$-helices and $\beta$-sheets was observed as a results of BSA exposure to pulsed $\mathrm{THz}$ radiation with the frequency of $3.3 \mathrm{THz}$ and the doses of 1.2 and $3.0 \mathrm{~J}$.

(a)

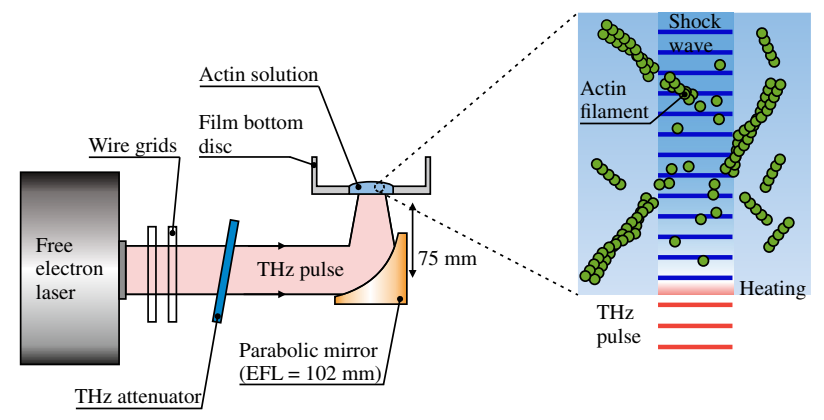

(b)

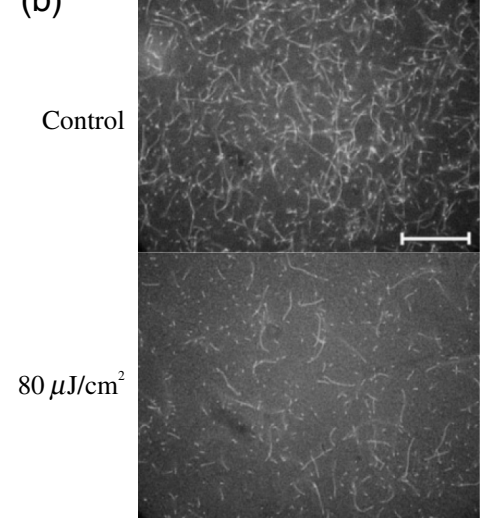

Fig. 10 Actin polymerization affected by the THz exposure in an aqueous solution. (a) A schematic of the experimental setup. Actin solution is placed atop of a film bottom dish. THz waves with the frequency of $4.0 \mathrm{THz}$ radiate this dish with a liquid sample from the bottom side. After the $\mathrm{THz}$ exposure, a portion of the actin solution is collected for the fluorescence microscopy. (b) Results of the fluorescence microscopy of the actin filaments in control sample (top) and that exposed to $\mathrm{THz}$ waves with the irradiance of $80 \mu \mathrm{J} / \mathrm{cm}^{2}$ (bottom). Adapted from Ref. 217 with the permission of Springer Nature. 
In Ref. 215, THz-wave induced structural changes were also demonstrated for such model systems, as short (tens of bases long) single-stranded DNA with the specified nucleotide sequences. As a result of their exposure to the broadband pulsed $\mathrm{THz}$ radiation with the 0.1 to $3.0 \mathrm{THz}$ spectral range, dissembling or interruption of assembling of deterministic secondary thermodynamic DNA structures in an aqueous solution was observed. Such effects were identified by analysis of fluorescent labels and electrophoresis. In turn, for such relatively large molecules as plasmids, there were practically no effects of $\mathrm{THz}$ waves on the molecular structure.

In Refs. 186 and 219, THz radiation was found to cause the DNA demethylation. It was shown that molecules of 5-methylcytidine have three major resonance peaks at the frequencies of $1.29,1.74$, and $2.14 \mathrm{THz}$ at a room temperature, whereas molecules of 2'-deoxycytidine did not show any distinct resonances in the 0.4 to $2.5 \mathrm{THz}$ range. ${ }^{220}$ The authors assumed that these $\mathrm{THz}$ molecular resonances of 5-methylcytidine are the fingerprints of methylation that are observed at the nucleoside level and can appear at the DNA level. ${ }^{220}$ Then, the frozen aqueous solutions of the normal cellular DNA (293 T cells), the corresponding methylated DNA (methylated $293 \mathrm{~T}$ ), and the cancer DNA from five types of human cancer cell lines were studied by THz pulsed spectroscopy at the temperature of $253 \mathrm{~K}$. A judiciously design procedure for the $\mathrm{THz}$ absorption spectra fitting allowed for isolating the broad absorption peak at $\simeq 1.7 \mathrm{THz}$, which was similar to the $1.74 \mathrm{THz}$ absorption peak of 5-methylcytidine with slightly shifted central frequency due to an impact of water molecules. ${ }^{220,221}$ In this way, the authors suggested that $\mathrm{THz}$ waves might cause resonant effect on global demethylation and, then, proceeded to the experimental confirmation of this hypothesis. ${ }^{186,219}$

In Fig. 11, a schematic of the THz-wave-induced demethylation of the methylated DNA is shown. High-power $\mathrm{THz}$ emitter was equipped with a bandpass filter, featuring the central frequency of $1.5 \mathrm{THz}$ and the bandwidth of $0.42 \mathrm{THz}$, aimed at matching the methylated DNA resonance. Magnitude of the resonance peaks observed by the $\mathrm{THz}$ pulsed spectrometer decreased after the high-power THz exposure. ${ }^{186,219}$ For the artificially methylated DNA samples from the human embryonic kidney cells (HEK293T line), demethylation was up to the level of normal values. For the hypermethylated DNA isolated from leukocytes of different cancer lines, it was up to $\simeq 70 \%$. Moreover, for the DNA from HEK293T cells, it was found that the demethylation in genes is observed mainly in the so-called $\mathrm{CpG}$ islands, i.e., regions with a high density of the cytosine-guanine dinucleotide sequences. ${ }^{219}$

It is worth noting that, in further studies, Tao et al. ${ }^{222}$ did not observe a 1.6-THz resonance absorption peak of the methylated nucleoside 5-methylcytidine in frozen aqueous solutions. This queries the above-mentioned results of studying the resonant effects of the THz DNA demethylation. In our opinion, this research direction deserves special attention and criticism, whereas further research efforts are necessary for the objective disclosure of $\mathrm{THz}$ capabilities to demethylation of DNA.

Parameters of the discussed experiments with exposure of biological molecules to $\mathrm{THz}$ waves and their main results are summarized in Tables 4-6. Thus, described experimental studies of the protein and DNA samples show that the main THz-induced effects are associated with
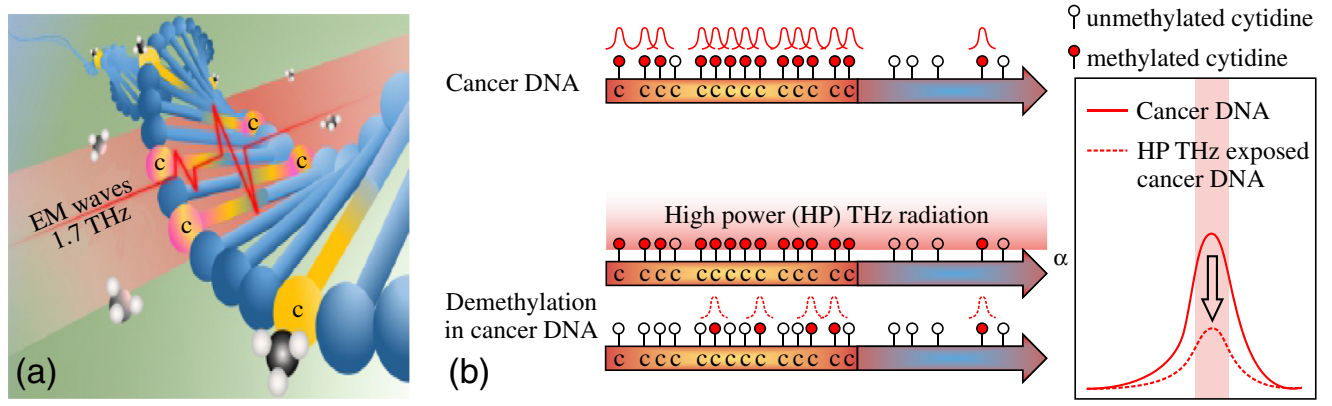

Fig. $11 \mathrm{THz}$-wave-induced DNA demethylation. (a) A scheme of the demethylation by a 1.7-THz resonant exposure of the methylated DNA. (b) Decrease in the amplitude of a resonant THz-wave absorption peak during the demethylation process. Reproduced from Ref. 186 with the permission of Springer Nature. 
Table 4 Exposure of some biological molecules to $\mathrm{THz}$ waves in the $\mathrm{CW}$ mode.

\begin{tabular}{|c|c|c|c|c|c|}
\hline Molecules & $\begin{array}{l}\text { Frequency, } \\
\text { THz }\end{array}$ & $\begin{array}{c}l, \\
\mathrm{~mW} / \mathrm{cm}^{2}\end{array}$ & $\begin{array}{l}\text { Duration, } \\
\text { min }\end{array}$ & Effects & Refs. \\
\hline \multirow[t]{2}{*}{ Trp } & 2.55 & 3000 & 1.5 & The fluorescence quenching, $10 \%$ & 208 \\
\hline & & 11700 & 1.5 & The fluorescence quenching, $54 \%$ & \\
\hline \multirow[t]{2}{*}{ Whey proteins } & 0.2 & 140 & 1.5 & The fluorescence quenching, $10 \%$ & 208 \\
\hline & 2.55 & 140 & 1.5 & The fluorescence quenching, $0.26 \%$ & \\
\hline \multirow[t]{2}{*}{ GFP } & 0.2 & 120 & 1.5 & The fluorescence quenching, $3 \%$ & 208 \\
\hline & 2.55 & 120 & 1.5 & The fluorescence enhancement, $5 \%$ & \\
\hline BSA & 3.67 & 20 & 60 & $\begin{array}{l}\text { Changes in the UV and CD spectra, } \\
\text { the fluorescence enhancement, } \\
\text { twofold decrease in the progesterone } \\
\text { binding constant }\end{array}$ & $\begin{array}{l}211 \\
212\end{array}$ \\
\hline $\begin{array}{l}\text { Alkaline } \\
\text { phosphatase }\end{array}$ & 0.1 & 0.008 & $90-120$ & Reduction in enzyme activity & 214 \\
\hline $\begin{array}{l}\text { Antigen antibody } \\
\text { complex }\end{array}$ & 0.1 & 0.008 & 90 & Decrease of interaction & 214 \\
\hline Lysozyme crystals & 0.4 & 62 & $25 \mathrm{~ms}$ & $\begin{array}{l}\text { A subtle longitudinal compression of } \\
\text { the } \alpha \text {-helix }\end{array}$ & 179 \\
\hline
\end{tabular}

Table 5 Exposure of some biological molecules to $\mathrm{THz}$ waves in the pulsed mode.

\begin{tabular}{|c|c|c|c|c|c|c|c|}
\hline Molecules & $\begin{array}{l}\text { Frequency } \\
\quad(\mathrm{THz})\end{array}$ & $\begin{array}{l}\text { Pulse } \\
\text { duration }\end{array}$ & $\begin{array}{l}\text { Repetition } \\
\text { rate }\end{array}$ & $\begin{array}{l}\text { Peak } \\
\text { power or } \\
\text { irradiance }\end{array}$ & $\begin{array}{l}\text { Duration, } \\
\text { min }\end{array}$ & Effects & Refs. \\
\hline BSA & $0.2-1.5$ & $2-3$ ps & $\sim 80 \mathrm{MHz}$ & $20 \mathrm{~mW}$ & 60 & $\begin{array}{l}\text { Increase the number of } \\
\text { reaction sites of BSA }\end{array}$ & 213 \\
\hline BSA & 3.3 & 120 ns & $3 \mathrm{~Hz}$ & $5 \mathrm{~mJ}$ & 3.3 & $\begin{array}{l}\text { Increase in the number of } \\
\beta \text {-structure and } \alpha \text {-helices; } \\
\text { decrease in the binding } \\
\text { capacity }\end{array}$ & $\begin{array}{l}216 \\
300\end{array}$ \\
\hline $\begin{array}{l}\text { Alcohol } \\
\text { dehydrogenase }\end{array}$ & 3.3 & 120 ns & $3 \mathrm{~Hz}$ & $5 \mathrm{~mJ}$ & 2.2 & $\begin{array}{l}\text { Nonlinear change in } \\
\text { enzymatic activity }\end{array}$ & 216 \\
\hline T7 endonuclease & $0.1-3.0$ & $\sim 1 \mathrm{ps}$ & $2.5 \mathrm{kHz}$ & $0.4 \mathrm{~mJ}$ & 10 & Increase in catalytic activity & 215 \\
\hline G-actin & 0.46 & $10 \mathrm{~ms}$ & $1 \mathrm{~Hz}$ & $\begin{array}{c}5.7 \\
\mathrm{~mJ} / \mathrm{cm}^{2}\end{array}$ & 20 & $\begin{array}{l}\text { The number of actin } \\
\text { filaments was increased } \\
\text { by } 3.5 \text {-fold }\end{array}$ & 301 \\
\hline Plasmid DNA & $0.1-3.0$ & $\sim 1 \mathrm{ps}$ & $2.5 \mathrm{kHz}$ & $0.4 \mathrm{~mJ}$ & 10 & No effect & 215 \\
\hline $\begin{array}{l}\text { dsDNA of up to } \\
\sim 20 \text { bp }\end{array}$ & $0.1-3.0$ & $\sim 1 \mathrm{ps}$ & $2.5 \mathrm{kHz}$ & $0.4 \mathrm{~mJ}$ & 10 & $\begin{array}{l}\text { Completely dissociated } \\
\text { dsDNA }\end{array}$ & 215 \\
\hline $\begin{array}{l}\text { The genomic } \\
\text { DNA samples }\end{array}$ & $1.5 \pm 0.21$ & - & - & $\begin{array}{l}2.4 \\
\mathrm{~mW} / \mathrm{cm}^{2}\end{array}$ & 30 & Global demethylation & 186 \\
\hline HEK293T DNA & $1.7 \pm 0.28$ & - & - & $\begin{array}{c}2.4 \\
\mathrm{~mW} / \mathrm{cm}^{2}\end{array}$ & 30 & $\begin{array}{l}\text { THz demethylation mainly } \\
\text { affected cytosine in CpGl } \\
(53 \%) \text {, where CpG sites } \\
\text { were abundant }\end{array}$ & 219 \\
\hline
\end{tabular}


Table 6 Exposure of some biological molecules to $\mathrm{THz}$ waves in the complex mode.

\begin{tabular}{lcccccccc}
\hline \hline Molecules & $\begin{array}{c}\text { Frequency } \\
(\mathrm{THz})\end{array}$ & $\begin{array}{c}\text { Micro- } \\
\text { pulse } \\
\text { duration }\end{array}$ & $\begin{array}{c}\text { Macro- } \\
\text { pulse } \\
\text { duration }\end{array}$ & $\begin{array}{c}\text { Repetition } \\
\text { rate of } \\
\text { macropulses }\end{array}$ & $\begin{array}{c}\text { Peak } \\
\text { power }\end{array}$ & $\begin{array}{c}\text { Duration } \\
(\mathrm{min})\end{array}$ & Effects & Refs. \\
\hline $\begin{array}{l}\text { Fibril of } \\
\text { calcitonin } \\
\text { peptide }\end{array}$ & $4.05,3.74$ & $10 \mathrm{ps}$ & $4 \mu \mathrm{s}$ & $5 \mathrm{~Hz}$ & $\begin{array}{c}\sim 1 \mathrm{~mJ} \\
\text { (macro) }\end{array}$ & 30 & $\begin{array}{c}\text { Decrease of } \beta \text {-sheet; } \\
\text { increase } \alpha \text {-helix, turn, } \\
\text { and others }\end{array}$ \\
G-actin & $4 \pm 1$ & $5 \mathrm{ps}$ & $\begin{array}{c}100 \text { pulses } \\
\text { per } \\
\text { macro- }\end{array}$ & $5 \mathrm{~Hz}$ & $\begin{array}{c}80,160, \\
250 \mu \mathrm{J} \\
\text { (micro) }\end{array}$ & 30 & $\begin{array}{l}\text { Decrease of actin } \\
\text { filaments }\end{array}$ & 217 \\
\hline \hline
\end{tabular}

changes in the conformation and biological activity of biopolymers. These effects might underlie more complex responses of living systems to $\mathrm{THz}$ waves, which are described below.

\subsection{Effects of THz Radiation on Cells and Cell Cultures}

Next, we overview the THz-wave effects on the separate cells and different cell cultures. For this aim, different types of cells are analyzed separately, with an emphasis on the blood, skin, cornea, nerve, and stem cells.

\subsubsection{Blood cells}

Considerable amount of data on the $\mathrm{THz}$ optical properties of blood and its components was accumulated up-to-date. ${ }^{2,223-225} \mathrm{THz}$-pulsed spectroscopy measurements, with the typical range of 0.1 to $3.2 \mathrm{THz}$, the average beam power of $10^{-7}$ to $10^{-9} \mathrm{~W}$, and the measurement duration of 1 to $5 \mathrm{~min}$, did not lead to any changes in the spectral and morphological properties of blood cells. ${ }^{226}$ Such low-power THz-pulsed radiation satisfies the discussed ICNIRP guidelines and is reportedly harmless for biological systems. ${ }^{41}$

At the same time, a number of research groups demonstrated considerable effects of $\mathrm{THz}$ waves on blood cells. In Ref. 227, exposure, for $3 \mathrm{~h}$, of human red blood cells (RBC) to the CW radiation of BWO, with the frequencies of 0.18 to $0.33 \mathrm{THz}$ and the irradiance of $3 \mathrm{~mW} / \mathrm{cm}^{2}$, decreases their osmotic resistance, which was attributed to the release of hemoglobin from erythrocytes. In Ref. 228, when human RBCs were exposed, for $1 \mathrm{~h}$, to the $\mathrm{CW} \mathrm{THz}$ radiation with the frequency of $3.68 \mathrm{THz}$ and the irradiance of $40 \mathrm{~mW} / \mathrm{cm}^{2}$, the hemoglobin release from erythrocytes with an addition of water in the ratio of $1: 2$ increased by seven times, as compared with the nonirradiated erythrocytes. From Ref. 46, it follows that viability of rat RBCs exposed, for $1 \mathrm{~h}$, to pulse $\mathrm{THz}$ radiation, with the spectral range of 0.1 to $1.75 \mathrm{THz}$, the pulse repetition rate of $76 \mathrm{MHz}$, the pulse duration of $1 \mathrm{ps}$, and the peak pulse power of $8.5 \mathrm{~mW}$, decreases to a greater extent than in control samples when erythrocytes are placed in the $0.54 \%$ to $0.48 \% \mathrm{NaCl}$ solutions. The cell viability was assessed using trypan blue dye, which penetrates into cells when its membrane is broken.

In Ref. 229, human RBC were exposed, for 5, 10, 15, 20, and $25 \mathrm{~s}$, to the Novosibirsk free electron laser radiation, with the spectral range of 2.05 to $2.31 \mathrm{THz}$, the pulse repetition rate of $5.6 \mathrm{MHz}$, the pulse duration of $120 \mathrm{ps}$, the peak pulse power of $<1 \mathrm{MW}$, and the average irradiance of 8 to $10 \mathrm{~W} / \mathrm{cm}^{2}$. A 5-s-long THz exposure did not lead to pronounced changes in the morphology of cells and did not reduce their aggregation. In turn, increase of the exposure time to 10 to $15 \mathrm{~s}$ changed the cell morphology (spherocytosis) and decreased the number of erythrocytes in the aggregates (as a linear function of the exposure duration). A 25-s-long exposure led to the destruction of cell membranes and the lysis of erythrocytes. The observed effects were attributed to the passage of powerful ultrasonic waves that were induced by the THz pulses at the laser pulse repetition rate of $5.6 \mathrm{MHz}$, through the irradiated medium. As a control, heating of erythrocytes to body temperature and their exposure to ultrasound were used, where such effect was not observed. These results indicated a THz-wave-induced change in the cell membrane permeability. 

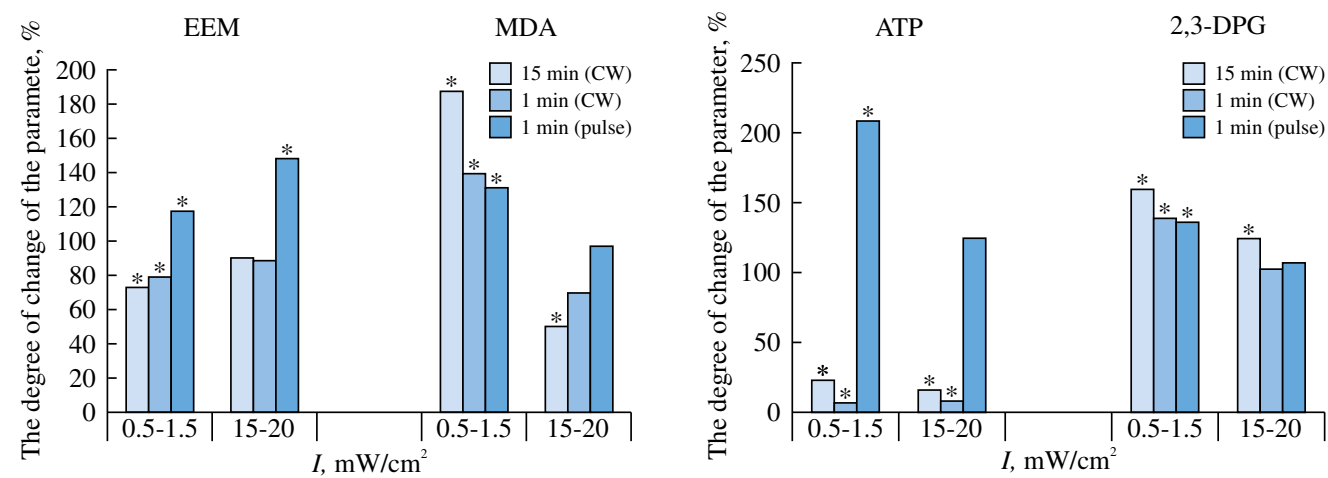

Fig. 12 Changes in blood cell parameters after the $\mathrm{THz}$ exposure with different irradiances, where $100 \%$ corresponds to the control level. EEM, erythrocytes electrophoretic mobility; MDA, malondialdehyde; ATP, adenosine triphosphate; 2,3-DPG, 2,3-diphosphoglycerate. The asterisk * indicates statistically significant differences $(p<0.05)$ as compared with the control group. Adapted from Ref. 230 with the permission of Springer Nature.

An important aspect of studying living organisms under the $\mathrm{THz}$ exposure is an evaluation of the antioxidant status of cells, particularly, of erythrocytes. In Ref. 230, RBCs were exposed to the $\mathrm{CW} \mathrm{THz}$ radiation, with the frequency of $0.263 \mathrm{THz}$ and the irradiance of 0.5 to $20 \mathrm{~mW} / \mathrm{cm}^{2}$, for 1 and $15 \mathrm{~min}$, and to the pulsed $\mathrm{THz}$ radiation, with the pulse repetition rate of $2.5 \mathrm{~Hz}$, the pulse duration of $200 \mathrm{~ms}$, and the average irradiance of 0.1 to $20 \mathrm{~mW} / \mathrm{cm}^{2}$, for $1 \mathrm{~min}$. As a result of the $\mathrm{THz}$ exposure, the intensity of lipid peroxidation (malondialdehyde concentration) in erythrocytes increased as compared with the nonirradiated control sample, whereas the observed effect depends on the exposure duration. In both regimes, a nonlinearity of the effect was observed, as shown in Fig. 12. At the irradiances of 0.5 to $1.5 \mathrm{~mW} / \mathrm{cm}^{2}$, oxidation was more pronounced than at 5 to $20 \mathrm{~mW} / \mathrm{cm}^{2}$. Such effects may indicate both induction of the oxidative stress upon $\mathrm{THz}$ irradiation and activation of the response of the cell antioxidant systems. ${ }^{230}$ Other parameters were also altered after such an exposure. The electrophoretic mobility of cells decreased after the $\mathrm{CW} \mathrm{THz} \mathrm{exposure} \mathrm{and,} \mathrm{conversely,} \mathrm{increased} \mathrm{after} \mathrm{the}$ pulsed one, regardless of the irradiance value. In turn, the metabolic parameters, such as ATP and 2, 3 diphosphoglycerate concentrations, depended on both the exposure regime and irradiance. $^{230}$

In Ref. 231, safety limits of blood leukocytes exposure to $\mathrm{THz}$ waves were studied, using several pulsed $\mathrm{THz}$ emitters and the method of DNA comets. ${ }^{232}$ The picosecond pulsed $\mathrm{THz}$ radiation, with the spectral range of 0.1 to $6.5 \mathrm{THz}$, the average irradiance of up to $200 \mu \mathrm{W} / \mathrm{cm}^{2}$, and the exposure duration of $20 \mathrm{~min}$, did not induce any DNA damage in blood leukocytes while heating of thus exposed sample did not exceed $1^{\circ} \mathrm{C}$. In Refs. 233-235, no effects of the human white blood cell exposure, for $20 \mathrm{~min}$, to the pulsed $\mathrm{THz}$ radiation, with the central frequencies of 0.12 and $0.13 \mathrm{THz}$, the pulse repetition rates of 21.1 and $73.7 \mathrm{kHz}$, the pulse duration of $50 \mathrm{ps}$, and the average irradiance of 30 to $230 \mu \mathrm{W} / \mathrm{cm}^{2}$, were observed, including the absence of the direct DNA damage, the chromosome apparatus changes, and the alteration of cell cycle kinetics. However, in Ref. 235, under certain conditions of cells' exposure in a $\mathrm{THz}$ resonant cavity, some signs of direct DNA damage appeared.

In Ref. 228, exposure, for 30 and 90 min, of the human total blood lymphocytes to the $\mathrm{CW}$ $\mathrm{THz}$ radiation, with the frequency of $3.68 \mathrm{THz}$ and the irradiance of $40 \mathrm{~mW} / \mathrm{cm}^{2}$, led to a decrease in the number of viable cells, which was more pronounced at high exposure time. It is worth noting that such $\mathrm{THz}$ exposure causes an increased proliferative activity of the surviving cells. In Ref. 236, similar cells were exposed, for 1, 2, and $24 \mathrm{~h}$, to the $\mathrm{CW} \mathrm{THz}$ radiation, with the frequency of $0.1 \mathrm{THz}$ and the irradiance of $31 \mu \mathrm{W} / \mathrm{cm}^{2}$, which was followed by studying four chromosomes $(1,10,11$, and 17) in cells during division. The observed results revealed an increase in aneuploidy of two chromosomes at 2- and 24-h exposure and changes in centromere replication of three and all four chromosomes at 2- and 24-h exposure, respectively. Thus, such a long-term $(\geq 1 \mathrm{~h}) \mathrm{THz}$ exposure induces significant genomic instability. 
In Ref. 237, human T-lymphocytes (Jurkat cell line) were exposed, for 5, 10, 20, 30, and $40 \mathrm{~min}$, to the $\mathrm{CW} \mathrm{THz}$ radiation with the frequency of $2.52 \mathrm{THz}$ and the irradiance of $227 \mu \mathrm{W} / \mathrm{cm}^{2}$. As a result, almost no changes in the lymphocytes survival were observed in the case of a short-term exposures ( $<20 \mathrm{~min})$. In turn, an exponential increase of the lymphocytes' death was observed for the long-term $\mathrm{THz}$ exposure $(\geq 20 \mathrm{~min}$ ) due to both apoptosis and necrosis of cells. Finally, for the 40-min-long THz exposure, up to $80 \%$ of cells died.

Studies of the global gene expression profile remain the most representative in the THz exposure technologies. For example, in Refs. 238-240, human T-lymphocytes (Jurkat cell line) were exposed to the 2.52-THz CW radiation with the irradiance of $636 \mathrm{~mW} / \mathrm{cm}^{2}$ for 30,40 , and $50 \mathrm{~min}$, accompanied by an increase in the sample temperature from $37^{\circ} \mathrm{C}$ to $44^{\circ} \mathrm{C}$. Thus, irradiated cells were then compared with the control group heated to the same temperatures. Pilot measurements revealed that a 40-min-long exposure to $\mathrm{THz}$ waves causes a change in the expression of 628 genes, whereas the 40-min-long bulk heating changes expression of 556 genes. ${ }^{238}$ Further measurements appeared to be even more illustrative, demonstrating a change in expression of 597 and 725 genes, respectively, with an overlap of only 61 genes. Completely different signaling and metabolic pathways were identified for the $\mathrm{THz}$ exposure and heating. There were 30 and 16 pathways for the THz exposure and heating, respectively. ${ }^{172,240}$ Quite interesting nonlinear effects were observed, i.e., some genes of the potassium and calcium channel proteins showed increased activity when exposed for $40 \mathrm{~min}$, as compared with the 30- and 50-min-long exposures. ${ }^{238} \mathrm{An}$ additional analysis of individual genes indicated that, although stress genes are activated during the $\mathrm{THz}$ exposure, this is not typical for all studied genes and is less pronounced as compared with a simple heating. ${ }^{239}$

Overall, studies of blood cell exposure to $\mathrm{THz}$ waves revealed the following biotropic effects:

- an increase in the cell membrane permeability;

- influence on various aspects of metabolism (including the oxidative stress), morphology, proliferation, and aggregation activity;

- gene and cytotoxic effects.

In some reactions, fingerprints of the compensatory mechanisms were found. Further extensive studies of the global gene expression profiling that captures many aspects of cellular life deserve special attention. THz effects are often highly constructive and sometimes nonlinear in relation to changes of the $\mathrm{THz}$ exposure parameters. The discussed effects of blood cell exposure to $\mathrm{THz}$ waves in different regimes are summarized in Table 7. Notice that no effects are observed at low exposure intensity (bottom six lines of the table); whereas various effects occur with the increased exposure (top 12 lines of the table).

\subsubsection{Skin and cornea cells}

In 2015, the Scientific Committee on Emerging and Newly Identified Health Risks published an opinion on the potential health effects of electromagnetic exposure. Given the expected increase in the use of $\mathrm{THz}$ technologies, it was recommended to pay special attention to studying the THz-wave effects on the skin, with an emphasis on the long-term low-intense exposure, and on the cornea, with an emphasis on the short-term high-intense exposure. ${ }^{241}$ Therefore, fibroblasts and keratinocytes of the skin, as well as epithelial cells of the cornea, are the most extensively studied cell types in the $\mathrm{THz}$ exposure technologies.

In Refs. 242 and 243, human dermal fibroblasts (HDF cell line) were exposed, for 5, 10, 20, 40 , and $80 \mathrm{~min}$, to the $\mathrm{CW} \mathrm{THz}$ radiation with the frequency of $2.52 \mathrm{THz}$ and the irradiance of $85 \mathrm{~mW} / \mathrm{cm}^{2}$. This exposure was accompanied by heating of a samples from $37^{\circ} \mathrm{C}$ to $40^{\circ} \mathrm{C}$, therefore, the control sample was heated to $40^{\circ} \mathrm{C}$ and studied as a reference. Additional genotoxic control samples were exposed, for $3 \mathrm{~min}$, to the $\mathrm{CW}$ UV radiation, with the wavelength of $254 \mathrm{~nm}$ and the average power of $38 \mathrm{~W}$. A 5- to 20-min-long $\mathrm{THz}$ exposure did not lead to a decrease in the number of living cells, whereas longer exposure slightly reduced it. At the same time, some increase in the cell proliferation was observed. As a results of the THz exposure, an increase in expression was noted for genes of the heat shock proteins, however, it was 
Table 7 Exposure of blood cells to THz waves in the different modes.

\begin{tabular}{|c|c|c|c|c|c|c|}
\hline Cells & $\begin{array}{l}\text { Frequency } \\
\quad(\mathrm{THz})\end{array}$ & Type & $\begin{array}{l}\text { Irradiance } \\
\left(\mathrm{mW} / \mathrm{cm}^{2}\right)\end{array}$ & $\begin{array}{l}\text { Duration } \\
\text { (min) }\end{array}$ & Effects & Refs. \\
\hline Human RBCs & 2.05 to 2.31 & Pulsed & 10000 & 0.42 & Lysis & 229 \\
\hline Jurkat cells & 2.52 & CW & 636 & 30 to 50 & $\begin{array}{l}\text { Activation of genes of intracellular } \\
\text { signal transduction pathways }\end{array}$ & 238 \\
\hline Jurkat cells & 2.52 & $\mathrm{CW}$ & 636 & 240 & $\begin{array}{l}\text { Increase expression of genes of } \\
\text { heat shock proteins, cell growth } \\
\text { factors, antiinflam matory cytokines }\end{array}$ & 239 \\
\hline Jurkat cells & 2.52 & $\mathrm{CW}$ & 227 & 20 to 40 & $\begin{array}{l}\text { Cell death due to both } \\
\text { apoptosis and necrosis of cells }\end{array}$ & 240 \\
\hline Human RBCs & 3.68 & $\mathrm{CW}$ & 40 & 60 & Decreased osmotic resistance & 228 \\
\hline $\begin{array}{l}\text { Human blood } \\
\text { lymphocytes }\end{array}$ & 3.68 & CW & 40 & 30,90 & Decreased cell viability & 228 \\
\hline Rat RBCs & 0.263 & $\mathrm{CW}$ & 0.5 to 20 & 1,15 & $\begin{array}{l}\text { Electrophoretic mobility of cells } \\
\text { decreases, destructive changes } \\
\text { of the cell morphofunctional state }\end{array}$ & 230 \\
\hline Rat RBCs & 0.263 & Pulsed & 0.1 to 20 & 1 & $\begin{array}{l}\text { Activation of the metabolic } \\
\text { processes }\end{array}$ & 230 \\
\hline $\begin{array}{l}\text { Human blood } \\
\text { lymphocytes }\end{array}$ & 0.13 & Pulsed & 2,5 & 20 & DNA damage & 235 \\
\hline Human RBCs & $0.18,0.33$ & $\mathrm{CW}$ & 3 & 180 & Decreased osmotic resistance & 227 \\
\hline $\begin{array}{l}\text { Human blood } \\
\text { lymphocytes }\end{array}$ & 0.1 & $\mathrm{CW}$ & 0.031 & 120,1440 & $\begin{array}{l}\text { Increased aneuploidy of } \\
\text { chromosomes } 11 \text { and } \\
17 \text { during cell division }\end{array}$ & 236 \\
\hline Rat RBCs & $0.1-1.75$ & Pulsed & 0.01 & 60 & $\begin{array}{l}\text { Increased rate of hypoosmotic } \\
\text { hemolysis }\end{array}$ & 46 \\
\hline $\begin{array}{l}\text { ICNIRP } \\
\text { standard }\end{array}$ & 0.002 to 0.3 & - & 1 & 30 & None & 40 \\
\hline $\begin{array}{l}\text { Human blood } \\
\text { lymphocytes }\end{array}$ & 0.1 & $\mathrm{CW}$ & 0.013 & 20 & None & 236 \\
\hline $\begin{array}{l}\text { Human blood } \\
\text { leukocytes }\end{array}$ & 0.5 to 6.5 & Pulsed & 0.008 & 20 & None & 231 \\
\hline $\begin{array}{l}\text { Human blood } \\
\text { leukocytes }\end{array}$ & 0.1 to 2.0 & Pulsed & 0.125 & 20 & None & 231 \\
\hline $\begin{array}{l}\text { Human blood } \\
\text { leukocytes }\end{array}$ & 0.1 to 1.0 & Pulsed & 0.2 & 20 & None & 231 \\
\hline $\begin{array}{l}\text { Human blood } \\
\text { lymphocytes }\end{array}$ & 0.12 to 0.13 & Pulsed & 0.03 to 0.25 & 20 & None & 233 \\
\hline
\end{tabular}

almost equal to that of conventional heating. No enhancement in the expression of DNA sensing and repair genes, which was observed under the UV irradiation, was found after the THz exposure. Overall, no considerable changes at a cellular and molecular level were identified. ${ }^{242,243}$ At a more intense exposure of the same cells to the THz-wave source with the irradiance of $227 \mathrm{~mW} / \mathrm{cm}^{2}$ and the duration varying from few seconds to $2 \mathrm{~min}$, the death of fibroblasts was observed after only the 12-s-long exposure. Finally, as a result of 1- and 2-minlong $\mathrm{THz}$ exposure, activation of the genes of some inflammatory cytokines was revealed. ${ }^{242}$ 
In Refs. 244 and 245, when human skin fibroblasts (HFFF2 and HDF cell lines) were exposed, for $20 \mathrm{~min}$, to the broadband pulse $\mathrm{THz}$ radiation, with the frequency of 0.1 to $0.15 \mathrm{THz}$, the pulse repetition rate of 21.1 to $26.3 \mathrm{kHz}$, the pulse duration of $50 \mathrm{ps}$, and the average irradiance of $0.4 \mathrm{~mW} / \mathrm{cm}^{2}$, authors observed aneuploidy effects, such as an increase in actin polymerization, chromosomal malsegregation, and micronucleus induction. Meanwhile, no signs of the DNA damage, such as expression of the corresponding proteins, phosphorylation of H2AX histone, and repair telomere length modulation, were noticed. Also, no THz-wave effects on the cell growth and survival, including changes in the prosurvival signaling proteins, were revealed. Thus, there was a clear aneugenic rather than clastogenic effect of $\mathrm{THz}$ radiation. ${ }^{244,245}$

In Ref. 246, HDFs were exposed, for $20 \mathrm{~min}$, to the CW THz radiation, with the frequency of $0.14 \mathrm{THz}$ and the irradiance of 35 to $354 \mathrm{~mW} / \mathrm{cm}^{2}$. Such parameters as proliferative activity, wound closure percentage, and the level of nitric oxide production in the irradiated cells were estimated. No tangible changes in the examined parameters were revealed. Therefore, lowfrequency $\mathrm{THz}$ radiation does not affect the functional activity of the HDFs. ${ }^{246}$

In Ref. 247, human skin fibroblasts (NB1RGB cell line) and human corneal epithelial cells (HCE-T cell line) were exposed, for 3, 70, and $94 \mathrm{~h}$, to the $\mathrm{CW}$ THz radiation, with the tunable output frequency in the range of 0.07 to $0.3 \mathrm{THz}$ and the irradiance of 0.4 to $1.3 \mu \mathrm{W} / \mathrm{cm}^{2}$. THz exposure at different frequencies did not reveal any changes in proliferation, morphology, and cell activity, as well as no signs of cytotoxicity. ${ }^{247}$ Exposure of the same cells, for 3, 70, and $94 \mathrm{~h}$, at separate frequencies in the range of 0.3 to $0.6 \mathrm{THz}$ with the irradiance of $<1 \mu \mathrm{W} / \mathrm{cm}^{2}$ also did not cause any effects on proliferation, survival, and cell morphology of both cell types. ${ }^{248}$

In Ref. 249, human corneal epithelial cells (HCE-T cell line) and human retinal pigment epithelial cells (ARPE-19 cell line) were exposed to the broadband pulsed THz radiation of synchrotron with a $\simeq 0.5 \mathrm{THz}$ cut-off frequency, a $1 \mathrm{kHz}$ pulse repetition rate, a 2-ps pulse duration, and a $0.85-2.25 \mathrm{~kW} / \mathrm{cm}^{2}$ peak irradiance (or a $0.14-0.37 \mathrm{~mW} / \mathrm{cm}^{2}$ average irradiance), and different exposure terms in the range of 140 to $230 \mathrm{~min}$ were examined. Results showed no signs of cytotoxicity, as well as no changes in the cell morphology and proliferation. It was suggested that cells, cultured and maintained under ideal standard conditions, are capable of compensating the $\mathrm{THz}$-wave effects even in the case of such high exposure intensities. ${ }^{249}$ Negative data were also obtained on the HCE-T cells, exposed to the $0.12-\mathrm{THz} \mathrm{CW}$ waves with the irradiance of $5 \mathrm{~mW} / \mathrm{cm}^{2}$, and the exposure duration of $24 \mathrm{~h}$. There was no statistically significant increase in genotoxicity, morphological changes, and alterations in the heat shock protein expression. ${ }^{171}$

In Ref. 250, human keratinocytes (NHK cell line) and human corneal epithelial cells (HCE-T cell line) were exposed to the pulsed $\mathrm{THz}$ radiation, with the central frequency of $0.14 \mathrm{THz}$, the pulse repetition rate of $50 \mathrm{kHz}$, the pulse duration of $80 \mathrm{~ns}$, the peak irradiance of 24 to $62 \mathrm{~mW} / \mathrm{cm}^{2}$ (the average irradiance of 0.1 to $0.25 \mathrm{~mW} / \mathrm{cm}^{2}$ ), for the different exposure durations ranging from $10 \mathrm{~min}$ to $24 \mathrm{~h}$. The effects of such $\mathrm{THz}$ exposure were then compared with those of the UVA (the 315 to $400 \mathrm{~nm}$ wavelenths) and UVB (280 to $315 \mathrm{~nm}$ ) exposures, as well as the $43^{\circ} \mathrm{C}$ heat shock treatment. No considerable changes in cell activity (viability and proliferation) and differentiation were detected in cases of a single $\mathrm{THz}$ exposure (with the duration of up to $24 \mathrm{~h}$ ) and a double one (with the 48-h-long time interval between the 24-h-long exposure cycles). THz waves did not induce a stress response, such as changes in the glutathione and the heat shock protein 70 levels. At the same time, all studied parameters of cells were sensitive to the UVB exposure and the heat shock. ${ }^{250}$

In Ref. 251, human skin fibroblasts (HDF cell line) and keratinocytes (HaCaT cell line) were exposed, for 2,8 , and $24 \mathrm{~h}$, to the $\mathrm{CW} \mathrm{THz}$ radiation, with the frequency of $0.106 \mathrm{THz}$ and the irradiance of 0.04 to $2 \mathrm{~mW} / \mathrm{cm}^{2}$. Although the authors considered $\mathrm{THz}$ irradiance of cells either below or above the aforementioned safety limits, they did not find any changes in proliferation rate and abnormalities in the genetic apparatus, such as increased micronucleus formation, formation of strand breaks, or alkali-labile sites in DNA. ${ }^{251}$ Similar negative results were obtained in Ref. 252, using the same cells, but another THz emitters with the output frequencies of 0.38 and $2.52 \mathrm{THz}$ and the irradiance in the range of 0.03 to $0.9 \mathrm{~mW} / \mathrm{cm}^{2}$, whereas the exposure durations were 2 and $8 \mathrm{~h}^{252}$ 

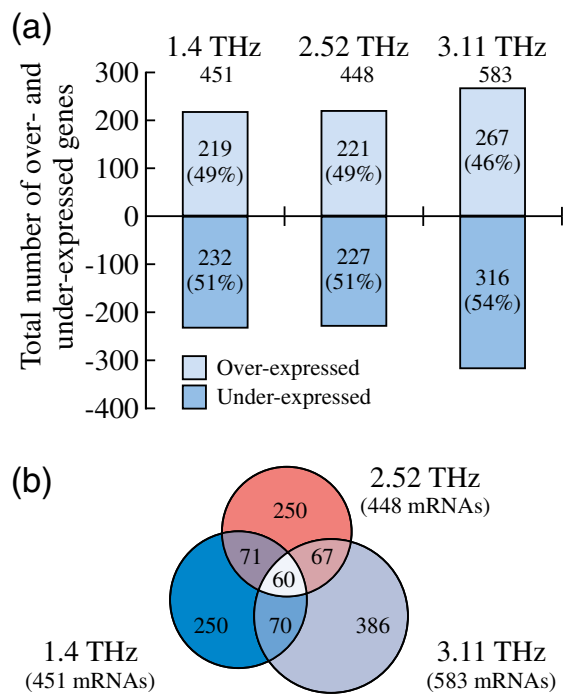

Fig. 13 Gene expression profiles of the human epidermal keratinocytes exposed to the $\mathrm{THz}$ radiation at different frequencies. (a) Total number of over- and underexpressed messenger RNAs (mRNA) at the 1.4, 2.52, and 3.11 THz exposures. (b) A Venn diagram indicating the number of unique and common differently expressed mRNAs at each THz exposure. Reprinted from Ref. 253 with the permission of SPIE.

The authors of Ref. 253 irradiated human epidermal keratinocytes (HEK001 cell line), for $20 \mathrm{~min}$, by the $\mathrm{CW} \mathrm{THz}$ radiation with the three distinct frequencies of $1.4,2.52$, and $3.11 \mathrm{THz}$ and the irradiance of $44 \mathrm{~mW} / \mathrm{cm}^{2}$. Viability of cells and expression of hyperthermic genes were not altered at such exposure conditions. Analysis of the total gene expression revealed 451, 448, and 583 differently expressed genes under exposure to the $1.4,2.52$, and $3.11 \mathrm{THz}$ waves, respectively. More than $50 \%$ of these genes in each group were unique, whereas $<25 \%$ in one group appeared to be common for all three regimes of the THz exposure. Bioinformatic analysis revealed activation of 6,17 , and 12 canonical metabolic and signaling pathways for the 1.4, 2.52, and $3.11 \mathrm{THz}$ exposure, respectively. These pathways were also unique for the considered exposure conditions, except for the extracellular signal regulated kinase 5, as shown in Fig. 13.

In Ref. 254, human skin keratinocytes from donors were exposed, for 10, 20, and $30 \mathrm{~min}$, to the radiation of the two broadband pulse $\mathrm{THz}$ emitters. The first one operated in the frequency range of 0.2 to $3.0 \mathrm{THz}$, possessed the pulse repetition rate of $80 \mathrm{MHz}$ and the pulse duration of 20 to $30 \mathrm{ps}$, and provided the average irradiance of $0.009 \mathrm{~mW} / \mathrm{cm}^{2}$. The second one features the following set of characteristics: 0.1 to $2.7 \mathrm{THz}, 250 \mathrm{kHz}, 250 \mathrm{fs}$, and $9 \mathrm{~mW} / \mathrm{cm}^{2}$. As a result of these experiments at both low and high intensities, $\mathrm{THz}$ radiation did not affect the cell activity (in general) and did not inhibit their capacity to differentiate, even despite the expected variability in the activity of the primary cells isolated from different donors. ${ }^{254}$

As shown in Fig. 14, HDFs and epidermal keratinocytes of the full thickness artificial human skin tissues model were exposed, for $10 \mathrm{~min}$, to the broadband pulsed $\mathrm{THz}$ radiation with the frequencies of 0.1 to $2.0 \mathrm{THz}$, the pulse repetition rate of $1 \mathrm{kHz}$, the pulse duration of $1.7 \mathrm{ps}$, and the average irradiances of 5.7 and $57 \mathrm{~mW} / \mathrm{cm}^{2} .{ }^{33,255}$ As a control, these cells were also exposed, for $2 \mathrm{~min}$, to the pulse UVA radiation with the pulse repetition rate of $1 \mathrm{kHz}$, the pulse duration of $50 \mathrm{fs}$, the central wavelengths of $400 \mathrm{~nm}$, and the pulse energy of $0.080 \mu \mathrm{J}$. Total gene expression analysis revealed a change in the expression of 397 and 442 genes, as a result of the low- and high-intense THz exposures, respectively, against 293 genes, as a result of the UV exposure. THz radiation selectively reduced the expression of genes associated with apoptosis and skin diseases, such as psoriasis and atopic dermatitis. With regard to the potential risk of carcinogenesis, a dual effect was observed since both anticancer and cancer-promoting genes were activated. Activity of the same genes, under the UV exposure, has a different dynamics than THz. THz exposure showed signs of DNA damage, along with an activation of the DNA damage repair mechanisms, such as histone H2AX phosphorylation and increase in the levels of some proteins. In general, the cellular response to $\mathrm{THz}$ radiation is significantly different from the UV-induced one. ${ }^{33,255}$ 

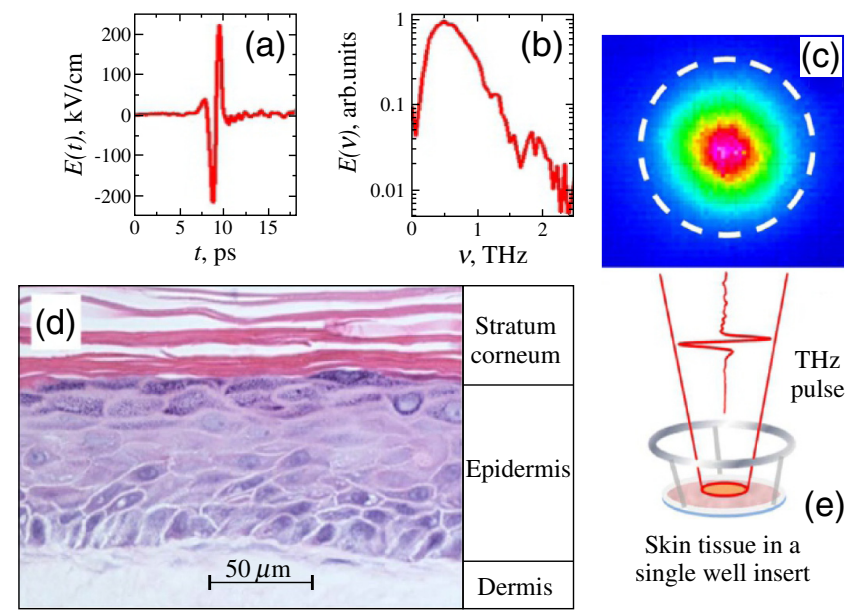

Down-regulated genes Up-regulated genes

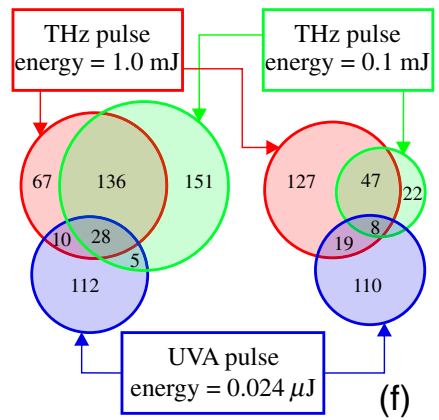

Skin tissue in a

single well insert

Fig. 14 Effects of the intense $\mathrm{THz}$ pulses on artificial human skin tissues model EpiDermFT. (a), (b) Time-dependent electric field of the THz pulse $E(t)$, as well as its Fourier spectrum $E(\nu)$, respectively. (c) Intensity of the $\mathrm{THz}$ focal spot $|\mathbf{E}|^{2}$. (d) Histology of an EpiDermFT tissue model. (e) Schematic of the THz exposure, where the EpiDermFT tissue model is mounted at the focal plane. (f) Venn diagrams summarizing the differently expressed genes in the EpiDermFT tissue model, as a result of exposure to either $1.0 \mathrm{~mJ} \mathrm{THz}$ wave or $0.14 \mathrm{~mJ}$ UVA radiation. Adapted from an open-access Ref. 33 with the permission of Springer Nature.

When similar object was exposed, for $10 \mathrm{~min}$, to broadband pulsed radiation with quite close parameters (the frequency range of 0.1 to $3.0 \mathrm{THz}$, the pulse repetition rate of $1 \mathrm{kHz}$, the pulse duration of $1 \mathrm{ps}$, the peak irradiance of $74 \mathrm{MW} / \mathrm{cm}^{2}$, or the average irradiance of $74 \mathrm{~mW} / \mathrm{cm}^{2}$ ) in Refs. 256-258, 1681 genes changed their expression, among which 1088 and 593 genes were down- and upregulated, respectively. Bioinformatic analysis showed that through the observed changes in the activity of many of these genes, the processes of initiation, maintenance, and progression of a cancer are suppressed; suppression of the glioma pathway is especially well indicated. Despite the fact that these predictions are based on observations in the skin tissue models, the gene-level mechanisms responsible for the negative perturbation are genes that encode for proteins involved in the calcium and mitogen-activated protein kinase signaling; these are ubiquitous and well-conserved across many different cell types, including skin and neural cells. ${ }^{258}$ Moreover, the authors observed explicit activation of an inflammatory response and suppression of a promitotic signaling, including the suppression of cellular functions, such as cell division, differentiation, motility, and apoptosis. Existence of an energy threshold for the observed effects is quite important: namely, at lower $\mathrm{THz}$ radiation intensities (the pulse energy of $<1.5 \mu \mathrm{J}$ or the electric field strength of $<187 \mathrm{kV} / \mathrm{cm}$ ), no significant changes were observed, as compared with the intense $\mathrm{THz}$ exposure $(2.4 \mu \mathrm{J}$ and $240 \mathrm{kV} / \mathrm{cm})$, that caused the genetic changes. ${ }^{256-258}$ Among the observed genomic response, special attention was paid to the THz-wave effect on calcium signaling pathway due to its general significance in biological regulation. An additional study of the differential gene expression profiles, in the case of the five different $\mathrm{THz}$ exposure irradiances in the range of 0.6 to $47 \mathrm{MW} / \mathrm{cm}^{2}$, revealed suppression of this pathway by $\mathrm{THz}$ radiation and enhancement of this effect with the exposure intensity. ${ }^{259}$

In Ref. 260, mouse keratinocytes of dorsal skin were exposed in vivo, for $1 \mathrm{~h}$, to the broadband pulsed THz radiation, with a $0.1-$ to $2.5-\mathrm{THz}$ spectral range, a $1-\mathrm{kHz}$ pulse repetition rate, a 310 -fs pulse duration, and a $0.032-\mathrm{mW} / \mathrm{cm}^{2}$ average irradiance. Analysis of the genome-wide expression profile showed a change in the activity of 149 genes involved in the processes of tissue growth and healing, organogenesis, and cell migration. Further bioinformatic analysis indicated a difference in the pattern of gene expression, as a result of the $\mathrm{THz}$ exposure, as compared to the UV and neutron ones. Relying on additional studies of individual genes, the authors concluded that general expression gene pattern, induced by $\mathrm{THz}$ radiation, is analogous to that by wound stimulus. ${ }^{260}$ In Ref. 261, mouse ear skin in vivo was exposed, for $30 \mathrm{~min}$, to the pulsed radiation with a $2.7-\mathrm{THz}$ central frequency, a $3-\mathrm{Hz}$ pulse repetition rate, a $4-\mu$ s pulse duration, and a $260-\mathrm{mW} / \mathrm{cm}^{2}$ average irradiance. Schematic of this exposure is shown in 
(a)

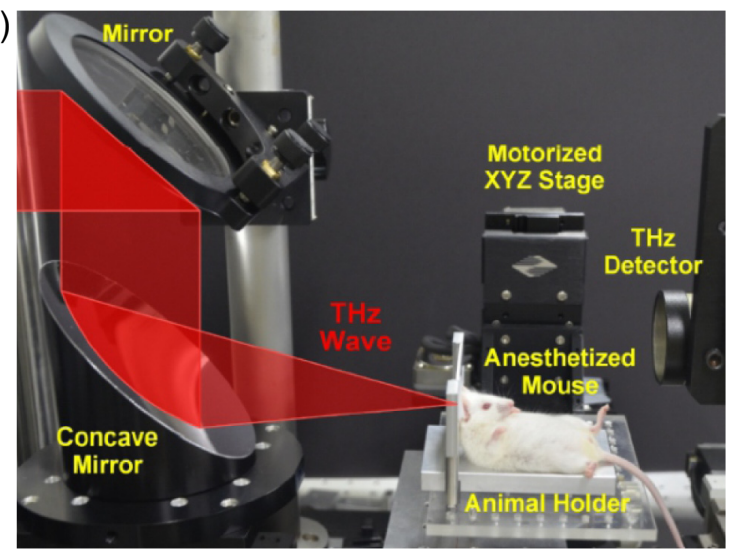

(b)
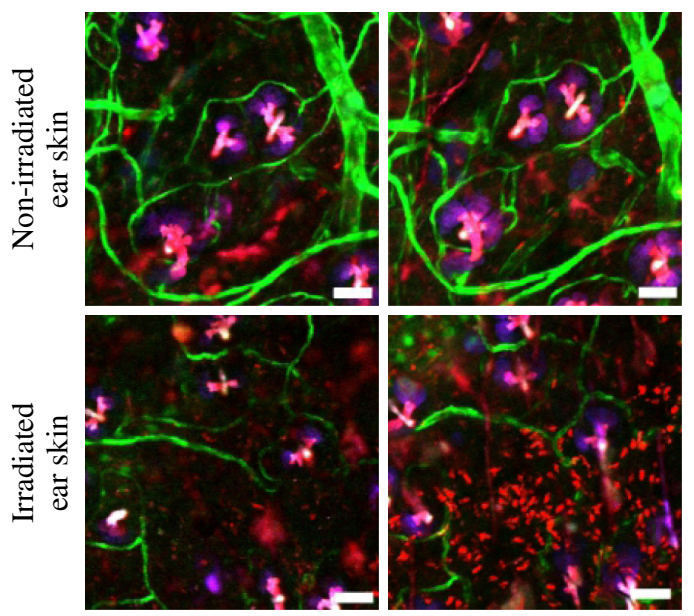

Fig. $15 \mathrm{THz}$ exposure of the mouse ear skin in vivo. (a) A photo of the $\mathrm{THz}$ setup. A living anesthetized mouse is placed on an animal holder that is fixed at a motorized 3D translation stage. (b) Distribution of neutrophils in the mouse ear skin before and after the $\mathrm{THz}$ exposure: Gr-1 + neutrophil (in red), Tie2 + blood vessel (green), and autofluorescent hair follicle (magenta). Adapted from Ref. 261 with the permission of the Optical Society of America.

Fig. 15. The observed results indicated an acute inflammatory response in the skin (the infiltration of neutrophils), whereas IR camera detected no notable THz-wave-induced change in the skin temperature. ${ }^{261}$ The results showed that such an acute inflammatory response can be initiated without structural disruption of the skin by $\mathrm{THz}$ radiation. THz exposure of living tissue in the in vivo conditions can possibly trigger various unexpected dynamic responses, which can not be mimicked appropriately in the simplified in vitro conditions. ${ }^{261}$

Thereby, the overviewed research demonstrated the main reaction of the skin and cornea cells on THz exposure. These cells act in multicellular organisms as the primary barrier that perceives $\mathrm{THz}$ waves as a factor of the external environment and protects against it. THz-wave-driven changes at cellular and molecular levels were revealed, both clearly negative, such as the DNA damage and aneuploidy effects, and relatively harmless, such as the increased cell proliferation. Many results of the THz exposure, including the ones observed in terms of geno- and cytotoxic effects, turned out to be negative, emphasizing that the considered regimes of $\mathrm{THz}$ exposure were lower than biologically significant thresholds. A comparison of the observed $\mathrm{THz}$ effects with other factors, such as the UV exposure and temperature stress, and with the whole-genome gene expression profiling aided by the bioinformatics, confirmed variability and specificity of the cellular response to $\mathrm{THz}$ waves.

Tables 8 and 9 show some remarkable results, both positive and negative, of the skin and cornea cells exposure to $\mathrm{THz}$ radiation. One should notice that $\mathrm{CW}$ exposure overall causes no damage when using the considered small-to-moderate THz exposure intensities. In turn, due to much higher peak power, pulsed $\mathrm{THz}$ exposure can cause DNA damage and changes in gene 
Cherkasova et al.: Cellular effects of terahertz waves

Table 8 Effects of CW THz radiation on the skin and cornea cells.

\begin{tabular}{|c|c|c|c|c|c|}
\hline Cells & $\begin{array}{l}\text { Frequency } \\
\qquad(\mathrm{THz})\end{array}$ & $\begin{array}{l}\text { Irradiance } \\
\left(\mathrm{mW} / \mathrm{cm}^{2}\right)\end{array}$ & $\begin{array}{l}\text { Duration } \\
\text { (min) }\end{array}$ & Effects & Refs. \\
\hline Human skin fibroblasts & 2.52 & 84.8 & 40,80 & $\begin{array}{l}\text { Number of viable cells decreased } \\
\text { by } 10 \% \text {; enhanced proliferation; } \\
\text { no DNA damage }\end{array}$ & 243 \\
\hline Human skin fibroblasts & 2.52 & 227 & 1,2 & $\begin{array}{l}\text { Activation of proinflammatory } \\
\text { cytokines and stress response }\end{array}$ & 237 \\
\hline $\begin{array}{l}\text { Human epidermal } \\
\text { keratinocytes } \\
\text { (HEK001 cell line) }\end{array}$ & $\begin{array}{l}1.4,2.52 \\
3.11\end{array}$ & 44 & 20 & $\begin{array}{l}\text { The activation of metabolic and } \\
\text { signaling pathways specific for } \\
\text { each frequency }\end{array}$ & 253 \\
\hline ICNIRP Standard & 0.002 to 0.3 & 1 & 30 & None & 40 \\
\hline Human skin fibroblasts & 0.14 & 35 to 354 & 20 & $\begin{array}{l}\text { No effect on proliferative activity, } \\
\text { wound closure percentage, and } \\
\text { the level of nitric oxide production }\end{array}$ & 246 \\
\hline $\begin{array}{l}\text { Human skin fibroblasts } \\
\text { (NB1RGB cell line) }\end{array}$ & 0.07 to 0.3 & $<0.001$ & $\begin{array}{l}180,4200 \\
5760\end{array}$ & $\begin{array}{l}\text { Not any effects on proliferation, } \\
\text { survival and cell morphology }\end{array}$ & 247 \\
\hline $\begin{array}{l}\text { Human corneal epithelial } \\
\text { cells (HCE-T cell line) }\end{array}$ & 0.07 to 0.3 & $<0.001$ & $\begin{array}{l}180,4200 \\
5760\end{array}$ & $\begin{array}{l}\text { Not any effects on proliferation, } \\
\text { survival and cell morphology }\end{array}$ & 247 \\
\hline $\begin{array}{l}\text { Human corneal epithelial } \\
\text { cells (HCE-T cell line) }\end{array}$ & 0.12 & 5 & 1440 & $\begin{array}{l}\text { No statistically significant increase } \\
\text { in genotoxicity, morphological } \\
\text { changes, and alterations in the } \\
\text { heat shock protein expression }\end{array}$ & 171 \\
\hline HaCaT and HDF cells & 0.106 & 0.04 to 2.0 & $\begin{array}{l}120,480 \\
1440\end{array}$ & $\begin{array}{l}\text { No induction of DNA strand } \\
\text { breaks or chromosomal damage }\end{array}$ & 251 \\
\hline HaCaT and HDF cells & $0.38,2.52$ & $\begin{array}{l}0.03 \text { to } 0.6 \\
0.05 \text { to } 0.9\end{array}$ & 120,480 & $\begin{array}{l}\text { No induction of DNA strand } \\
\text { breaks or chromosomal damage }\end{array}$ & 252 \\
\hline
\end{tabular}

Table 9 Effects of pulse $\mathrm{THz}$ radiation on the skin and cornea cells.

\begin{tabular}{|c|c|c|c|c|c|}
\hline Cells & $\begin{array}{l}\text { Frequency } \\
\quad(\mathrm{THz})\end{array}$ & $\begin{array}{l}\text { Irradiance } \\
\left(\mathrm{mW} / \mathrm{cm}^{2}\right)\end{array}$ & $\begin{array}{l}\text { Duration } \\
\text { (min) }\end{array}$ & Effects & Refs. \\
\hline Artificial human skin & 0.1 to 2.0 & $5.7,57$ & 10 & $\begin{array}{l}\text { Formation of DNA double strand breaks, } \\
\text { activates DNA damage response }\end{array}$ & $\begin{array}{l}33 \\
255\end{array}$ \\
\hline Artificial human skin & 0.1 to 3.0 & 0.9 to 74 & 10 & $\begin{array}{l}\text { Suppression of the Ras signaling and } \\
\text { calcium signaling pathways }\end{array}$ & 259 \\
\hline Mouse ear skin in vivo & 0.1 to 2.5 & 0.032 & 60 & Activation of genes included in tissue growth & 260 \\
\hline Mouse ear skin in vivo & 2.7 & 260 & 30 & $\begin{array}{l}\text { An acute inflammatory response was } \\
\text { initiated without structural disruption of } \\
\text { the skin }\end{array}$ & 261 \\
\hline $\begin{array}{l}\text { Human fibroblast } \\
\text { culture }\end{array}$ & 0.1 to 0.15 & 0.4 & 20 & $\begin{array}{l}\text { No DNA damage; enhanced actin } \\
\text { polymerization }\end{array}$ & 244 \\
\hline $\begin{array}{l}\text { Human corneal epithelial } \\
\text { cells (HCE-T cell line) }\end{array}$ & 0.5 & $\begin{array}{l}0.14 \text { to } \\
0.37\end{array}$ & $\begin{array}{l}140 \text { to } \\
230\end{array}$ & $\begin{array}{l}\text { No signs of cytotoxicity, no changes in } \\
\text { the cell morphology and proliferation }\end{array}$ & 249 \\
\hline $\begin{array}{l}\text { Human keratinocytes } \\
\text { (NHK cell line) }\end{array}$ & 0.14 & $\begin{array}{l}0.1 \text { to } \\
0.25\end{array}$ & $\begin{array}{l}10 \text { to } \\
1440\end{array}$ & $\begin{array}{l}\text { No considerable changes in cell viability, } \\
\text { proliferation and differentiation }\end{array}$ & 250 \\
\hline $\begin{array}{l}\text { Primary human } \\
\text { keratinocytes }\end{array}$ & $\begin{array}{l}0.2 \text { to } 3.0 \\
0.1 \text { to } 2.7\end{array}$ & $0.009,9$ & $\begin{array}{l}10,20 \\
30\end{array}$ & No effect on cell activity and differentiation & 254 \\
\hline
\end{tabular}


expression. Thus, considerable attention should be paid to determine safe limits of such pulsed exposure to skin and cornea, with an observed rapid developments of $\mathrm{THz}$ technology and, particularly, $\mathrm{THz}$ wireless communications.

\subsubsection{Nerve cells}

In Ref. 262, effects of the CW laser THz waves on the isolated neurons of the supraesophageal galglion of the Lymnea stagnalis were investigated at $0.71,1.63,2.45,2.56,3.68$, and $4.28 \mathrm{THz}$, whereas the irradiance and the exposure duration were 2 to $20 \mathrm{~mW} / \mathrm{cm}^{2}$ and $1 \mathrm{~h}$. At $0.71 \mathrm{THz}$, the adhesive characteristics of membranes were altered, and the contacts between the nerve cells and a substrate were disturbed. At $3.68 \mathrm{THz}$, the structural changes occurred in the somatic membrane, axons, and growth cone. The effects were delayed and manifested themselves only 40 to $50 \mathrm{~h}$ after the exposure. During this period, redistribution of pigment granules occurred, and the membrane cytocortical layer became heterogeneous. Then, anomalous outgrowth-like structures with the arbitrary orientation grew, whereas classical neurites did not form. ${ }^{262}$ In the same experiment, the response of cell membrane to the $\mathrm{THz}$ exposure was not identical at the different stages of the neural network formation. The aforementioned effects occurred at the initial stage of the neural network regeneration, i.e., before formation of the neuron outgrowths. Other phenomena were observed in neurons (with the outgrowths already formed) at the stage of the neuron network formation, namely, the disturbance in the neurites' growth zone and the cessation of their further growth, which caused disorders in the interneuron links' formation, ${ }^{262,263}$ as shown in Fig. 16.

In Ref. 263, the same biological object, namely, the isolated neurons of the Lymnea stagnalis, was exposed, for $1 \mathrm{~min}$, to the pulsed $\mathrm{THz}$ radiation with the central frequencies of 2.1 and $2.3 \mathrm{THz}$, the pulse repetition rate of 5.6 to $11.2 \mathrm{MHz}$, the pulse duration of 30 to $100 \mathrm{ps}$, and the average irradiance of 0.3 to $30 \mathrm{~mW} / \mathrm{cm}^{2}$. Exposure at $2.3 \mathrm{THz}$ and $30 \mathrm{~mW} / \mathrm{cm}^{2}$ caused a gradual decrease in the membrane potential, accompanied by the morphological disorders of membrane and intracellular structures, as well as by the cell death within $2 \mathrm{~h}$ after the exposure. At $3 \mathrm{~mW} / \mathrm{cm}^{2}$, cell death occurred within $3 \mathrm{~h}$ after the exposure; whereas at $0.3 \mathrm{~mW} / \mathrm{cm}^{2}$, part of cells remained vital, and the number of vital cells stabilized within $2 \mathrm{~h}$ after the exposure. However, when resorting to $2.1 \mathrm{THz}$, even with the minimal irradiance of $0.3 \mathrm{~mW} / \mathrm{cm}^{2}$, no viable cells were detected in $1 \mathrm{~h}$ after the exposure. ${ }^{263}$

In Refs. 263 and 264, barrier properties of the neuron membrane were studied after the exposure to $\mathrm{THz}$ radiation of a free electron laser possessing the frequency of $2.3 \mathrm{THz}$ and irradiance in the range of 0.5 to $20 \mathrm{~mW} / \mathrm{cm}^{2}$ (see Fig. 17). Such exposure causes a dose-dependent nonspecific permeability of the cell membrane that was uncovered by studying the vital dye trypan blue transmission through the membrane into the cytoplasm. The dye was distributed nonuniformly in cytoplasm, being localized in separate regions. This effect is reportedly due to the THz-wave-induced formation of hydrophilic pores in the cell membrane. It is reversible, because the membrane potential and functional reactions of cells return to the normal values within 1 day

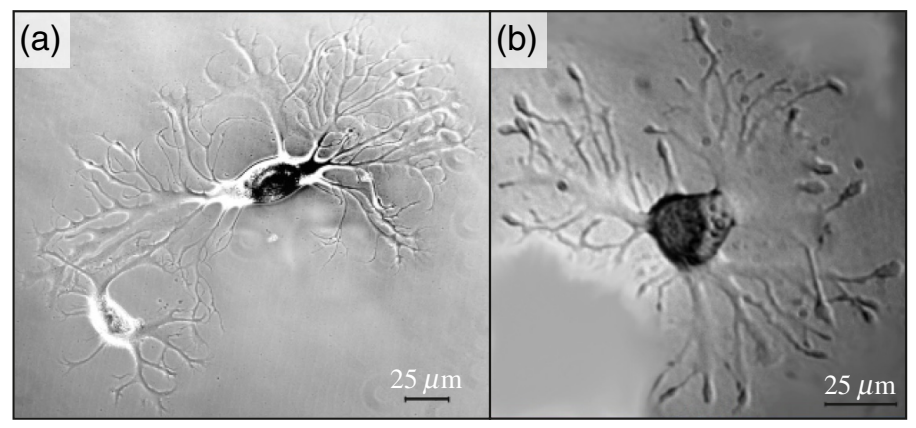

Fig. 16 Effect of the 3.68-THz CW radiation on the isolated neurons at the stage of the neural network formation. (a) Microscopy of the unaltered neural network. (b) Neural network formed after the THz exposure. In panel (b), disturbances in the neurites' growth zone, and cessation of their further growth, including the disordering in the interneuronic links, are observed. Courtesy of the authors. 


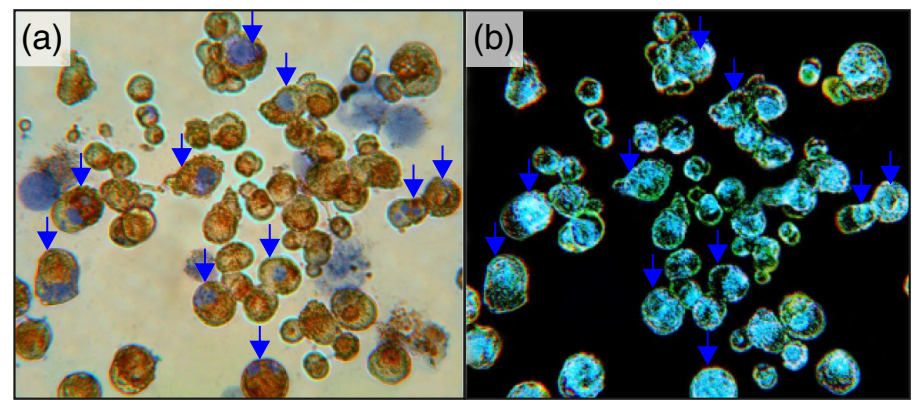

Fig. 17 Neurons after the 2.3-THz CW exposure with the irradiance of $0.5 \mathrm{~mW} / \mathrm{cm}^{2}$ and the duration of 1 min. (a) White light microscopy of the trypan blue-stained cells. (b) Fluorescence microscopy of the trypan blue + BCECF-AM-stained cells. Reprinted from Ref. 263 with the permission of NSU publishing.

after the exposure. ${ }^{263,264}$ Exposure of cells to the 2.0-THz THz waves with similar parameters did not cause significant changes in the majority of cells. Only sole neurons were colored uniformly, and their membrane potential was decreased or equal to zero, whereas their amount did not differ from the reference values. ${ }^{264}$ The control of membrane recovery after the disturbance was carried out using the BCECF-AM dye (7'-bis(2-carboxyethyl)-5(6)-carboxyfluorescein acetoxymethyl ester). This dye can penetrate through the undamaged plasmatic membrane, and it is transformed by the intracellular esterases of living neurons into its fluorescent form BCECF. Fluorescence of noncolored cells and some cells that captured tripan blue was discovered. Membrane of such cells can be recovered after disturbance, and they can retain fluorescence probes inside. ${ }^{263}$

To test the assumption concerning the THz-wave-induced formation of hydrophilic lipid pores and to reveal the underlying mechanisms before the THz exposure, antioxidants were introduced into the salt solution surrounding neurons, along with a dye (lucifer yellow) that does not penetrate through the intact membranes. It was found that phenol antioxidant histochrom significantly reduces the penetration of the dye into the cell. This may indicate that hydrophilic pores are formed in the cell membrane due to the free radical processes that can be blocked by antioxidants. ${ }^{265}$ Thus, $\mathrm{THz}$ radiation may cause reversible disturbance of the membrane barrier properties, serving as an inductor of the biologically active compounds' delivery into cells. In turn, antioxidants may be applied to manage this process, providing protection from unfavorable THz-wave effects. ${ }^{265}$

In Ref. 266, a dose-dependent cytotoxic effect was demonstrated during exposure for 1 to 5 min of the rat glial cells ( $\mathrm{C} 6$ cell line) to the $\mathrm{CW}$ THz radiation of BWO, with the output frequencies in the range of 0.12 to $0.18 \mathrm{THz}$ and the irradiance of $3.2 \mathrm{~mW} / \mathrm{cm}^{2}$. A relative number of apoptotic cells increased while sample heating did not exceed $0.1^{\circ} \mathrm{C}$. This study posed a problem of possible biological harm caused by such common CW THz-wave sources as BWOs. ${ }^{266}$

Reference 267 demonstrated an impact of the broadband pulsed $\mathrm{THz}$ radiation, with the frequencies in the range of 0.05 to $2.0 \mathrm{THz}$, the irradiances of $0.5,5$, and $50 \mu \mathrm{W} / \mathrm{cm}^{2}$, and the exposure duration of $3 \mathrm{~min}$, on the neurite growth in the sensory ganglia of 10- to 12-day chicken embryos. An increase in the stimulating effect by $24 \%$ was observed at the lowest power density of $0.5 \mu \mathrm{W} / \mathrm{cm}^{2}$. At the same time, at higher intensities of 5 and $50 \mu \mathrm{W} / \mathrm{cm}^{2}$, no notable changes were found. These observations highlighted nonlinear THz-wave effects in relation to the electromagnetic-beam power.

In Ref. 268, the neuron-like pheochromocytoma (PC12) cells were exposed, for $10 \mathrm{~min}$, to the 0.3 - to $19.5-\mathrm{THz}$ radiation of a synchrotron. During such exposure, the average temperature of the sample was $25.24 \pm 0.37^{\circ} \mathrm{C}$. High-resolution scanning electron microscopy confirmed permeabilization of the cell membrane. For this aim, translocation of silica nanoparticles into the PC12 cells was visualized. Analysis of the microscopy data revealed formation of atypically large (up to $1 \mu \mathrm{m}$ ) blebs on the surface of PC12 cells exposed to THz waves, as shown in Fig. 18. Significant differences between the metabolic activity of the THz-wave-treated PC12 cells and of 

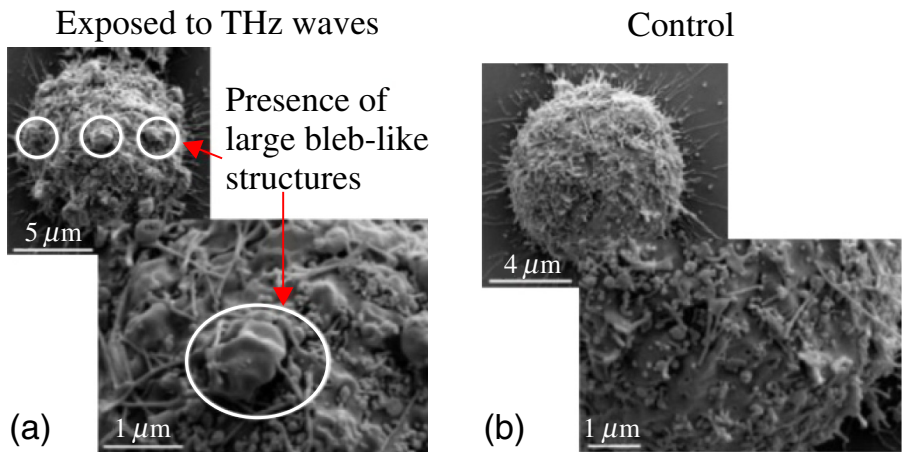

Fig. 18 Scanning electron microscopy of the PheoChromocytoma (PC12) cells after 10-min-long $\mathrm{THz}$ exposure. As a result of the $\mathrm{THz}$ exposure, formation of blebs on the PC12 cells was demonstrated, as highlighted by white circles in (a); whereas blebs were not found in the untreated PC12 cells, as evident from (b). Adapted from Ref. 268 with the permission of MDPI.

the control ones were not found. However, a higher population of the THz-treated PC12 cells responded to the nerve growth factor by extending longer neurites as compared with the untreated PC12 cells. ${ }^{268}$

Exposure to the 0.06- $\mathrm{THz} \mathrm{CW}$ radiation of the pyramidal rat neurons was studied in Ref. 269. For 1-min-long THz exposure at low irradiances $\left(40\right.$ to $\left.840 \mathrm{nW} / \mathrm{cm}^{2}\right)$, considerable changes in the neuronal firing rate and plasma membrane properties were notable. After resorting to higher irradiances (100 to $600 \mu \mathrm{W} / \mathrm{cm}^{2}$ ), dose-dependent increase in the plasma membrane permeability of the intact segmental ganglia of the adult leech (particularly, in the studied Retzius neurons) was observed. ${ }^{270}$ In Ref. 271 , THz exposure, for $1 \mathrm{~min}$, of individual neurons in the leech midbody ganglia at even higher irradiances $\left(1\right.$ to $\left.4 \mathrm{~mW} / \mathrm{cm}^{2}\right)$ revealed different effects of $\mathrm{THz}$ waves and equivalent thermal heating on narrowing of the action potential half-width and the firing rate. Possible explanation of this effect is the interaction between the $\mathrm{THz}$ wave and the neuronal plasma membrane. In Ref. 272, Romanenko et al. extended their studies by examining the direct effect of $0.06 \mathrm{THz}$ radiation with higher power density $\left(80\right.$ to $\left.170 \mathrm{~mW} / \mathrm{cm}^{2}\right)$ on sensory neurons from the leech, namely, the thermosensitive nociceptor. Both experiments and simulations showed a notable decrease in the voltage threshold of the action potential formation, as compared with the thermal heating. This effect was attributed to the sensitization of the transient potential of the vanilloid 1-like receptor in the leech nociceptor.

In Ref. 273, the cultured primary hippocampal neurons were exposed, for $20 \mathrm{~min}$, to the $\mathrm{CW}$ source (Terasense Group Inc.), with the frequency of $0.1 \mathrm{THz}$ and the irradiance of $33 \mathrm{~mW} / \mathrm{cm}^{2}$. The cells were cultured in the $37^{\circ} \mathrm{C}$ constant temperature incubator and, then, irradiated from the bottom side of the culture dish. RNA-sequencing was performed to identify the expression of 29 genes, as a result of the $\mathrm{THz}$ exposure. No considerable difference in the temperature between the culture medium of the sham group and the radiated group was observed. The expression levels of several heat shock proteins genes were not significantly upregulated by the THz exposure. The neuron cells did not undergo serious apoptosis response as well. The authors concluded that $\mathrm{THz}$ waves can affect various biomolecule interactions, such as binding of GTPase, phospholipid, tropomyosin, BMP receptor, and long-chain fatty acid, as well as regulate the synapse function and calcium signaling pathway. The upregulation of free intracellular calcium, observed ex vivo, along with the correlated morphological changes in the leech ganglia neuron were also demonstrated at $0.06 \mathrm{THz}$ with the power of $100 \mathrm{~mW} .{ }^{274}$

The discussed effects of the neuron cells' exposure to THz waves in CW mode are summarized in Tables 10 and 11. Cytotoxicity effects were observed during a number of experiments on exposure of cells and cell models to THz waves with different parameters. THz-wave-induced changes in the structure and functions of the cytoplasmic membrane, including the distortions of the membrane potential, are evident. The processes of nerve tissue regeneration act as an additional factor that modulates the THz-wave effects. In general, THz exposure of nerve cells paves the ways to the development of methods aimed at the noninvasive and selective action on the molecular and cellular regulatory mechanisms. 
Table 10 Effects of $\mathrm{CW} \mathrm{THz} \mathrm{radiation} \mathrm{on} \mathrm{the} \mathrm{neurons} \mathrm{cells.}$

\begin{tabular}{|c|c|c|c|c|c|}
\hline Cells & $\begin{array}{l}\text { Frequency } \\
\text { (THz) }\end{array}$ & $\begin{array}{l}\text { Irradiance } \\
\left(\mathrm{mW} / \mathrm{cm}^{2}\right)\end{array}$ & $\begin{array}{l}\text { Duration } \\
\text { (min) }\end{array}$ & Effects & Refs. \\
\hline Glial cells & $\begin{array}{l}0.12 \text { to } \\
0.18\end{array}$ & 3.2 & 1 & $\begin{array}{l}\text { Number of apoptotic cells increased } \\
1.5 \text {-fold }\end{array}$ & 266 \\
\hline Glial cells & $\begin{array}{l}0.12 \text { to } \\
0.18\end{array}$ & 3.2 & 5 & $\begin{array}{l}\text { Number of apoptotic cells increased } \\
2.4 \text {-fold }\end{array}$ & 266 \\
\hline Neurons of $L$. stagnalis & 0.71 & $10-20$ & 60 & $\begin{array}{l}\text { Alteration of adhesive properties of } \\
\text { neuron membrane }\end{array}$ & 262,263 \\
\hline Neurons of $L$. stagnalis & $\begin{array}{l}1.63,2.45 \\
2.56\end{array}$ & $2-20$ & 60 & None & 262,263 \\
\hline Neurons of $L$. stagnalis & 3.68 & $2-5$ & 60 & None & 262,263 \\
\hline Neurons of $L$. stagnalis & 3.68 & $10-20$ & 60 & $\begin{array}{l}\text { Alteration of neuron membrane and } \\
\text { formation of the interneuron connection } \\
\text { (structural changes of the somatic } \\
\text { membrane, axons and growth cone) }\end{array}$ & 262,263 \\
\hline Neurons of $L$. stagnalis & 4.28 & 2 to 20 & 60 & None & 262,263 \\
\hline $\begin{array}{l}\text { The pyramidal rat } \\
\text { neurons }\end{array}$ & 0.06 & $\begin{array}{l}4 \cdot 10^{-5} \text { to } \\
84 \cdot 10^{-5}\end{array}$ & 1 & $\begin{array}{l}\text { Considerable changes in the neuronal } \\
\text { firing rate and membrane }\end{array}$ & 269 \\
\hline $\begin{array}{l}\text { Retzius neurons of } \\
\text { leech }\end{array}$ & 0.06 & 0.1 to 0.6 & 1 & $\begin{array}{l}\text { Dose-dependent increase in the } \\
\text { plasma membrane permeability }\end{array}$ & 270 \\
\hline Neurons of leech & 0.06 & 1 to 4 & 1 & $\begin{array}{l}\text { Narrowing of the action potential } \\
\text { half-width }\end{array}$ & 271 \\
\hline $\begin{array}{l}\text { Thermosensitive } \\
\text { nociceptor of leech }\end{array}$ & 0.06 & 80 to 170 & 1 & $\begin{array}{l}\text { Notable decrease in the voltage } \\
\text { threshold of the action potential } \\
\text { formation }\end{array}$ & 272 \\
\hline $\begin{array}{l}\text { Primary hippocampal } \\
\text { neurons }\end{array}$ & 0.1 & 33 & 20 & $\begin{array}{l}\text { Changing various biomolecule } \\
\text { interactions as well as regulate } \\
\text { the synapse function and calcium } \\
\text { signaling pathway }\end{array}$ & 273 \\
\hline $\begin{array}{l}\text { The leech ganglia } \\
\text { neuron }\end{array}$ & 0.06 & 100 & 1 & $\begin{array}{l}\text { Upregulation of free intracellular } \\
\text { calcium and morphological changes }\end{array}$ & 274 \\
\hline
\end{tabular}

\subsubsection{Stem cells}

Stem cells are extremely sensitive to the environmental stimuli. Therefore, they can be considered as a favorable model for studying the effects of biological system exposure to weak electromagnetic fields including the THz waves. Pluripotency is a unique attribute of stem cells. Thus, a maintenance of the pluripotent state or, vice versa, an increase in the rate of spontaneous or induced differentiation are important features to be investigated, from the point of view of both their high sensitivity and their practical significance.

In Ref. 275, human embryonic stem cells (hESM01 cell line) were exposed, for $1 \mathrm{~h}$, to the pulsed THz radiation, with the central frequency of $2.3 \mathrm{THz}$, the peak irradiance of $4 \mathrm{~kW} / \mathrm{cm}^{2}$ (the average irradiance of $\simeq 0.14 \mathrm{~W} / \mathrm{cm}^{2}$ ). The whole genome analysis revealed the altered expression of 73 genes, whereas only 1 of those genes (namely, PRDM14, which suppresses differentiation) was specific to the pluripotent state. In total, $74 \%$ of the THz-sensitive proteincoding genes belong to the class of ubiquitously expressed genes. Bioinformatic analysis of the affected genes revealed 15 functional classes that were mostly related to mitochondria. Additional studies did not demonstrate signs of genotoxicity (structural chromosomal aberrations and phosphorylation of histone $\mathrm{H} 2 \mathrm{AX}$ ), morphological signs of spontaneous differentiation, and 
Table 11 Effects of pulsed $\mathrm{THz}$ radiation on the neurons cells.

\begin{tabular}{|c|c|c|c|c|c|}
\hline Cells & $\begin{array}{l}\text { Frequency } \\
\quad(\mathrm{THz})\end{array}$ & $\begin{array}{l}\text { Irradiance } \\
\left(\mathrm{mW} / \mathrm{cm}^{2}\right)\end{array}$ & $\begin{array}{l}\text { Duration } \\
\text { (min) }\end{array}$ & Effects & Refs. \\
\hline Neurons of L. stagnalis & 2.1 & 0.3 & 1 & Cell death after $60 \mathrm{~min}$ & 263 \\
\hline Neurons of L. stagnalis & 2.3 & 0.3 & 1 & Membrane changes & 263,264 \\
\hline Neurons of L. stagnalis & 2.3 & 3 & 1 & Cell death after $120 \mathrm{~min}$ & 263,264 \\
\hline Neurons of L. stagnalis & 2.3 & 30 & 1 & Cell death after $180 \mathrm{~min}$ & 263,264 \\
\hline Neurons of L. stagnalis & 2.3 & 2 to 20 & 0.6 & $\begin{array}{l}\text { Reversible membrane } \\
\text { permeability }\end{array}$ & 265 \\
\hline The sensory ganglia & 0.05 to 2.0 & 0.0005 & 3 & Stimulating effect by $24 \%$ & 267 \\
\hline The sensory ganglia & 0.05 to 2.0 & $0.005,0.05$ & 3 & None & 267 \\
\hline PC12 cells & 0.3 to 19.5 & - & 10 & $\begin{array}{l}\text { Formation of atypically large } \\
\text { blebs on the surface of cells }\end{array}$ & 268 \\
\hline
\end{tabular}

any effect on the mitotic index. In Ref. 249, similar human embryonic stem cells (hES07 cell line) were exposed to the broadband pulsed $\mathrm{THz}$ radiation, with the cut-off frequency of $\simeq 0.5 \mathrm{THz}$, the pulse repetition rate of $1 \mathrm{kHz}$, the pulse duration of $2 \mathrm{ps}$, the peak irradiances in the range of $1.75 \mathrm{~kW} / \mathrm{cm}^{2}$ (the average irradiance of 0.21 to $0.29 \mathrm{~mW} / \mathrm{cm}^{2}$ ). The exposure duration varied in the range of 120 to $375 \mathrm{~min}$. The authors observed no changes in the cell morphology, attachment, differentiation, and proliferation.

In Ref. 188, bone marrow mesenchymal stem cells were exposed, for $25 \mathrm{~min}$, to the 0.1 - to $4.5-\mathrm{THz}$ pulsed $\mathrm{THz}$ radiation with a $75-\mu \mathrm{J}$ pulse energy and $\mathrm{a} \simeq 10-\mathrm{MV} / \mathrm{cm}$ field strength. Cell viability analysis was carried out $24 \mathrm{~h}$ after the exposure, for which the fluorescent staining with propidium iodide and Hoechst dyes was applied. This study did not reveal any increase in the number of dead cells, as compared with the control group.

Human-induced pluripotent stem cells (hiPSCs) were exposed to the pulsed $\mathrm{THz}$ radiation with the central frequency of $0.8 \mathrm{THz}$ and the electric field of $0.5 \mathrm{MV} / \mathrm{cm}$ in Ref. 276. The estimated temperature rise was only $0.3 \mathrm{mK}$, which could not trigger to the expression of heat shock proteins. The genes, strongly affected by $\mathrm{THz}$ irradiation, were regulated by zinc-finger proteins. The authors supposed that gene expression was induced nonthermally by the electric field of the THz pulse, which might be caused by the movement of zinc ions within the cell compartments.

Mouse mesenchymal stem cells (MSC cell line) were studied in Ref. 277. Cells were preliminarily induced to differentiate toward adipocytes. They were exposed, for 2, 4, 6, and $9 \mathrm{~h}$, to the broadband pulsed $\mathrm{THz}$ waves with the frequency range of 1 to $30 \mathrm{THz}$ (the maximal intensity is centered at $\simeq 10 \mathrm{THz}$ ), the pulse repetition rate of $1 \mathrm{kHz}$, the pulse duration of $35 \mathrm{fs}$, the peak power of $\simeq 30 \mathrm{MW}$, and the average irradiance of $\simeq 1 \mathrm{~mW} / \mathrm{cm}^{2}$. Analysis of the genome-wide expression profile showed a clearly visible change in the profile only after a 9-h exposure; namely, 2204 genes changed their activity. Additional analysis of individual genes and visually increased accumulation of the lipid-like droplets in the cellular cytoplasm justified acceleration of the cells' differentiation into adipocytes under prolonged irradiation. Further studies that involved a 12-h-long $\mathrm{THz}$ exposure of cells to the radiation of the same source as well as their 2-h-long $\mathrm{THz}$ exposure to the $\mathrm{CW}$ radiation (the frequency of $2.52 \mathrm{THz}$ and the power of $<150 \mathrm{~mW}$ ) revealed changes in the activity of 381,122 , and 236 genes at 12 -h broadband pulsed, 2-h broadband pulsed, and 2-h CW exposure regimes, respectively. Finally, it was found that a 2-h-long $\mathrm{THz}$ exposure (regardless of the applied $\mathrm{THz}$ sources) affects genes transcriptionally active in pluripotent stem cells. ${ }^{278,279}$ The authors note that the transcriptional response to $\mathrm{THz}$ irradiation indirectly indicates manifestation of gene-specific intrinsic double-stranded DNA breathing dynamics, and the THz-field effects are most likely at the level of DNA transcription. ${ }^{277-279}$ 
There is still a quite small amount of investigation in the area of stem cell exposure to $\mathrm{THz}$ waves. The observed effects, both at the cellular and genetic levels, can be divided into two categories: general and stem-cell-specific. Effects from the first category, such as cyto- and genotoxicity, have not yet been found against the background of changes in the expression of many genes. Among the effects from the second category, available data allow us to consider $\mathrm{THz}$ radiation as a potential tool for noncontact control of gene expression and modulation of cell differentiation.

\subsection{Effects of THz Waves on Fluorescent Cellular Biosensors}

Fluorescent cellular biosensors, described in this section, generally have a form of cells with artificial genetic constructs, which include a promoter of a sensor gene (it reacts to the effect of one or another chemical or physical factor) and a reporter gene of fluorescence protein (its activity is regulated by the promoter of the sensor gene). ${ }^{280}$ The development of such biosensors includes assembly of the hybrid genetic constructs and their introduction into bacterial cells, as shown in Fig. 19.

When exposed to the investigated factor, the promoter of a sensor gene activates the reporter gene and, accordingly, the production of the fluorescence protein, thus, leading to a well-detectable fluorescent signal. The biosensory approach to study $\mathrm{THz}$ bioeffects makes it possible to trace the $\mathrm{THz}$ response of a gene, the promoter of which was used in the assembly of the genetic construct.

E. coli biosensor cells with the promoter of a sensor gene of catalase (kat G gene) were exposed, for 5,10 , and $15 \mathrm{~min}$, to pulse $\mathrm{THz}$ irradiation, with the central frequencies of $1.50,2.00$, and $2.31 \mathrm{THz}$, the pulse repetition rate of 2.8 to $11.2 \mathrm{MHz}$, the pulse duration of $50 \mathrm{ps}$, the peak power of $1 \mathrm{MW}$, or the average irradiance of $1.4 \mathrm{~W} / \mathrm{cm}^{2}$. THz radiation was intense enough to heat the samples up to $33^{\circ} \mathrm{C}$ to $37^{\circ} \mathrm{C}$; therefore, the control samples were subjected to the bulk heating at $37^{\circ} \mathrm{C}$. In addition, a positive control was applied; namely, exposure to the hydrogen peroxide (a typical inductor for the kat $G$ gene) and two additional controls: heat $\left(42^{\circ} \mathrm{C}\right.$ for $\left.5 \mathrm{~min}\right)$ and cold $\left(30^{\circ} \mathrm{C}\right.$ for $\left.15 \mathrm{~min}\right)$ shock. As a result, it was shown that $\mathrm{THz}$ radiation activates this biosensor (i.e., the catalase gene in the $E$. coli genome) at all studied $\mathrm{THz}$ frequencies, and the effect appears to be dose-dependent. There was no activation at 5-min-long exposure as well as after the heat/cold shock. At the same time, activation was observed in some experiments at 10-min-long exposure and in all experiments at 15-min-long exposure. Figure 20 shows that the effect of $\mathrm{THz}$ waves turned out to be more pronounced than that of a positive control; it persisted for more than $4 \mathrm{~h}$ after the exposure, which is equal to about eight life cycles of $E$. coli.

At the same time, radiation did not affect cell survival. ${ }^{281}$ Later, the activity of $E$. coli biosensors with the promoter of a sensor gene $\operatorname{cop} A$ (involved in the homeostasis of copper ions) and the promoter of a sensor gene $e m r R$ (involved in multidrug resistance) was studied using the same THz source with the central frequency of $2.31 \mathrm{THz}$ and exposure duration of $15 \mathrm{~min}$. The similar temperature conditions were applied. There were also corresponding positive controls that involved exposure to copper (II) sulfate and salicylic acid. As a result, the emrR promoter was not activated during the $\mathrm{THz}$ exposure, but there was a prolonged activation (by analogy with $k a t G$ ) of the copA promoter, but in less extent in comparison with the positive control;

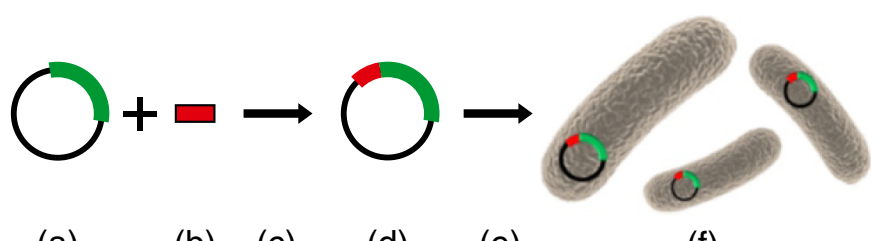

$\begin{array}{lllll}(a) & \text { (b) } \quad \text { (c) } & \text { (d) } \quad \text { (e) } & \text { (f) }\end{array}$

Fig. 19 The general scheme of the biosensor development: (a) a base vector with a fluorescence protein gene, (b) a sensory gene promoter, (c) an assembly, (d) a hybrid genetic construct, (e) an introduction of the resulting construct into cells, and (f) biosensors. Courtesy of D.S. Serdyukov. 


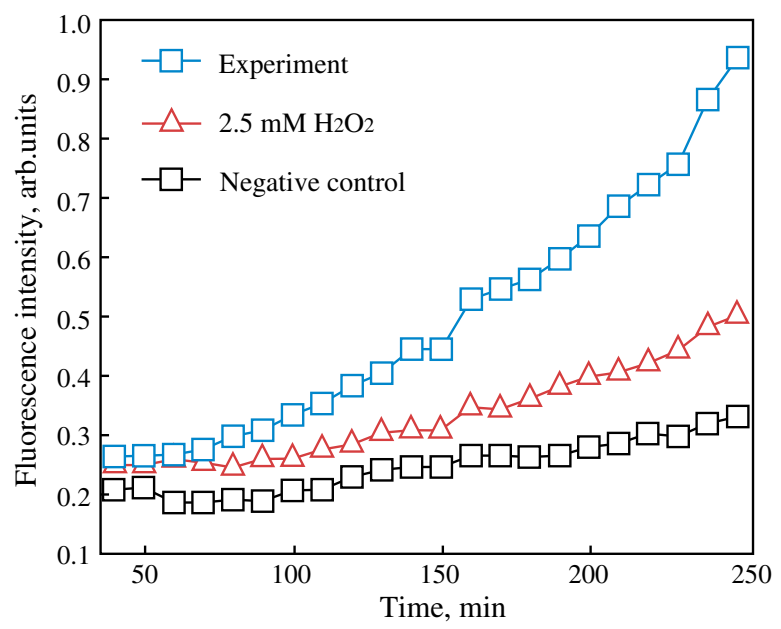

Fig. 20 Fluorescence dynamics of the E. coli biosensor cells with the promoter of a sensor gene katG after their 15-min-long exposure to $2.0 \mathrm{THz}$ radiation, as compared with the bulk heating to $37^{\circ} \mathrm{C}$ (negative control) and with the exposure to hydrogen peroxide. Adapted from Ref. 281 with the permission of John Wiley and Sons, Inc.

heat shock had no effect. ${ }^{282}$ Long-term THz-dependent responses of E. coli stress systems associated with oxidative stress and copper ion metabolism were demonstrated. The absence of a reaction of the antibiotic resistance system emphasizes the specificity of the cellular response. $^{281-283}$

Recently, similar E. coli biosensor technology was applied to study the activities of promoters that regulate the production of transcription factors MatA, YdeO, ChbR, and TdcR. ${ }^{284,285}$ Being exposed, for 15 and $30 \mathrm{~min}$, to the intense-pulsed $\mathrm{THz}$ radiation, with the frequency of $2.31 \mathrm{THz}$, the pulse repetition rate of $5.6 \mathrm{MHz}$, the pulse duration of $100 \mathrm{ps}$, and the average irradiance of $\simeq 140 \mathrm{~mW} / \mathrm{cm}^{2}$, the samples were heated up to the temperatures of $35^{\circ} \mathrm{C}$ to $37^{\circ} \mathrm{C}$, and all four biosensors were activated, as compared with the bulk heating at $37^{\circ} \mathrm{C}$. However, when exposed, for 15 and $30 \mathrm{~min}$, to the low-intensity $0.14-\mathrm{THz} \mathrm{CW}$ radiation with the irradiance of $2 \mathrm{~mW} / \mathrm{cm}^{2}$, the samples were heated up to $\simeq 26^{\circ} \mathrm{C}$ (which is $\leq 1^{\circ} \mathrm{C}$ above an ambient room temperature), and only three biosensors were activated, displaying the biosynthesis of YdeO, ChbR, and TdcR. In almost all of these cases, a dose-dependent effect was observed, i.e., the activation was more pronounced (or was only observed) at 30-min-long exposure, as compared to the 15-min-long one. In addition, as an example of THz-dependent activation of the $t d c R$ gene, the significant influence of the type of vessel for irradiation and the composition of the nutrient medium was shown. Chemical exposure (five different toxins separately) or heat shock (heating up to $42^{\circ} \mathrm{C}$ ) did not cause the activation. Thus, four $\mathrm{THz}$-sensitive biosensors were obtained, which serve as indicators of various cellular functions: biofilm development (MatA), response to various stress (YdeO), uptake and metabolism of chitobiose (ChbR), and transport and metabolism of threonine and serine (TdcR).

Thereby, the described research results justify that nowadays biosensors are considered as a promising platform for research and monitoring of the $\mathrm{THz}$ anthropogenic factors.

\section{Discussions}

Evidently, during the last few decades, large amounts of data have been accumulated regarding biological effects of $\mathrm{THz}$ waves. Sometimes, we observed contradicting results of the THz exposure, which poses important problems of adequate designing, planning, and performing of the $\mathrm{THz}$ exposure experiments. As described earlier, only a combination of accurate knowledge about the exposure parameters, a number of control measurements (tests), and maintenance of the suitable ambient environment can lead to reproducible and verified experimental data.

Despite a considerable interest paid to the biological effects of $\mathrm{THz}$ waves, further research is required for the development of safe limits of $\mathrm{THz}$ waves. Obviously, such safe limits should 
account for not only the thermal THz-wave effects (as the common ICNIRP standards do) $40,192,193$ but also for the nonthermal. Development of the THz dosimetry is of crucial importance for biomedical applications of $\mathrm{THz}$ technology in such demanding branches as label-free diagnosis of malignant and benign neoplasms, ${ }^{3,4,8-16}$ sensing of glycated tissues and blood in context of diabetes diagnosis, ${ }^{1,19-21}$ determining the degree of traumatic injuries ${ }^{22}$ and viability ${ }^{30}$ of tissues, and even emerging methods of single cells, microorganisms, bacteria, and viruses sensing. ${ }^{286-291}$ Also, THz dosimetry is of crucial importance for the rapidly developing $6 \mathrm{G}$ wireless communications that will reportedly span sub-THz and THz frequencies. ${ }^{292}$ There is no doubt that such a wide range of $\mathrm{THz}$ technology applications, which involve interaction between $\mathrm{THz}$ waves and different biological systems, would stimulate the development of $\mathrm{THz}$ safe limits in the nearest future.

Studies of the THz-wave biological effects involving modern methods of cytology, genetics, and molecular biology can uncover $\mathrm{THz}$ therapeutic avenue. As mentioned above, THz waves are capable of regulating the gene expression, changing the membrane permeability, and DNA demethylation. Being adequately studied and regulated, such a versatile impact of $\mathrm{THz}$ waves on living cell opens a variety of THz technology applications in medical therapy of cancers, inflammatory, and neurodegenerative deceases. Finally, we notice that development of such THz therapeutic applications would require further progress in $\mathrm{THz}$ components, including highly efficient uncooled CW and pulsed THz emitters, 6,7,126-128,130,132-135 elements of bulk (open space) and fiber/waveguide optics ${ }^{293-299}$ aimed at the THz-wave delivery to the hardly accessible tissues and internal organs. Such elements are still to be developed.

\section{Conclusion}

Recent research results in the area of THz-wave effects on biological systems of the different organization levels, such as biomolecules, cells, and organism, were discussed. Despite the considerable data accumulated in this demanding research direction, we still possess quite limited knowledge about biological effects of $\mathrm{THz}$ waves. Further research and engineering efforts are required to develop adequate safe limits of $\mathrm{THz}$-wave exposure and to objectively uncover strengths and weaknesses of THz technology in different branches of medial therapy. Thus, this review summarizes up-to-date knowledge in the area of cell exposure to $\mathrm{THz}$ radiation and paves the ways to the $\mathrm{THz}$ dosimetry and therapeutic avenues.

\section{Disclosures}

The authors declare no conflict of interest.

\section{Acknowledgments}

This work was financed by the Ministry of Science and Higher Education of the Russian Federation in the framework of state support for the creation and development of world-class research centers, "Digital Biodesign and Personalized Healthcare" (\# 075-15-2020-926).

\section{Code, Data, and Materials Availability}

All data generated or analyzed during this study are included in this article.

\section{References}

1. X. Yang et al., "Biomedical applications of terahertz spectroscopy and imaging," Trends Biotechnol. 34(10), 810-824 (2016).

2. O. Smolyanskaya et al., "Terahertz biophotonics as a tool for studies of dielectric and spectral properties of biological tissues and liquids," Prog. Quantum Electron. 62, 1-77 (2018). 
3. K. Zaytsev et al., "The progress and perspectives of terahertz technology for diagnosis of neoplasms: a review," J. Opt. 22(1), 013001 (2020).

4. G. Musina et al., "Prospects of terahertz technology in diagnosis of human brain tumors: a review," J. Biomed. Photonics Eng. 6(2), 020201 (2020).

5. O. Cherkasova et al., "Diagnosis of glioma molecular markers by terahertz technologies," Photonics 8(1), 22 (2021).

6. Y.-S. Lee, Principles of Terahertz Science and Technology, Springer, New York (2009).

7. H. Guerboukha, K. Nallappan, and M. Skorobogatiy, "Toward real-time terahertz imaging," Adv. Opt. Photonics 10(4), 843-938 (2018).

8. R. Woodward et al., "Terahertz pulse imaging of ex vivo basal cell carcinoma," J. Invest. Dermatol. 120(1), 72-78 (2003).

9. V. Wallace et al., "Terahertz pulsed imaging of basal cell carcinoma ex vivo and in vivo," Br. J. Dermatol. 151(2), 424-432 (2004).

10. K. Zaytsev et al., "In vivo terahertz spectroscopy of pigmentary skin nevi: pilot study of non-invasive early diagnosis of dysplasia," Appl. Phys. Lett. 106(5), 053702 (2015).

11. A. Fitzgerald et al., "Terahertz pulsed imaging of human breast tumors," Radiology 239(2), 533-540 (2006).

12. C. Reid et al., "Terahertz pulsed imaging of freshly excised human colonic tissues," Phys. Med. Biol. 56(14), 4333-4353 (2011).

13. S. Oh et al., "Study of freshly excised brain tissues using terahertz imaging," Biomed. Opt. Express 5(8), 2837-2842 (2014).

14. A. Gavdush et al., "Terahertz spectroscopy of gelatin-embedded human brain gliomas of different grades: a road toward intraoperative THz diagnosis," J. Biomed. Opt. 24(2), 027001 (2019).

15. A. Gavdush et al., "Terahertz dielectric spectroscopy of human brain gliomas and intact tissues ex vivo: double-Debye and double-overdamped-oscillator models of dielectric response," Biomed. Opt. Express 12(1), 69-83 (2021).

16. M. Konnikova et al., "Malignant and benign thyroid nodule differentiation through the analysis of blood plasma with terahertz spectroscopy," Biomed. Opt. Express 12(2), 1020-1035 (2021).

17. A. Kucheryavenko et al., "Terahertz dielectric spectroscopy and solid immersion microscopy of ex vivo glioma model 101.8: brain tissue heterogeneity," Biomed. Opt. Express 12(8), 5272-5289 (2021).

18. A. Nikitkina et al., "Terahertz radiation and the skin: a review," J. Biomed. Opt. 26(4), 043005 (2021).

19. O. Cherkasova, M. Nazarov, and A. Shkurinov, "Noninvasive blood glucose monitoring in the terahertz frequency range," Opt. Quantum Electron. 48(3), 217 (2016).

20. G. Hernandez-Cardoso et al., "Terahertz imaging for early screening of diabetic foot syndrome: a proof of concept," Sci. Rep. 7, 42124 (2017).

21. O. Smolyanskaya et al., "Multimodal optical diagnostics of glycated biological tissues," Biochemistry (Moscow) 84(S1), 124-143 (2019).

22. H. Zhao et al., "High-sensitivity terahertz imaging of traumatic brain injury in a rat model," J. Biomed. Opt. 23(3), 036015 (2018).

23. J. Shi et al., "Automatic evaluation of traumatic brain injury based on terahertz imaging with machine learning," Opt. Express 26(5), 6371-6381 (2018).

24. Y. Wang et al., "Terahertz spectroscopic diagnosis of early blast-induced traumatic brain injury in rats," Biomed. Opt. Express 11(8), 4085-4098 (2020).

25. Y. Cao et al., "Qualitative and quantitative detection of liver injury with terahertz timedomain spectroscopy," Biomed. Opt. Express 11(2), 982-993 (2020).

26. A. Shchepetilnikov et al., "Quantitative analysis of water content and distribution in plants using terahertz imaging," Opt. Eng. 59(6), 061617 (2020).

27. K. Zaytsev et al., "Special section guest editorial: advances in terahertz biomedical science and applications," J. Biomed. Opt. 26(4), 043001 (2021).

28. E. Iomdina et al., "Terahertz scanning of the rabbit cornea with experimental UVB-induced damage: in vivo assessment of hydration and its verification," J. Biomed. Opt. 26(4), 043010 (2021). 
29. G. Musina et al., "Moisture adsorption by decellularized bovine pericardium collagen matrices studied by terahertz pulsed spectroscopy and solid immersion microscopy," Biomed. Opt. Express 12(9), 5368-5386 (2021).

30. N. Bajwa et al., "Non-invasive terahertz imaging of tissue water content for flap viability assessment," Biomed. Opt. Express 8(1), 460-474 (2017).

31. M.-O. Mattsson, O. Zeni, and M. Simko, "Is there a biological basis for therapeutic applications of millimetre waves and THz waves?" J. Infrared Millimeter Terahertz Waves 39(9), 863-878 (2018).

32. S. Romanenko et al., "The interaction between electromagnetic fields at megahertz, gigahertz and terahertz frequencies with cells, tissues and organisms: risks and potential," J. R. Soc. Interface 14(137), 20170585 (2017).

33. L. Titova et al., "Intense $\mathrm{THz}$ pulses down-regulate genes associated with skin cancer and psoriasis: a new therapeutic avenue?" Sci. Rep. 3, 2363 (2013).

34. G. Wilmink and J. Grundt, "Invited review article: current state of research on biological effects of terahertz radiation," J. Infrared Millimeter Terahertz Waves 32(10), 1074-1122 (2011).

35. H. Hintzsche and H. Stopper, "Effects of terahertz radiation on biological systems," Crit. Rev. Environ. Sci. Technol. 42(22), 2408-2434 (2012).

36. I. Il'ina, D. Sitnikov, and M. Agranat, "State-of-the-art of studies of the effect of terahertz radiation on living biological systems," High Temp. 56(5), 789-810 (2018).

37. O. Cherkasova et al., "Effects of terahertz radiation on living cells: a review," Opt. Spectrosc. 128(6), 855-866 (2020).

38. "Scientific Committee on Emerging and Newly Identified Health Risks (SCENIHR) opinion on potential health effects of Exposure to Electromagnetic Fields (EMF)," Health effects of EMF, pp. 1-288 (2015).

39. "IEEE standard for safety levels with respect to human exposure to radio frequency electromagnetic fields, $3 \mathrm{kHz}$ to $300 \mathrm{GHz}$," IEEE Std C95.1 (2005).

40. International Commission on Non-Ionizing Radiation Protection (ICNIRP), "Guidelines for limiting exposure to time varying electric, magnetic, and electromagnetic fields (up to $300 \mathrm{GHz}$ )," Health Phys. 74(4), 494-522 (1998).

41. A. Berry et al., "Do in vivo terahertz imaging systems comply with safety guidelines?" J. Laser Appl. 15(3), 192-198 (2003).

42. T. Kleine-Ostmann et al., "Field exposure and dosimetry in the $\mathrm{THz}$ frequency range," IEEE Trans. Terahertz Sci. Technol. 4(1), 12-25 (2014).

43. L. Alexandrov et al., "Evaluating the role of coherent delocalized phonon-like modes in DNA cyclization," Sci. Rep. 7, 9731 (2017).

44. J. Son, Terahertz Biomedical Science and Technology, CRC Press, Boca Raton (2014).

45. P. Weightman, "Prospects for the study of biological systems with high power sources of terahertz radiation," Phys. Biol. 9(5), 053001 (2012).

46. V. Fedorov, V. Vechkanov, and O. Papafilova, "Influence of terahertz radiation on minimal osmotic resistance of red blood cells," Biomed. Radioelectron. 5, 39-44 (2014).

47. M. M. Nazarov et al., "Terahertz time-domain spectroscopy of biological tissues," Quantum Electron. 38, 647-654 (2008).

48. E. Pickwell et al., "Simulation of terahertz pulse propagation in biological systems," Appl. Phys. Lett. 84(12), 2190-2192 (2004).

49. A. Ishimaru, Electromagnetic Wave Propagation, Radiation, and Scattering: From Fundamentals to Applications, 2nd ed., IEEE Press, Piscataway, New Jersey (2017).

50. M. Zhadobov et al., "Millimeter-wave interactions with the human body: state of knowledge and recent advances," Int. J. Microwave Wireless Technolog. 3(2), 237-247 (2011).

51. V. Tuchin, Tissue Optics: Light Scattering Methods and Instruments for Medical Diagnostics, 3rd ed., SPIE, Bellingham, Washington (2015).

52. V. Tuchin, "Tissue optics and photonics: biological tissue structures," J. Biomed. Photonics Engi. 1(1), 3-21 (2015).

53. U. Møller et al., "Terahertz reflection spectroscopy of Debye relaxation in polar liquids," J. Opt. Soc. Am. B 26(9), A113-A125 (2009). 
54. E. Pickwell et al., "Simulating the response of terahertz radiation to basal cell carcinoma using ex vivo spectroscopy measurements," J. Biomed. Opt. 10(6), 064021 (2005).

55. G. Walker et al., "Modelling the propagation of terahertz radiation through a tissue simulating phantom," Phys. Med. Biol. 49(10), 1853-1864 (2004).

56. E. Pickwell et al., "In vivo study of human skin using pulsed terahertz radiation," Phys. Med. Biol. 49(9), 1595-1607 (2004).

57. M. Ney and I. Abdulhalim, "Modeling of reflectometric and ellipsometric spectra from the skin in the terahertz and submillimeter waves region," J. Biomed. Opt. 16(6), 067006 (2011).

58. A. Fitzgerald, E. Pickwell-MacPherson, and V. Wallace, "Use of finite difference time domain simulations and Debye theory for modelling the terahertz reflection response of normal and tumour breast tissue," PLoS One 9, e99291 (2014).

59. B. Truong et al., "The potential of the double-Debye parameters to discriminate between basal cell carcinoma and normal skin," IEEE Trans. Terahertz Sci. Technol. 5(6), 990-998 (2015).

60. B. Truong et al., "A dielectric model of human breast tissue in terahertz regime," IEEE Trans. Biomed. Eng. 62(2), 699-707 (2015).

61. K. J. Tielrooij et al., "Dielectric relaxation dynamics of water in model membranes probed by terahertz spectroscopy," Biophys J 97(9), 2484-2492 (2009).

62. T. Torii et al., "Measurements of glucose concentration in aqueous solutions using reflected $\mathrm{THz}$ radiation for applications to a novel sub- $\mathrm{THz}$ radiation non-invasive blood sugar measurement method," Digit Health 3, 2055207617729534 (2017).

63. L. Duponchel et al., "Terahertz microfluidic sensor for in situ exploration of hydration shell of molecules," Chemometr. Intell. Lab. Syst. 123, 28-35 (2013).

64. N. A. Morozov, "Periodic systems of the structure of matter: the theory of the formation of chemical elements in Russian," Izdatelskii Dom Sytina, Moscow (1907).

65. M. Nazarov, O. Cherkasova, and A. Shkurinov, "A comprehensive study of albumin solutions in the extended terahertz frequency range," J. Infrared Millimeter Terahertz Waves 39, 840-853 (2018).

66. O. Cherkasova et al., "THz spectroscopy of bound water in glucose: direct measurements from crystalline to dissolved state," J. Infrared Millimeter Terahertz Waves 41, 1057-1068 (2020).

67. M. Asaki et al., "Dielectric relaxation of electrolyte solutions using terahertz transmission spectroscopy," J. Chem. Phys. 116(19), 8469-8482 (2002).

68. S. Funkner et al., "Watching the low-frequency motions in aqueous salt solutions: the terahertz vibrational signatures of hydrated ions," J. Am. Chem. Soc. 134(2), 1030-1035 (2012).

69. N. Vinh et al., "High-precision gigahertz-to-terahertz spectroscopy of aqueous salt solutions as a probe of the femtosecond-to-picosecond dynamics of liquid water," J. Chem. Phys. 142(16), 164502 (2015).

70. E. Buixaderas, S. Kamba, and J. Petzelt, "Lattice dynamics and central-mode phenomena in the dielectric response of ferroelectrics and related materials," Ferroelectrics 308(1), 131-192 (2004).

71. K. Cole and R. Cole, "Dispersion and absorption in dielectrics I. Alternating current characteristics," J. Chem. Phys. 9(4), 341-351 (1941).

72. K. Cole and R. Cole, "Dispersion and absorption in dielectrics II. Direct current characteristics," J. Chem. Phys. 10(2), 98-105 (1942).

73. D. Davidson, "Dielectric relaxation in liquids: I. The representation of relaxation behavior," Can. J. Chem. 39(3), 571-594 (1961).

74. S. Havriliak and S. Negami, "A complex plane analysis of dispersions in some polymer systems," J. Polym. Sci. Part C Polym. Symp. 14(1), 99-117 (1966).

75. S. Yurchenko and K. Zaytsev, "Spectroscopy of nafion in terahertz frequency range," J. Appl. Phys. 116(11), 113508 (2014).

76. N. Chernomyrdin et al., "Reflection-mode continuous-wave $0.15 \lambda$-resolution terahertz solid immersion microscopy of soft biological tissues," Appl. Phys. Lett. 113(11), 111102 (2018). 
77. V. Zhelnov et al., "Object-dependent spatial resolution of the reflection-mode terahertz solid immersion microscopy," Opt. Express 29(3), 3553-3566 (2021).

78. C. Joseph et al., "Imaging of ex vivo nonmelanoma skin cancers in the optical and terahertz spectral regions. Optical and terahertz skin cancers imaging," J. Biophotonics 7(5), 295-303 (2014).

79. B. Fan, V. Neel, and A. Yaroslavsky, "Multimodal imaging for nonmelanoma skin cancer margin delineation," Lasers Surg. Med. 49(3), 319-326 (2017).

80. A. Yaroslavsky et al., "Delineating nonmelanoma skin cancer margins using terahertz and optical imaging," J. Biomed. Photonics Eng. 3(1), 010301 (2017).

81. G. Komandin et al., "BWO generators for terahertz dielectric measurements," IEEE Trans. Terahertz Sci. Technol. 3(4), 440-444 (2013).

82. L. Hu et al., "Experimental demonstration of a $0.34-\mathrm{THz}$ backward-wave oscillator with a sinusoidally corrugated slow-wave structure," IEEE Trans. Electron Devices 65(6), 2149-2155 (2018).

83. A. Dobroiu et al., "Terahertz imaging system based on a backward-wave oscillator," Appl. Opt. 43, 5637-5646 (2004).

84. M. Mineo and C. Paoloni, "Corrugated rectangular waveguide tunable backward wave oscillator for terahertz applications," IEEE Trans. Electron Devices 57(6), 1481-1484 (2010).

85. W. He et al., "Generation of broadband terahertz radiation using a backward wave oscillator and pseudospark-sourced electron beam," Appl. Phys. Lett. 107(13), 133501 (2015).

86. M. T. San et al., "Study on operation of oversized backward wave oscillator for broadband terahertz radiation," IEEE Trans. Plasma Sci. 46(3), 530-538 (2018).

87. T. Shibuya et al., "Terahertz-wave generation using a 4-dimethylamino-n-methyl-4stilbazolium tosylate crystal under intra-cavity conditions," Appl. Phys. Express 1(4), 042002 (2008).

88. W. Shi et al., "Efficient, tunable, and coherent $0.18-5.27-\mathrm{THz}$ source based on GaSe crystal," Opt. Lett. 27, 1454-1456 (2002).

89. W. Shi and Y. J. Ding, "Tunable terahertz waves generated by mixing two copropagating infrared beams in gap," Opt. Lett. 30, 1030-1032 (2005).

90. Y. J. Ding, "Progress in terahertz sources based on difference-frequency generation invited," J. Opt. Soc. Am. B 31, 2696-2711 (2014).

91. K. Kawase, J. Shikata, and H. Ito, "Terahertz wave parametric source," J. Phys. D Appl. Phys. 35(3), R1-R14 (2002).

92. K. Kawase et al., "Coherent tunable THz-wave generation from $\mathrm{LiNbO}_{3}$ with monolithic grating coupler," Appl. Phys. Lett. 68(18), 2483-2485 (1996).

93. M.-H. Wu et al., "Terahertz parametric generation and amplification from potassium titanyl phosphate in comparison with lithium niobate and lithium tantalate," Opt. Express 24, 25964-25973 (2016).

94. K. Kawase et al., "Injection-seeded terahertz-wave parametric generator with wide tunability," Appl. Phys. Lett. 80(2), 195-197 (2002).

95. H. Minamide et al., "Kilowatt-peak terahertz-wave generation and sub-femtojoule terahertz-wave pulse detection based on nonlinear optical wavelength-conversion at room temperature," J. Infrared Millimeter Terahertz Waves 35, 25-37 (2014).

96. S. Hayashi et al., "Ultrabright continuously tunable terahertz-wave generation at room temperature," Sci. Rep. 4, 5045 (2014).

97. K. Zhong et al., "Optically pumped terahertz sources," Science China Technological Sciences 60, 1801-1818 (2017).

98. G. W. Chantry, Long-Wave Optics: The Science and Technology of Infrared and NearMillimetre Waves. Volume 1 - Principles, Academic Press Inc., London and Orlando, Florida (1984).

99. G. W. Chantry, Long-Wave Optics: The Science and Technology of Infrared and NearMillimetre Waves. Volume 2 - Applications, Academic Press Inc., London and Orlando, Florida (1984).

100. P. Chevalier et al., "Widely tunable compact terahertz gas lasers," Science 366(6467), 856-860 (2019). 
101. M. Wienold, A. Zubairova, and H.-W. Hübers, "Laser emission at $4.5 \mathrm{THz}$ from ${ }^{15} \mathrm{NH}_{3}$ and a mid-infrared quantum-cascade laser as a pump source," Opt. Express 28, 23114-23121 (2020).

102. C. Liu et al., "Tunable terahertz gas laser based on a germanium spectrum splitter," Appl. Phys. B: Lasers Opt. 126(8), 133 (2020).

103. F. Maiwald et al., "Terahertz frequency multiplier chains based on planar Schottky diodes," Proc. SPIE 4855, 447-458 (2003).

104. M. Asada, S. Suzuki, and N. Kishimoto, "Resonant tunneling diodes for sub-terahertz and terahertz oscillators," Jpn. J. Appl. Phys. 47, 4375-4384 (2008).

105. A. Maestrini et al., "Schottky diode-based terahertz frequency multipliers and mixers," C.R. Phys. 11(7), 480-495 (2010).

106. J. Ward et al., "Capability of THz sources based on Schottky diode frequency multiplier chains," in IEEE MTT-S Int. Microwave Symp. Digest (IEEE Cat. No.04CH37535), Vol. 3, pp. 1587-1590 (2004).

107. A. Maestrini et al., "A 1.7-1.9 THz local oscillator source," IEEE Microwave Wireless Compon. Lett. 14(6), 253-255 (2004).

108. A. Maestrini et al., "Local oscillator chain for 1.55 to $1.75 \mathrm{THz}$ with $100-\mu \mathrm{W}$ peak power," IEEE Microwave Wireless Compon. Lett. 15(12), 871-873 (2005).

109. J. Rieh, D. Yoon, and J. Yun, "An overview of solid-state electronic sources and detectors for terahertz imaging," in 12th IEEE Int. Conf. Solid-State and Integr. Circuit Technol., pp. 1-4 (2014).

110. T. Ishibashi et al., "Unitraveling-carrier photodiodes for terahertz applications," IEEE J. Sel. Top. Quantum Electron. 20(6), 79-88 (2014).

111. S. Preu et al., "Tunable, continuous-wave terahertz photomixer sources and applications," J. Appl. Phys. 109(6), 061301 (2011).

112. K. A. McIntosh et al., "Terahertz photomixing with diode lasers in low-temperature-grown GaAs," Appl. Phys. Lett. 67(26), 3844-3846 (1995).

113. R. Safian, G. Ghazi, and N. Mohammadian, "Review of photomixing continuous-wave terahertz systems and current application trends in terahertz domain," Opt. Eng. 58(11), 110901 (2019).

114. D. J. Ironside et al., "Enhancing $\mathrm{THz}$ generation in photomixers using a metamaterial approach," Opt. Express 27, 9481-9494 (2019).

115. S. Kumar, "Recent progress in terahertz quantum cascade lasers," IEEE J. Sel. Top. Quantum Electron. 17(1), 38-47 (2011).

116. M. A. Belkin and F. Capasso, "New frontiers in quantum cascade lasers: high performance room temperature terahertz sources," Phys. Scr. 90, 118002 (2015).

117. S. Jung et al., "Terahertz difference-frequency quantum cascade laser sources on silicon," Optica 4, 38-43 (2017).

118. L. Li et al., "Terahertz quantum cascade lasers with $>1 \mathrm{~W}$ output powers," Electron. Lett. 50(4), 309-311 (2014).

119. B. S. Williams et al., "High-power terahertz quantum cascade lasers," Electron. Lett. 42(2), 89-91 (2006).

120. X. Wang et al., "High-power terahertz quantum cascade lasers with $0.23 \mathrm{~W}$ in continuous wave mode," AIP Adv. 6(7), 075210 (2016).

121. K. Fujita et al., "Recent progress in terahertz difference-frequency quantum cascade laser sources," Nanophotonics 7(11), 1795-1817 (2018).

122. D. H. Auston, K. P. Cheung, and P. R. Smith, "Picosecond photoconducting hertzian dipoles," Appl. Phys. Lett. 45(3), 284-286 (1984).

123. P. R. Smith, D. H. Auston, and M. C. Nuss, "Subpicosecond photoconducting dipole antennas," IEEE J. Quantum Electron. 24(2), 255-260 (1988).

124. C. Fattinger and D. Grischkowsky, "Terahertz beams," Appl. Phys. Lett. 54(6), 490-492 (1989).

125. D. Auston, "Picosecond optoelectronic switching and gating in silicon," Appl. Phys. Lett. 26(3), 101-103 (1975).

126. N. M. Burford and M. O. El-Shenawee, "Review of terahertz photoconductive antenna technology," Opt. Eng. 56(1), 010901 (2017). 
127. D. Lavrukhin et al., "Shaping the spectrum of terahertz photoconductive antenna by frequency-dependent impedance modulation," Semicond. Sci. Technol. 34(3), 034005 (2019).

128. A. Yachmenev et al., "Metallic and dielectric metasurfaces in photoconductive terahertz devices: a review," Opt. Eng. 59(6), 061608 (2019).

129. A. Yachmenev et al., "Arsenides-and related III-V materials-based multilayered structures for terahertz applications: carious designs and growth technology," Prog. Cryst. Growth Charact. Mater. 66(2), 100485 (2020).

130. C. Berry et al., "Significant performance enhancement in photoconductive terahertz optoelectronics by incorporating plasmonic contact electrodes," Nat Commun 4, 1622 (2013).

131. S. Yang et al., "7.5\% optical-to-terahertz conversion efficiency offered by photoconductive emitters with three-dimensional plasmonic contact electrodes," IEEE Trans. Terahertz Sci. Technol. 4(5), 575-581 (2014).

132. S. Lepeshov et al., "Enhancement of terahertz photoconductive antenna operation by optical nanoantennas," Laser Photonics Rev. 11(1), 1600199 (2017).

133. D. Lavrukhin et al., "Terahertz photoconductive emitter with dielectric-embedded highaspect-ratio plasmonic grating for operation with low-power optical pumps," $A I P A d v$. 9(1), 015112 (2019).

134. D. Lavrukhin et al., "Plasmonic photoconductive antennas for terahertz pulsed spectroscopy and imaging systems," Opt. Spectrosc. 126, 580-586 (2019).

135. D. Lavrukhin et al., "Emission efficiency of terahertz antennas with conventional topology and metal metasurface: a comparative analysis," Opt. Spectrosc. 128, 1018-1025 (2020).

136. A. Rice et al., "Terahertz optical rectification from $<110>$ zinc-blende crystals," Appl. Phys. Lett. 64(11), 1324-1326 (1994).

137. A. Schneider et al., "Generation of terahertz pulses through optical rectification in organic dast crystals: theory and experiment," J. Opt. Soc. Am. B 23, 1822-1835 (2006).

138. M. Venkatesh et al., "Generation of efficient THz radiation by optical rectification in DAST crystal using tunable femtosecond laser pulses," Indian J. Phys. 91, 319-326 (2017).

139. K.-L. Yeh et al., "Generation of $10 \mu \mathrm{J}$ ultrashort terahertz pulses by optical rectification," Appl. Phys. Lett. 90(17), 171121 (2007).

140. D. Jang et al., "Scalable terahertz generation by large-area optical rectification at $80 \mathrm{TW}$ laser power," Opt. Lett. 44, 5634-5637 (2019).

141. F. Meyer et al., "Single-cycle, $\mathrm{MHz}$ repetition rate $\mathrm{THz}$ source with $66 \mathrm{~mW}$ of average power," Opt. Lett. 45, 2494-2497 (2020).

142. C. Vicario et al., "High efficiency THz generation in DSTMS, DAST and OH1 pumped by Cr:forsterite laser,” Opt. Express 23, 4573-4580 (2015).

143. C. P. Hauri et al., "Strong-field single-cycle THz pulses generated in an organic crystal," Appl. Phys. Lett. 99(16), 161116 (2011).

144. S. Tripathi et al., "A fiber-laser pumped, high-power terahertz wave source based on optical rectification of femtosecond pulses in 4-dimethylamino-n-methyl-4-stilbazolium tosylate crystal," Appl. Phys. Express 6(7), 072703 (2013).

145. D. S. Sitnikov et al., "Cell proliferation under intense pulses of terahertz radiation," J. Phys. Conf. Ser. 1787, 012030 (2021).

146. A. V. Ovchinnikov et al., "A source of $\mathrm{THz}$ radiation with electric field strength of more than $1 \mathrm{MV} \mathrm{cm}-1$ on the basis of $100-\mathrm{Hz}$ femtosecond Cr: forsterite laser system," Quantum Electron. 48, 554-558 (2018).

147. M. Agranat et al., "Damage in a thin metal film by high-power terahertz radiation," Phys. Rev. Lett. 120(8), 085704 (2018).

148. C. Vicario et al., "Generation of $0.9-\mathrm{mJ} \mathrm{THz}$ pulses in DSTMS pumped by a $\mathrm{Cr}: \mathrm{Mg}_{2} \mathrm{SiO}_{4}$ laser," Opt. Lett. 39(23), 6632-6635 (2014).

149. D. Sitnikov, I. Ilina, and A. Pronkin, "Experimental system for studying bioeffects of intense terahertz pulses with electric field strength up to $3.5 \mathrm{MV} / \mathrm{cm}$," Opt. Eng. 59(6), 061613 (2020).

150. D. Sitnikov et al., "System for long-term irradiation of living cell culture with highintensity THz pulses," High Temp. 58, 36-43 (2020).

151. T. Idehara et al., "The gyrotrons as promising radiation sources for $\mathrm{THz}$ sensing and imaging," Appl. Sci. 10(3), 980 (2020). 
152. M. Thumm, "Gyro-devices and their applications," in IEEE Int. Vacuum Electron. Conf., pp. 521-524 (2011).

153. N. Kumar et al., "A review on the sub-THz/THz gyrotrons," Infrared Phys. Technol. 76, 38-51 (2016).

154. T. Idehara et al., "A THz gyrotron FU CW III with a 20T superconducting magnet," in 33rd Int. Conf. Infrared, Millimeter and Terahertz Waves, pp. 1-2 (2008).

155. T. Idehara and S. P. Sabchevski, "Development and application of gyrotrons at FIR UF," IEEE Trans. Plasma Sci. 46(7), 2452-2459 (2018).

156. M. Thumm, "State-of-the-art of high-power gyro-devices and free electron masers," J. Infrared Millimeter Terahertz Waves 41, 1-140 (2020).

157. R. J. Temkin, "Development of terahertz gyrotrons for spectroscopy at MIT," Terahertz Sci. Technol. 1, 1-9 (2014).

158. Y. Tatematsu et al., "Development of second harmonic gyrotrons, gyrotron FU CW GII and Gyrotron FU CW GIII, equipped with internal mode converters," J. Infrared Millimeter Terahertz Waves 35(2), 169-178 (2014).

159. T. Saito et al., "Performance test of CW $300 \mathrm{GHz}$ gyrotron FU CW I," Int. J. Infrared Millim. Waves 28(12), 1063-1078 (2007).

160. V. E. Zapevalov et al., "High-power oscillator of continuous electromagnetic radiation with a frequency of $300 \mathrm{GHz}$," Radiophys. Quantum Electron. 50(6), 420-428 (2007).

161. M. Y. Glyavin et al., "Terahertz gyrotrons: state of the art and prospects," J. Commun. Technol. Electron. 59(8), 792-797 (2014).

162. K. Sakamoto et al., "Development of $100 \mathrm{GHz}$ band high power gyrotron for fusion experimental reactor," in 18th Int. Atomic Energy Agency Fusion Energy Conf. (2001).

163. M. Y. Glyavin, A. G. Luchinin, and G. Y. Golubiatnikov, "Generation of 1.5-kW, 1-THz coherent radiation from a gyrotron with a pulsed magnetic field," Phys. Rev. Lett. 100, 015101 (2008).

164. M. Y. Glyavin and A. G. Luchinin, "Powerful terahertz gyrotrons based on pulsed magnets," Terahertz Sci. Technol. 2(4), 150-155 (2009).

165. A. Ramundo-Orlando and G. P. Gallerano, "Terahertz radiation effects and biological applications," J. Infrared Millimeter Terahertz Waves 30, 1308-1318 (2009).

166. T. T. L. Kristensen et al., "Modeling terahertz heating effects on water," Opt. Express 18, 4727-4739 (2010).

167. O. Spathmann et al., "Numerical computation of temperature elevation in human skin due to electromagnetic exposure in the THz frequency range," IEEE Trans. Terahertz Sci. Technol. 5(6), 978-989 (2015).

168. U. Malik et al., "Heat transfer and mapping of $\mathrm{THz}$ radiation absorption in biological tissue using mathematica based simulink transform," Malays. J. Fundamental Appl. Sci. 14, 500-508 (2018).

169. W. Liu et al., "Thermal analysis of cornea heated with terahertz radiation," Appl. Sci. 9(5), 917 (2019).

170. H. Hintzsche et al., "Terahertz radiation induces spindle disturbances in human-hamster hybrid cells," Radiat. Res. 175(5), 569-574 (2011).

171. S. Koyama et al., "Twenty four-hour exposure to a $0.12 \mathrm{THz}$ electromagnetic field does not affect the genotoxicity, morphological changes, or expression of heat shock protein in HCE-T cells," Int. J. Environ. Res. Public Health 13(8), 793 (2016).

172. I. Echchgadda et al., "Terahertz radiation: a non-contact tool for the selective stimulation of biological responses in human cells," IEEE Trans. Terahertz Sci. Technol. 6(1), 54-68 (2016).

173. V. Fedorov, S. Popova, and A. Pisarchik, "Dynamic effects of submillimeter wave radiation on biological objects of various levels of organization," Int. J. Infrared Millim. Waves 24(8), 1235-1254 (2003).

174. H. Fröhlich, "Long-range coherence and energy storage in biological systems," Int. J. Quantum Chem. 2(5), 641-649 (1968).

175. A. Davydov, "The theory of contraction of proteins under their excitation," J. Theor. Biol. 38(3), 559-569 (1973). 
176. V. Kislov, N. Devyatkov, and O. Betskii, "Low intensity millimeter waves in medicine and biology," Crit. Rev. Biomed. Eng. 28(1and2), 247-268 (2000).

177. H. Fröhlich, "The biological effects of microwaves and related questions," Adv. Electron. Electron Phys. 53, 85 (1980).

178. H. Fröhlich, Biological Coherence and Response to External Stimuli, Springer, Berlin, Heidelberg (1988).

179. I. V. Lundholm et al., "Terahertz radiation induces non-thermal structural changes associated with fröhlich condensation in a protein crystal," Struct. Dyn. 2(5), 054702 (2015).

180. J. Preto, "Classical investigation of long-range coherence in biological systems," Chaos: Interdis. J. Nonlinear Sci. 26(12), 123116 (2016).

181. J. Preto, "Semi-classical statistical description of fröhlich condensation," J. Biol. Phys. 43, 167-184 (2017).

182. Z. Zhang, G. S. Agarwal, and M. O. Scully, "Quantum fluctuations in the Fröhlich condensate of molecular vibrations driven far from equilibrium," Phys. Rev. Lett. 122, 158101 (2019).

183. B. Alexandrov et al., "DNA breathing dynamics in the presence of a terahertz field," Phys. Lett. A 374(10), 1214-1217 (2010).

184. S. M. Chitanvis, "Can low-power electromagnetic radiation disrupt hydrogen bonds in dsDNA?" J. Polym. Sci. Part B Polym. Phys. 44(18), 2740-2747 (2006).

185. A. Bugay, "Interaction of terahertz radiation with DNA," Nanosystems 3(1), 51-55 (2012).

186. H. Cheon et al., "Detection and manipulation of methylation in blood cancer DNA using terahertz radiation," Sci. Rep. 9, 6413 (2019).

187. G. N. Kulipanov et al., "Novosibirsk free electron laser-facility description and recent experiments," IEEE Trans. Terahertz Sci. Technol. 5(5), 798-809 (2015).

188. D. S. Sitnikov et al., "Studying the effect of high-power coherent terahertz pulses on mesenchymal stem cells," J. Phys. Conf. Ser. 1147, 012060 (2019).

189. L. V. Titova, F. A. Hegmann, and O. Kovalchuk, "Biological effects of broadband terahertz pulses," ch. 12 in Terahertz Biomedical Science and Technology, J.-H. Son, Ed., 1st ed., pp. 241-264, CRC Press, Boca Raton (2014).

190. L. David, M. G. Martin, and H. Martina, "Solvation dynamics of biomolecules: modeling and terahertz experiments," HFSP J. 2(6), 314-323 (2008).

191. Z. Zhu et al., "Transition to a superpermeation phase of confined water induced by a terahertz electromagnetic wave," J. Phys. Chem. Lett. 11(1), 256-262 (2020).

192. International Commission on Non-Ionizing Radiation Protection (ICNIRP), "Guidelines for limiting exposure to electromagnetic fields (100 kHz to $300 \mathrm{GHz})$," Health Phys. 118(5), 483-524 (2020).

193. International Commission on Non-Ionizing Radiation Protection, "ICNIRP Guidelines on Limits of Exposure to Laser Radiation of Wavelengths between $180 \mathrm{~nm}$ and 1,000 $\mu \mathrm{m}$," Health Phys. 105(3), 271-295 (2013).

194. M. Simkó and M.-O. Mattsson, "5G wireless communication and health effects: a pragmatic review based on available studies regarding 6 to $100 \mathrm{GHz}$," Int. J. Environ. Res. Public Health 16, 3406 (2019).

195. L. Hardell, R. Nyberg, and O. Kovalchuk, "Appeals that matter or not on a moratorium on the deployment of the fifth generation, 5G, for microwave radiation," Mol. Clin. Oncol. 12(3), 247-257 (2020).

196. K. Li et al., "Relationship between power density and surface temperature elevation for human skin exposure to electromagnetic waves with oblique incidence angle from $6 \mathrm{GHz}$ to $1 \mathrm{THz}$, , Phys. Med. Biol. 64(6), 065016 (2019).

197. I. Laakso et al., "Human exposure to pulsed fields in the frequency range from 6 to $100 \mathrm{GHz}$, , Phys. Med. Biol. 62, 6980-6992 (2017).

198. K. Sasaki et al., "Monte Carlo simulations of skin exposure to electromagnetic field from $10 \mathrm{GHz}$ to $1 \mathrm{THz}$," Phys. Med. Biol. 62, 6993-7010 (2017).

199. Z. Vilagosh, A. Lajevardipour, and A. W. Wood, "Computational absorption and reflection studies of normal human skin at $0.45 \mathrm{THz}$," Biomed. Opt. Express 11, 417-431 (2020).

200. A. Matei et al., "Far-infrared spectra of amino acids," Chem. Phys. 316(1), 61-71 (2005). 
201. W. Yi et al., "Broadband terahertz spectroscopy of amino acids," Instrum Sci. Technol. 45(4), 423-439 (2017).

202. O. P. Cherkasova et al., "Terahertz spectroscopy of biological molecules," Radiophys. Quantum Electron. 52, 518 (2009).

203. S. Fan et al., "The growth of biomedical terahertz research," J. Phys. D Appl. Phys. 47, 374009 (2014).

204. G. Acbas et al., "Optical measurements of long-range protein vibrations," Nat. Commun. 5, 3076 (2014)

205. B. M. Fischer, M. Walther, and P. U. Jepsen, "Far-infrared vibrational modes of DNA components studied by terahertz time-domain spectroscopy," Phys. Med. Biol. 47, 3807-3814 (2002).

206. F. Wang et al., "Terahertz spectra of DNA nucleobase crystals: a joint experimental and computational study," Spectrochim. Acta Part A 179, 255-260 (2017).

207. A. Markelz, A. Roitberg, and E. Heilweil, "Pulsed terahertz spectroscopy of DNA, bovine serum albumin and collagen between 0.1 and 2.0 THz," Chem. Phys. Lett. 320(1), 42-48 (2000).

208. G. Kaur and X.-C. Zhang, "Nonlinear interaction of amino acids and proteins with terahertz waves," ch. 12 in Terahertz Biomedical Science and Technology, J.-H. Son, Ed., 1 ed., pp. 211-240, CRC Press, Boca Raton (2014).

209. I. Litvinov et al., "Portable uncooled shutterless camera operating in the long-wavelength infrared range; part I: camera calibration," Proc. SPIE 11457, 1145700 (2020).

210. I. Litvinov et al., "Portable uncooled shutterless camera operating in the long-wavelength infrared range; part II: digital image processing," Proc. SPIE 11457, 114570P (2020).

211. O. P. Cherkasova et al., "Influence of terahertz laser radiation on the spectral characteristics and functional properties of albumin," Opt. Spectrosc. 107, 534 (2009).

212. O. P. Cherkasova et al., "Terahertz radiation influence on peptide conformation," Proc. SPIE 6727, 672721 (2007).

213. E. F. Nemova et al., "A study on molecular mechanisms of terahertz radiation interaction with biopolymers based on the example of bovine serum albumin," Biophysics (Nagoyashi) 65, 410-415 (2020).

214. A. Homenko et al., "Effects of $100 \mathrm{GHz}$ radiation on alkaline phosphatase activity and antigen-antibody interaction," Bioelectromagnetics 30(3), 167-175 (2009).

215. A. A. Greschner et al., "Room-temperature and selective triggering of supramolecular DNA assembly/disassembly by nonionizing radiation," J. Am. Chem. Soc. 141(8), 3456-3469 (2019).

216. V. M. Govorun et al., "Far-infrared radiation effect on the structure and properties of proteins," Int. J. Infrared Millim. Waves 12, 1469-1474 (1991).

217. S. Yamazaki et al., "Propagation of $\mathrm{THz}$ irradiation energy through aqueous layers: demolition of actin filaments in living cells," Sci. Rep. 10, 9008 (2020).

218. T. Kawasaki, K. Tsukiyama, and A. Irizawa, "Dissolution of a fibrous peptide by terahertz free electron laser," Sci. Rep. 9, 10636 (2019).

219. H. Cheon et al., "Effective demethylation of melanoma cells using terahertz radiation," Biomed. Opt. Express 10, 4931-4941 (2019).

220. H. Cheon et al., "Terahertz molecular resonance of cancer DNA," Sci. Rep. 6, 37103 (2016).

221. S.-Y. Jeong et al., "Determining terahertz resonant peaks of biomolecules in aqueous environment," Opt. Express 28, 3854-3863 (2020).

222. Y. H. Tao et al., "Reproducibility of terahertz peaks in a frozen aqueous solution of 5-methylcytidine," J. Infrared Millimeter Terahertz Waves 42, 588-606 (2021).

223. O. Cherkasova, M. Nazarov, and A. Shkurinov, "Study of blood and its components by terahertz pulsed spectroscopy," EPJ Web Conf. 195, 10003 (2018).

224. O. Cherkasova et al., "Analysis of blood plasma at terahertz frequencies," Opt. Spectrosc. 120, 50-57 (2016).

225. M. Nazarov et al., "A complex study of the peculiarities of blood serum absorption of rats with experimental liver cancer," Opt. Spectrosc. 126, 721-729 (2019). 
226. H. Chen et al., "Quantify glucose level in freshly diabetic's blood by terahertz time-domain spectroscopy," J. Infrared Millimeter Terahertz Waves 39, 399-408 (2018).

227. S. Ilyina et al., "On the possible role of water in the transmission of millimeter-wave radiation to biological objects," Biophysics (Nagoya-shi) 24(3), 513-518 (1979).

228. A. G. Khamoyan, E. Y. Shevela, and E. R. Chernykh, "Investigation of possibility of submillimeter laser using as instrument for diagnostics in medicine," Proc. SPIE 6734, 673404 (2007).

229. A. Munzarova, A. Kozlov, and E. Zelentsov, "Effect of terahertz laser irradiation on red blood cells aggregation in healthy blood," Vestnik NSU Phys. Ser. 8(2), 117-123 (2013).

230. A. V. Deryugina et al., "Electrokinetic and biochemical changes in erythrocytes under the action of terahertz range electromagnetic waves," Biophysics (Nagoya-shi) 62(6), 914-918 (2017).

231. A. A. Angeluts et al., "Study of terahertz-radiation-induced DNA damage in human blood leukocytes," Quantum Electron. 44, 247-251 (2014).

232. A. Gapeev, N. Romanova, and N. Chemeris, "Changes in the chromatin structure of lymphoid cells under the influence of low-intensity extremely high-frequency electromagnetic radiation against the background of inflammatory process," Biophysics (Nagoya-shi) 56(4), 688 (2011).

233. O. Zeni et al., "Cytogenetic observations in human peripheral blood leukocytes following in vitro exposure to THz radiation: a pilot study," Health Phys. 92(4), 349-357 (2007).

234. M. Scarfi et al., "THz exposure of whole blood for the study of biological effects on human lymphocytes," J. Biol. Phys. 29, 171-176 (2003).

235. A. Doria et al., "THz radiation studies on biological systems at the ENEA FEL facility," Infrared Phys. Technol. 45, 339-347 (2004).

236. A. Korenstein-Ilan et al., "Terahertz radiation increases genomic instability in human lymphocytes," Radiat. Res. 170, 224-234 (2008).

237. G. J. Wilmink et al., "Determination of death thresholds and identification of terahertz (THz)-specific gene expression signatures," Proc. SPIE 7562, 75620K (2010).

238. G. Wilmink et al., "Terahertz radiation preferentially activates the expression of genes responsible for the regulation of plasma membrane properties," in Int. Conf. Infrared, Millimeter, and Terahertz Waves, p. 12442107 (2011).

239. J. E. Grundt et al., "Terahertz radiation triggers a signature gene expression profile in human cells," in Int. Conf. Infrared, Millimeter, and Terahertz Waves, p. 12442108 (2011).

240. I. Echchgadda et al., "Terahertz stimulate specific signaling pathways in human cells," in 39th Int. Conf. Infrared, Millimeter, and Terahertz Waves, p. 14770846 (2014).

241. Scientific Committee on Emerging Newly Identified Health Risks, "Opinion on potential health effects of exposure to electromagnetic fields," Bioelectromagnetics 36(6), 480-484 (2015).

242. G. J. Wilmink et al., "Quantitative investigation of the bioeffects associated with terahertz radiation," Proc. SPIE 7562, 75620L (2010).

243. G. J. Wilmink et al., "In vitro investigation of the biological effects associated with human dermal fibroblasts exposed to $2.52 \mathrm{THz}$ radiation," Lasers Surg. Med. 43(2), 152-163 (2011).

244. A. D. Amicis et al., "Biological effects of in vitro THz radiation exposure in human foetal fibroblasts," Mutation Res./Genetic Toxicol. Environ. Mutagenesis 793, 150-160 (2015).

245. V. Franchini et al., "Study of the effects of 0.15 terahertz radiation on genome integrity of adult fibroblasts," Environ. Mol. Mutagen. 59(6), 476-487 (2018).

246. O. Cherkasova et al., "Studying the effect of $0.14 \mathrm{THz}$ radiation on human dermal fibroblasts," AIP Conf. Proc. 2098(1), 020004 (2019).

247. N. Yaekashiwa et al., "Investigation of the non-thermal effects of exposing cells to 70-300 GHz irradiation using a widely tunable source," J. Radiat. Res. 59(2), 116-121 (2018).

248. N. Yaekashiwa et al., "Verification of non-thermal effects of $0.3-0.6 \mathrm{THz}-$ waves on human cultured cells," Photonics 6, 33 (2019).

249. R. Williams et al., "The influence of high intensity terahertz radiation on mammalian cell adhesion, proliferation and differentiation," Phys. Med. Biol. 58, 373-391 (2012). 
250. N. Bourne et al., "The effects of terahertz radiation on human keratinocyte primary cultures and neural cell cultures," Alternatives Lab. Animals 36(6), 667-684 (2008).

251. H. Hintzsche et al., "Terahertz electromagnetic fields $(0.106 \mathrm{THz})$ do not induce manifest genomic damage in vitro," PLoS One 7, e46397 (2012).

252. H. Hintzsche et al., "Terahertz radiation at $0.380 \mathrm{THz}$ and $2.520 \mathrm{THz}$ does not lead to DNA damage in skin cells in vitro," Radiat. Res. 179(1), 38-45 (2012).

253. I. Echchgadda et al., "Effects of different terahertz frequencies on gene expression in human keratinocytes," Proc. SPIE 9321, 93210Q (2015).

254. R. Clothier and N. Bourne, "Effects of $\mathrm{THz}$ exposure on human primary keratinocyte differentiation and viability," J. Biol. Phys. 29, 179-185 (2003).

255. L. Titova et al., "Intense $\mathrm{THz}$ pulses cause $\mathrm{H} 2 \mathrm{AX}$ phosphorylation and activate DNA damage response in human skin tissue," Biomed. Opt. Express 4(4), 559-568 (2013).

256. C. M. Hough et al., "Genomic mechanisms of THz-induced cancer dysregulation in human skin," in 44th Int. Conf. Infrared, Millimeter, and Terahertz Waves, pp. 1-3 (2019).

257. C. M. Hough et al., "Global gene expression in human skin tissue induced by intense terahertz pulses," Terahertz Sci. Technol. 11(1), 28-33 (2018).

258. C. Hough et al., "Topology-based prediction of pathway dysregulation induced by intense terahertz pulses in human skin tissue models," J. Infrared Millimeter Terahertz Waves 39, 887-898 (2018).

259. C. Hough et al., "Intense terahertz pulses inhibit ras signaling and other cancer-associated signaling pathways in human skin tissue models," J. Phys. Photonics 3(3), 034004 (2021).

260. K.-T. Kim et al., "High-power femtosecond-terahertz pulse induces a wound response in mouse skin," Sci. Rep. 3, 2296 (2013).

261. Y. Hwang et al., "In vivo analysis of THz wave irradiation induced acute inflammatory response in skin by laser-scanning confocal microscopy," Opt. Express 22, 11465-11475 (2014).

262. J. S. Olshevskaya et al., "Effect of terahertz electromagnetic waves on neurons systems," in IEEE Region 8 Int. Conf. Comput. Technol. Electr. and Electron. Eng., pp. 210-211 (2008).

263. J. S. Olshevskaya et al., "Cell membrane permeability under the influence of terahertz (submillimeter) laser radiation," Vestnik NSU. Ser. Phys. 5(4), 177 (2010).

264. J. S. Olshevskaya et al., "Influence of terahertz (submillimeter) laser radiation on neurons in vitro," I.P. Pavlov J. Higher Nervous Activity 59(3), 353-539 (2009).

265. T. Zapara, S. Treskova, and A. Ratushniak, "Effect of antioxidants on the interaction of terahertz (submillimeter) laser radiation and neuronal membrane," J. Surf. Invest. 9, 869-871 (2015).

266. M. Borovkova et al., "Investigation of terahertz radiation influence on rat glial cells," Biomed. Opt. Express 8, 273-280 (2017).

267. M. V. Tsurkan et al., "Changing growth of neurites of sensory ganglion by terahertz radiation," Proc. SPIE 8261, 82610S (2012).

268. P. Perera et al., "PC 12 pheochromocytoma cell response to super high frequency terahertz radiation from synchrotron source," Cancers (Basel) 11, 162 (2019).

269. V. Pikov et al., "Modulation of neuronal activity and plasma membrane properties with low-power millimeter waves in organotypic cortical slices," J. Neural Eng. 7, 045003 (2010).

270. V. Pikov and P. H. Siegel, "Millimeter wave-induced changes in membrane properties of leech Retzius neurons," Proc. SPIE 7883, 788356 (2011).

271. S. Romanenko et al., "Effects of millimeter wave irradiation and equivalent thermal heating on the activity of individual neurons in the leech ganglion," J. Neurophysiol. 112(10), 2423-2431 (2014).

272. S. Romanenko et al., "Millimeter wave radiation activates leech nociceptors via TRPV1like receptor sensitization," Biophys. J. 116(12), 2331-2345 (2019).

273. S. Shang et al., " $0.1 \mathrm{THz}$ exposure affects primary hippocampus neuron gene expression via alternating transcription factor binding," Biomed. Opt. Express 12, 3729-3742 (2021).

274. S. Romanenko et al., "EX vivo effect of $60 \mathrm{GHz}$ MMW radiation on leech neuron intracellular calcium alteration," in IEEE Ukrainian Microwave Week, pp. 612-616 (2020). 
275. A. Bogomazova et al., "No DNA damage response and negligible genome-wide transcriptional changes in human embryonic stem cells exposed to terahertz radiation," Sci. Rep. 5, 7749 (2015).

276. T. Tachizaki et al., "Terahertz pulse-altered gene networks in human induced pluripotent stem cells," Opt. Lett. 45, 6078-6081 (2020).

277. J. Bock et al., "Mammalian stem cells reprogramming in response to terahertz radiation," PLoS One 5, e15806 (2011).

278. B. S. Alexandrov et al., "Non-thermal effects of terahertz radiation on gene expression in mouse stem cells," Biomed. Opt. Express 2, 2679-2689 (2011).

279. B. S. Alexandrov et al., "Specificity and heterogeneity of terahertz radiation effect on gene expression in mouse mesenchymal stem cells," Sci. Rep. 3, 1184 (2013).

280. Y. Lei, W. Chen, and A. Mulchandani, "Microbial biosensors," Anal. Chim. Acta 568(1), 200-210 (2006).

281. E. V. Demidova et al., "Studying the non-thermal effects of terahertz radiation on E. coli/ pKatG-GFP biosensor cells," Bioelectromagnetics 34(1), 15-21 (2013).

282. E. V. Demidova et al., "Impact of terahertz radiation on stress-sensitive genes of $E$. coli cell," IEEE Trans. Terahertz Sci. Technol. 6(3), 435-441 (2016).

283. S. Peltek et al., "Stress-induced systems in Escherichia coli and their response to terahertz radiation," Russian J. Genetics Appl. Res. 7, 858-868 (2017).

284. D. S. Serdyukov et al., "Study on the effects of terahertz radiation on gene networks of Escherichia coli by means of fluorescent biosensors," Biomed. Opt. Express 11, 5258-5273 (2020).

285. D. S. Serdyukov et al., "Fluorescent bacterial biosensor $E$. coli/pTdcR-TurboYFP sensitive to terahertz radiation," Biomed. Opt. Express 12, 705-721 (2021).

286. A. Mazhorova et al., "Label-free bacteria detection using evanescent mode of a suspended core terahertz fiber," Opt. Express 20(5), 5344-5355 (2012).

287. A. Berrier et al., "Selective detection of bacterial layers with terahertz plasmonic antennas," Biomed. Opt. Express 3(11), 2937-2949 (2012).

288. S. Park et al., "Detection of microorganisms using terahertz metamaterials," Sci. Rep. 4, 4988 (2014).

289. D. Datta et al., "Terahertz vibrational signature of bacterial spores arising from nanostructure decorated endospore surface," J. Biophotonics 11(7), e201700398 (2018).

290. S. Boev et al., "A study of the effect of terahertz electromagnetic radiation on microbial cell viability," Biophysics (Nagoya-shi) 64, 416-423 (2019).

291. L. Yu et al., "The medical application of terahertz technology in non-invasive detection of cells and tissues: opportunities and challenges," RSC Adv. 9(17), 9354-9363 (2019).

292. T. Nagatsuma, G. Ducournau, and C. Renaud, "Advances in terahertz communications accelerated by photonics," Nat. Photonics 10, 371-379 (2016).

293. H. Guerboukha et al., "Planar porous components for low-loss terahertz optics," Adv. Opt. Mater. 7(15), 1900236 (2019).

294. M. Islam et al., “Terahertz optical fibers," Opt. Express 28(11), 16089-16117 (2020).

295. K. Zaytsev et al., "Overcoming the Abbe diffraction limit using a bundle of metalcoated high-refractive-index sapphire optical fibers," Adv. Opt. Mater. 8(18), 2000307 (2020).

296. A. Gavdush et al., "Proof of concept for continuously-tunable terahertz bandpass filter based on a gradient metal-hole array," Opt. Express 28(18), 26228-26238 (2020).

297. V. E. Ulitko et al., "Nanoporous $\mathrm{SiO}_{2}$ based on annealed artificial opals as a favorable material platform of terahertz optics," Opt. Mater. Express 10(9), 2100-2113 (2020).

298. G. Katyba et al., "Sapphire waveguides and fibers for terahertz applications," Prog. Cryst. Growth Charact. Mater. 67(3), 100523 (2021).

299. V. Ulitko et al., "Opal-based terahertz optical elements fabricated by self-assembly of porous $\mathrm{SiO}_{2}$ nanoparticles," Opt. Express 29(9), 13764-13777 (2021).

300. V. A. Batanov et al., "Compact Raman $\mathrm{CH}_{3} \mathrm{~F}, \mathrm{NH}_{3}$ optically pumped FIR laser," Int. J. Infrared Millim. Waves 11, 435-442 (1990).

301. S. Yamazaki et al., "Actin polymerization is activated by terahertz irradiation," Sci. Rep. 8, 9990 (2018). 
Olga P. Cherkasova is a professor at Novosibirsk State Technical University and a head of the Laboratory of Biophysics at the Institute of Laser Physics of the Siberian Branch of the Russian Academy of Sciences, Novosibirsk, Russia. Her research interests include interaction between $\mathrm{THz}$ radiation and biological objects, as well as applications of $\mathrm{THz}$ technology for diagnosis of diabetes, malignant, and benign neoplasms with different nosologies and localizations.

Danil S. Serdyukov graduated from the Department of Natural Sciences of the Novosibirsk State University, Russia. He is a junior researcher at the Institute of Laser Physics of the Siberian Branch of the Russian Academy of Sciences, Russia. His research interests include development of the fluorescent cellular biosensors, as well as studies of their interactions with $\mathrm{THz}$ radiation.

Eugenia F. Nemova graduated from the Department of Physics of the Novosibirsk State University, Russia. She is a junior researcher at the Institute of Laser Physics of the Siberian Branch of the Russian Academy of Sciences, Novosibirsk, Russia. Her research interests include studies of the THz-radiation effects on conformations of biopolymers. Her research skills are supplemented by popular science communication and teaching science for children.

Alexander S. Ratushnyak, Dr. S., is a head of Biomedical Informatics Laboratory at the Institute of Computational Technologies of the Siberian Branch of the Russian Academy of Sciences. His research interests include interaction of $\mathrm{THz}$ radiation with neurons.

Anna S. Kucheryavenko is a junior researcher in the Laboratory of Shaped Crystals of the Institute of Solid State Physics of RAS, Chernogolovka, and in the Laboratory of Submillimeter Spectroscopy of the Prokhorov General Physics Institute of RAS, Moscow. Her current research interests include medical instruments and $\mathrm{THz}$ technologies in medical diagnosis and therapy. She is a member of SPIE.

Irina N. Dolganova is a research assistant in the Laboratory of Shaped Crystals of the Institute of Solid State Physics of RAS, Chernogolovka, and in the Institute for Regenerative Medicine of Sechenov University, Moscow. She received her PhD in 2017. Her current research interests include medical instruments and optical and $\mathrm{THz}$ technologies in medical diagnosis and treatment. She is a member of SPIE.

Guofu Xu received his BSc degree in optical information science and technology from the Army Engineering University of PLA, China, in 2012, and his MEng degree in electrical theory and advanced technology from Hefei University of Technology, China, in 2019. He is currently pursuing his PhD under the supervision of Prof. Maksim Skorobogatiy at Polytechnique Montréal, where he is involved in the development of optical waveguide components for $\mathrm{THz}$ applications.

Maksim Skorobogatiy, Dr., P. Eng., graduated from MIT in 2001 with a PhD in physics and from MIT with the MSc in electrical engineering in 2000. He is currently a full professor at Polytechnique Montréal, Canada, where he holds a Tier 1 Canada Research Chair in ubiquitous THz photonics. In 2017, he was elevated to fellow of the Optical Society of America for his pioneering contributions to the development of microstructured and photonic crystal fibers.

Igor V. Reshetov is a member of the Russian Academy of Sciences. He holds a Doctor of Science degree in the medical sciences. He is currently a professor and head of the Cluster Oncology Department, as well as a practicing surgeon at Sechenov University, Moscow, Russia. His research interests include plastic and reconstructive microsurgery in oncology, head and neck tumors, including technologies for treatment, reconstruction, rehabilitation, and development of novel technologies for medical diagnosis of human body malignancies.

Peter S. Timashev graduated from Lomonosov Moscow State University of Fine Chemical Technologies, Moscow, Russia. He received his PhD from Karpov Institute of Physical Chemistry, Moscow, Russia, in 2004, and his DSc degree in 2016. He is the director of both Sechenov Biomedical Science and Technology Park and the Institute for Regenerative Medicine, Sechenov University, Moscow, Russia. He is an author of more than 200 publications and 11 patents and is a laureate of the Moscow Government Prize. 
Igor E. Spektor received his $\mathrm{PhD}$ in engineering sciences at Moscow Technical Institute of Forestry in 1997 for his research work in the Space Research and Development Center, Korolev, Moscow region, Russia, where he studied the methods and instruments of the intense heat flow measurements. Since 1998, he has been with the A.M. Prokhorov General Physics Institute of the Russian Academy of Sciences (GPI RAS), Moscow, Russia. He is a head of the Department of Submillimeter Spectroscopy at GPI RAS. His research interests include components, instruments, and methods of BWO dielectric spectroscopy and imaging, as well as THz-pulsed spectroscopy.

Kirill I. Zaytsev holds a PhD in optics engineering. He is a head of the Laboratory of Broadband Dielectric Spectroscopy at Prokhorov General Physics Institute of RAS, an associate professor at Bauman Moscow State Technical University, and a senior researcher at Sechenov University. His research interests include applied physics, optics and biophotonics, terahertz science and technology, dielectric spectroscopy, inverse problems in optics, computational electrodynamics, and optical engineering. He is a member of SPIE.

Valery V. Tuchin is a corresponding member of the RAS, head of optics and biophotonics, director of Science Medical Center at Saratov State University. He is a fellow of SPIE and OSA, an honored scientist of the Russian Federation, an honored professor of Finland, and a recipient of the SPIE Joseph W. Goodman Book Writing Award (2016), the Michael S. Feld Biophotonics Award (2019), and the medals of D.S. Rozhdestvensky (2018), and A. M. Prokhorov (2021). His works have been cited over 32,000 times. 